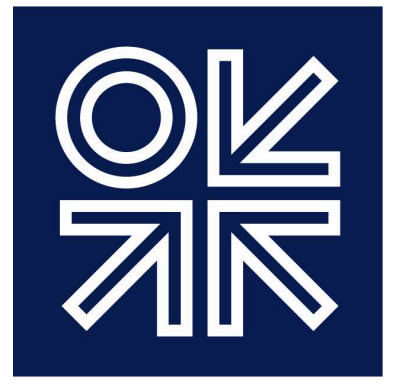

THE OXFORD INSTITUTE FOR ENERGY STUDIES

December 2013

\title{
Auctions for Oil and Gas Exploration Leases in India:
}

An Empirical Analysis

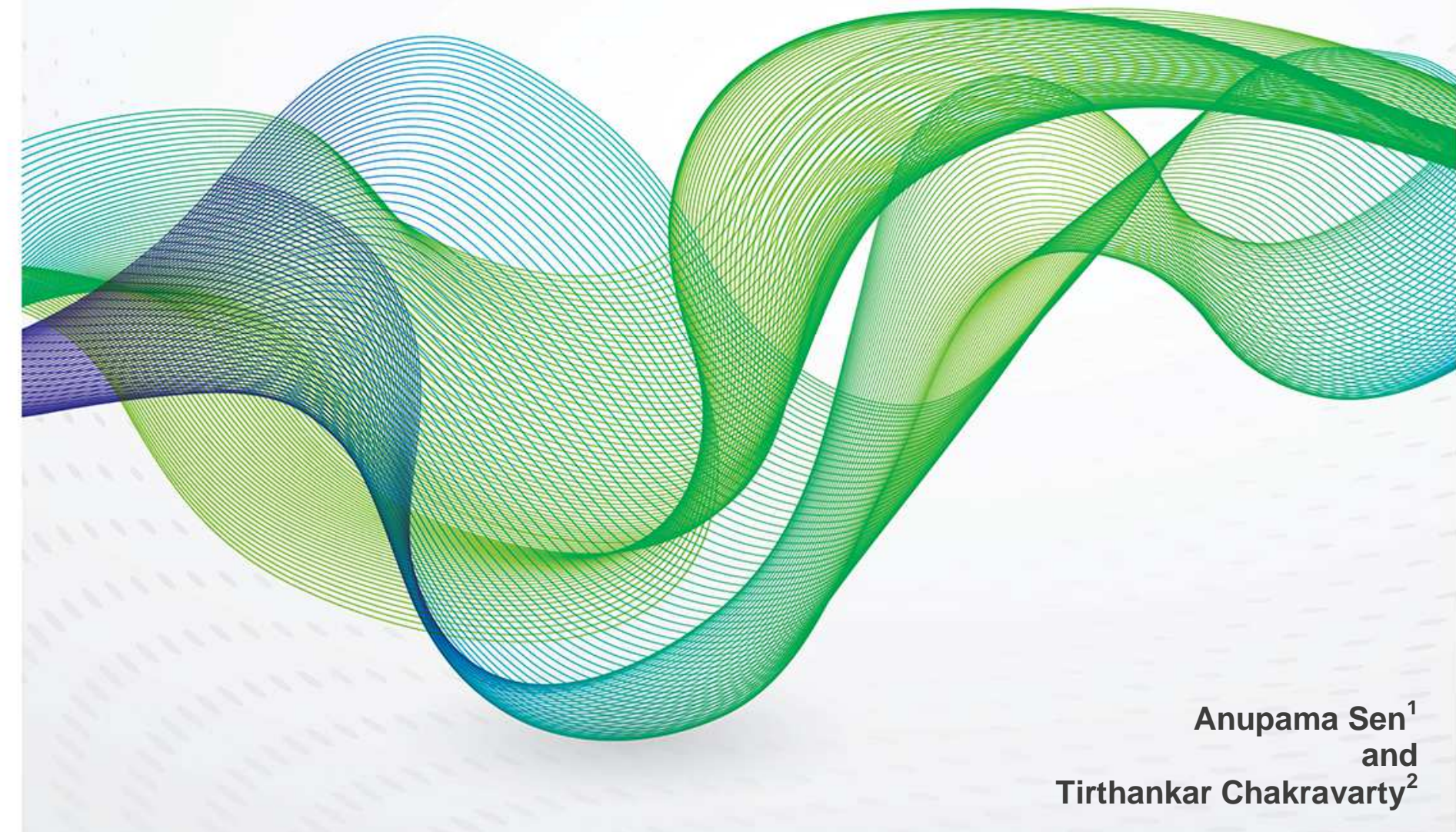


The contents of this paper are the authors' sole responsibility. They do not necessarily represent the views of the Oxford Institute for Energy Studies or any of its members.

Copyright $(9) 2013$

Oxford Institute for Energy Studies

(Registered Charity, No. 286084)

This publication may be reproduced in part for educational or non-profit purposes without special permission from the copyright holder, provided acknowledgment of the source is made. No use of this publication may be made for resale or for any other commercial purpose whatsoever without prior permission in writing from the Oxford Institute for Energy Studies.

ISBN 978-1-907555-85-5 

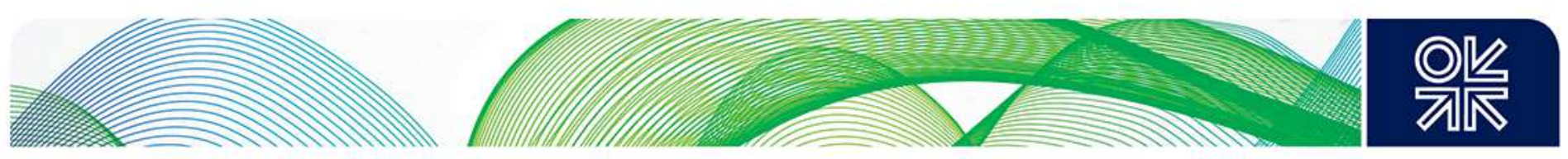

\section{Abstract}

This paper addresses the following policy question: why, despite nearly 15 years of operation of India's New Exploration Licensing Policy (NELP), representing two full exploration cycles has this regime yielded inconclusive results, both in terms of a firm indication of India's resource potential, and increased domestic production? This paper argues that a substantial part of the reason for this lack of performance may lie in auctions and market design, and uses data for the period 1999-2010, covering nine rounds of auctions, to explore three lines of argument relating to some unintended consequences of the NELP. First, the regime has led to a highly concentrated market in upstream acreages where a small number of firms hold the largest amounts of acreage. Second, the regime has led to a 'holdup' problem that can be attributed to information asymmetries between the government and bidders, where winning bidders may later not fulfil their work programme commitments within the stipulated timeframe. Third, the lack of a clearer definition of the objectives of the auction and their relative importance, specifically, optimality versus efficiency, may have acted as a constraint on the effectiveness of the regime. We use a combination of theory and empirics to explore these three hypotheses. At the end of the paper we draw the results together, showing that problems relating to auctions and market design may have led to a cycle of information asymmetry and inefficiency, the net effect of which has been a slowdown in India's domestic production, shortages in meeting supply targets, and the need for expensive imports. We suggest some policy options and areas for further research. 

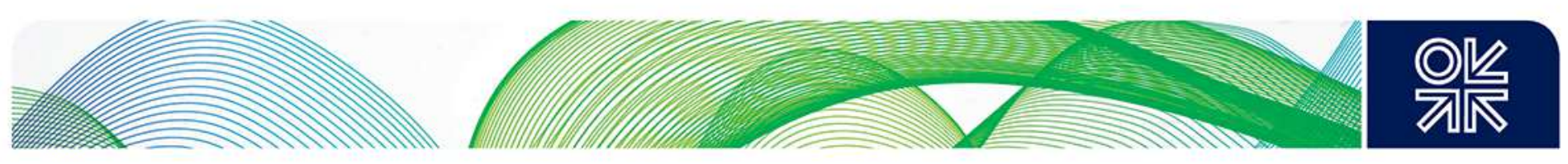

\section{Acknowledgments}

We are extremely grateful to Christopher Allsopp for his support, from providing advice in the early stages of research right through to reading numerous drafts. We would also like to thank Anil K. Jain for sharing with us his knowledge on Indian energy, and without whom it would have been very difficult to meet with key decision-makers in Indian government and industry. Colleagues at the OIES, including Bassam Fattouh, Howard Rogers, David Ledesma, Jonathan Stern, lan Wybrew-Bond, John Rhys, Malcolm Keay, Benito Mueller and Lavan Mahadeva, helped either through discussion, feedback, or direction towards relevant people and literature. Special thanks to Mark Williams for providing excellent comments and suggestions which helped improve the conclusions.

This working paper would have been impossible to write without the individuals and organizations in the Indian energy sector - far too many to name on one page - who gave very generously of their time in contributing to this research. We are very grateful to the Ministry of Petroleum and Natural Gas and the Directorate General of Hydrocarbons for their time and for encouraging academic work on this subject. We are equally grateful to industry in the Indian energy sector for their time and encouragement. Discussions carried out in the course of research covered a spectrum of stakeholders and opinions, including government, industry, and academia, covering as wide a range of views as possible. Our views in this paper are based on our analysis and interpretation of the research questions and data, and do not represent those of any individual or organization. Any remaining errors are our own. 


\section{Contents}

Abstract ii

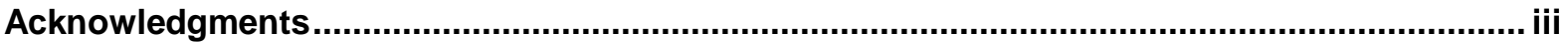

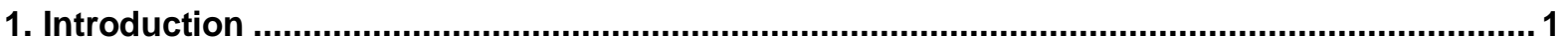

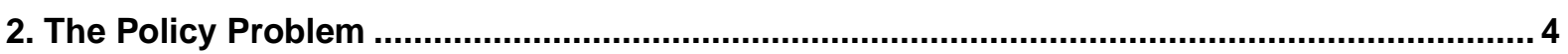

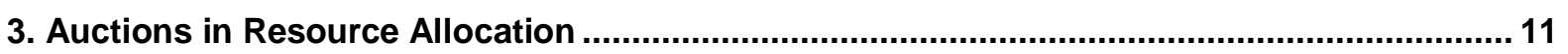

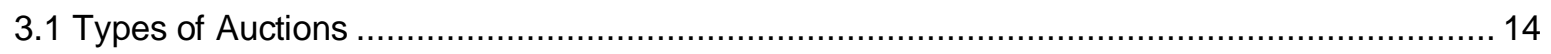

4. Auctions for Oil and Gas Exploration Licences in India ....................................................... 16

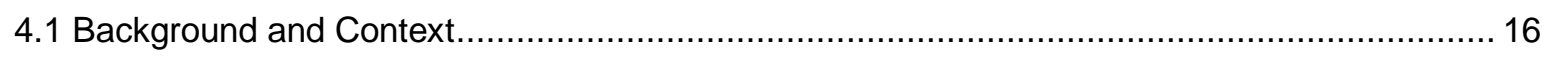

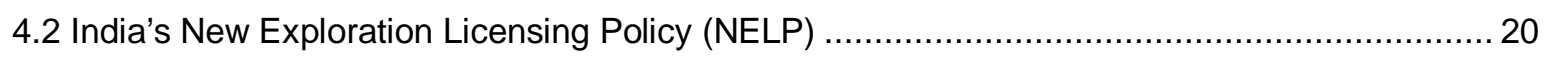

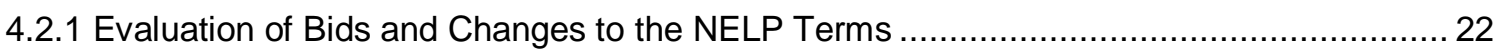

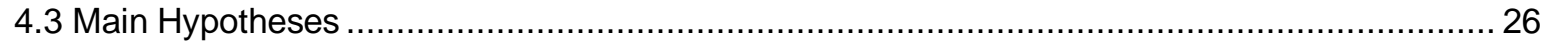

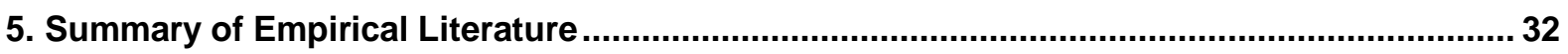

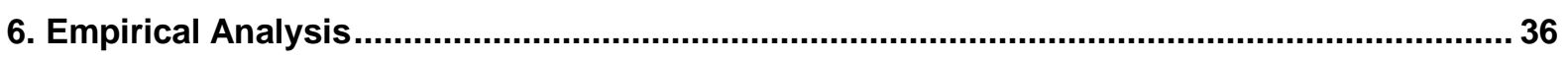

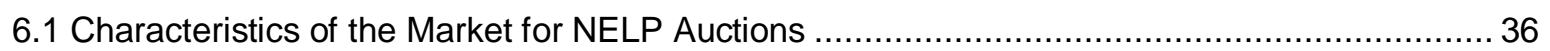

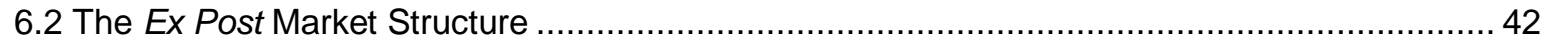

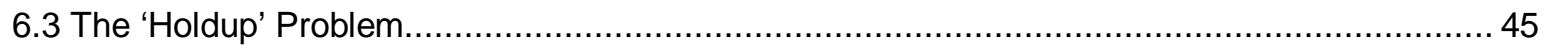

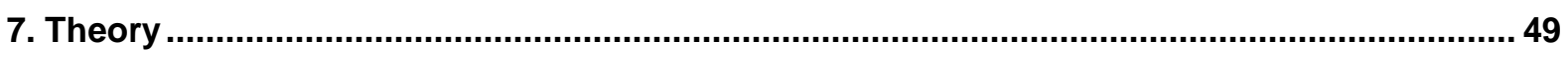

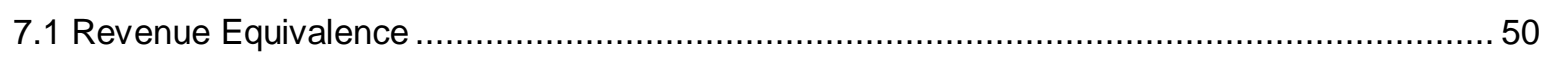

7.2 Auction Objectives: Optimality versus Efficiency, and Parallels with Third Degree Price

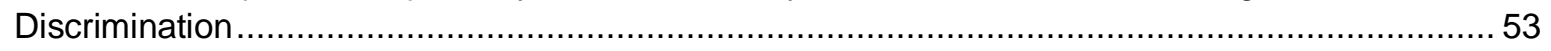

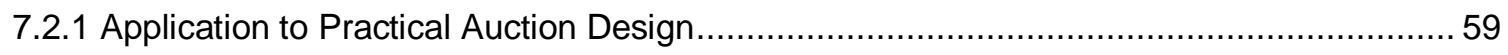

8. Modelling the NELP Auction Rounds - Extended Descriptive Statistics............................... 62

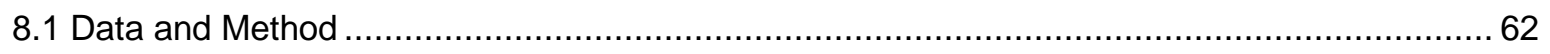

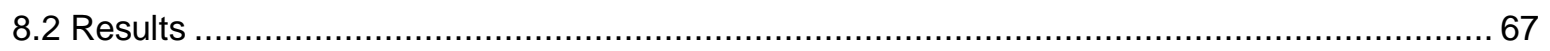

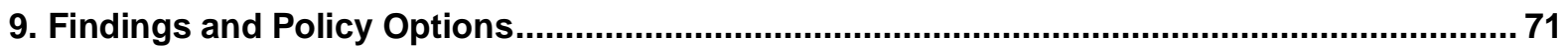

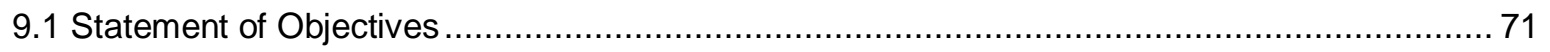

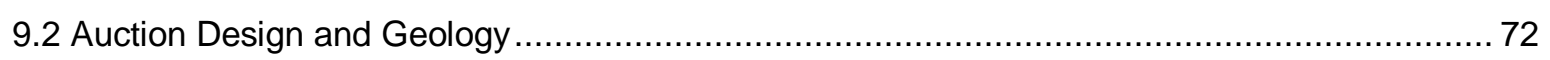

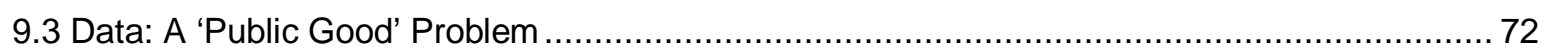

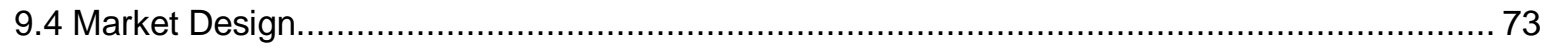

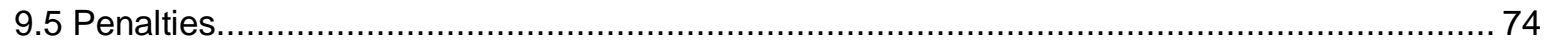

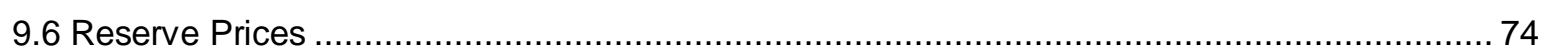

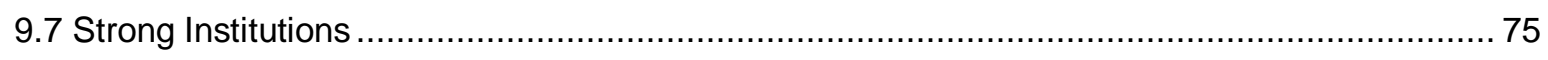

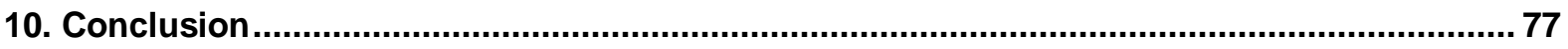

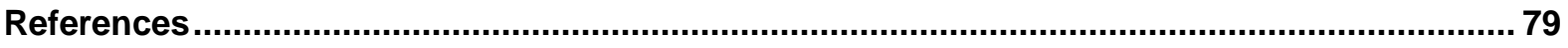


Appendix A: Market Concentration in Bidding Rounds..................................................... 88

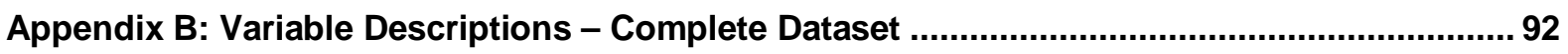

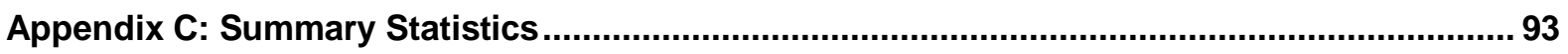

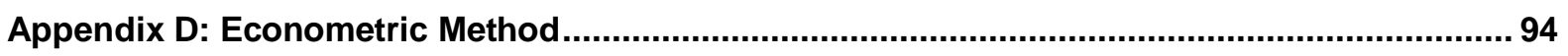

\section{Tables}

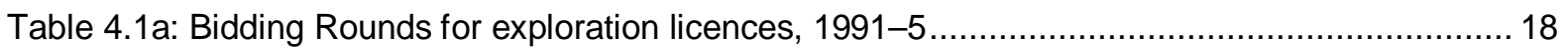

Table 4.1b Bidding Rounds for developing discovered fields (reserves), 1992-3 ........................... 18

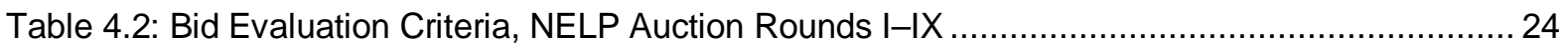

Table 4.3 Participation of International Majors in Bidding Rounds, India vs Brazil ............................ 29

Table 6.1: An Analysis of Participation in Bidding Rounds over Two Policy Periods.......................... 41

Table 6.2: 'Money Left on the Table' - Notional Indicators.................................................................. 48

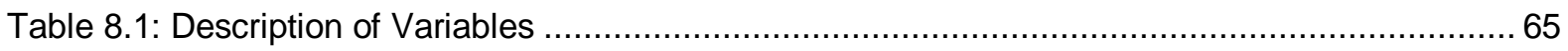

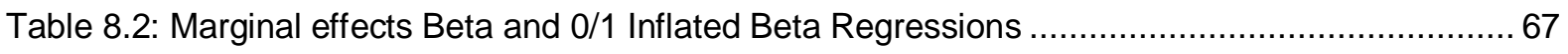

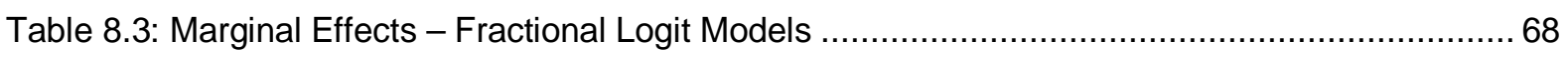

\section{Figures}

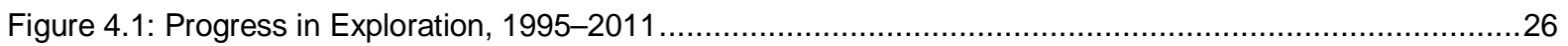

Figure 4.2: Percentage of Blocks for which Investment Commitments Not Met.............................................28

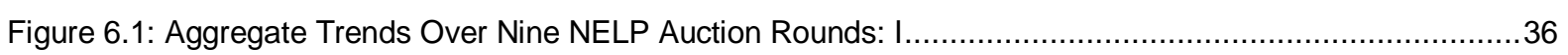

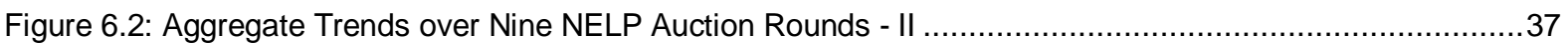

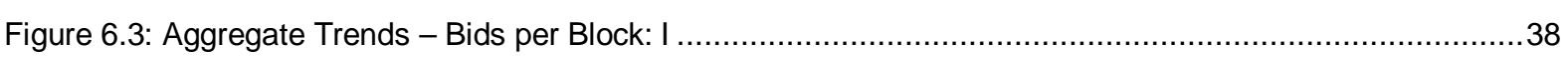

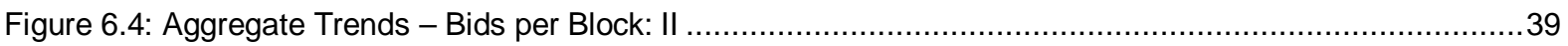

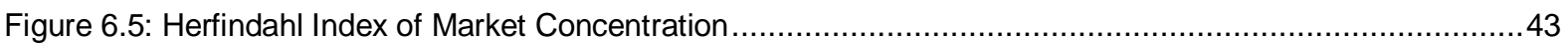

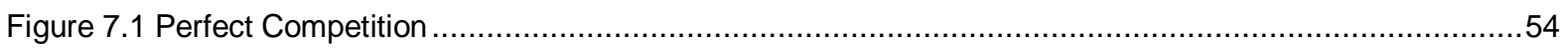

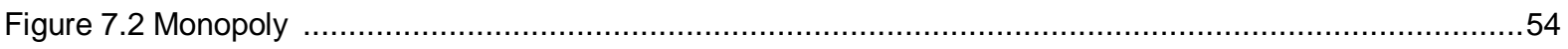

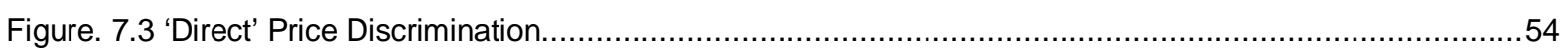

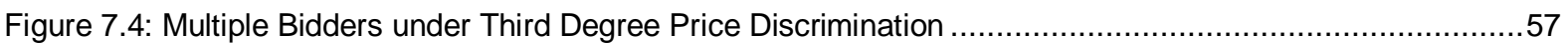

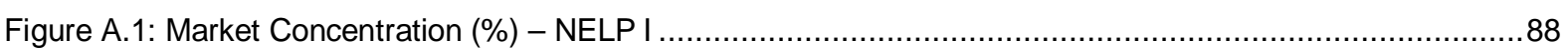

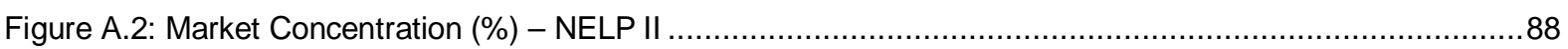

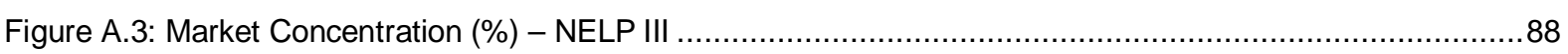

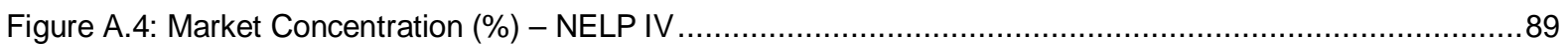

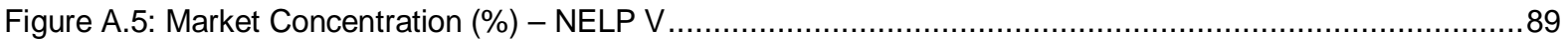

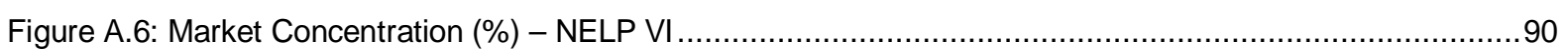

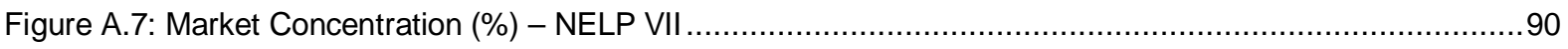

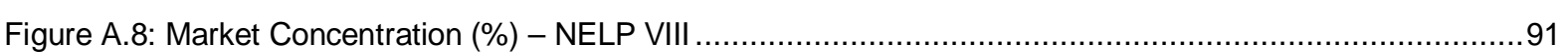

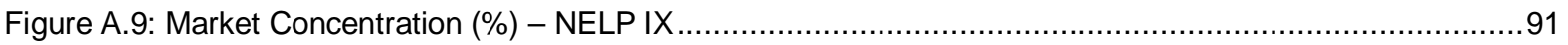



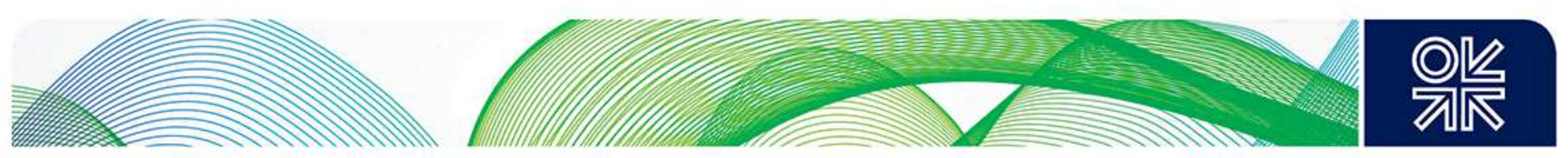

\section{Introduction}

This paper focuses on the allocation system for hydrocarbons exploration leases in India - one of the world's fastest growing economies and consumer markets, but also a country with the largest number of people living below the poverty line in a single nation. These extremes are representative of the policy conflicts currently being faced in the Indian energy sector - the struggle to move from a centrally planned system to one where government and markets work in complementary roles to deliver a visibly rational and efficient system, whilst fulfilling important distributional objectives.

Recent forecasts have highlighted the problems of India's rising energy consumption and the ways of meeting it. The International Energy Agency forecasts that by 2035, India and China will be responsible for most of the increase in world energy demand, with primary energy consumption in India tripling to roughly 1500 mtoe from its 2012 levels (IEA, 2012). The US Energy Information Administration forecasts a slightly lower increase to roughly 1100 mtoe by 2030 (EIA, 2011). In contrast, India's 12th Five Year Plan suggests that by about 2020, India will have developed the capability to meet only about a third of projected future increase from domestic energy resources (Gol, 2013). Whilst these forecasts are debatable, what is clear is the fact that roughly half of India's current population of around 1.2 billion people lack access to any form of modern commercial energy - this suggests that enormous future additions to primary energy consumption will need to be met.

These forecasts, or similar, are often used to support the abundant literature emphasizing the need to ensure India's 'energy security' - a nebulous concept subject to varying definitions (Energy and Climate Change Committee, 2011). Indian policymakers have in the past based their strategies on the pursuit of energy security through a rush to contract supplies from resource-rich countries, which given the world's changeable political and economic climate is arguably an inherently insecure (although not an economically unviable) strategy.

However, in making the leap from domestic energy shortages to securing expensive imports to bridge the gap, an important factor has often been overlooked - the fact that a significant part of India's 'energy problem' may be resolved by focusing on domestic policy relating to elementary economic concepts - such as resource allocation, pricing, and taxation.

\footnotetext{
${ }^{1}$ It can be used to describe the reliability of supplies, the resilience of the supply infrastructure to attack or natural disaster, the supply of affordable fuels, or the extent of national self-sufficiency. It is also used to refer more generally to the absence of interruptions to supplies of electricity, gas, and petroleum products to end users (Energy and Climate Change Committee, 2011).
} 

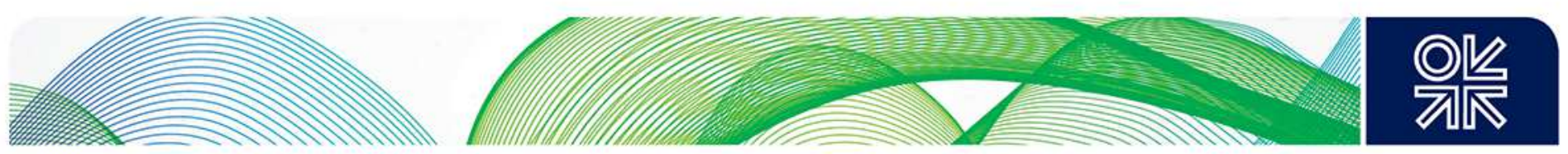

Specifically, this implies allocating domestic resources to entities that value them the most and are likely to develop them efficiently and quickly, and reforming the pricing and taxation system to provide the correct incentives to energy producers and consumers, enabling the pursuit of broader goals on supply, the environment, and poverty alleviation.

This paper focuses on the first of these factors - resource allocation - which in India takes place through auctions under the 'New Exploration Licensing Policy' or NELP. Resource allocation is also one of the first steps in the process of developing a country's natural resources sector. The design and implementation of allocation systems inevitably has long-term impacts on energy supply. It can also have subsequent impacts on the timing of receipt of fiscal revenues by governments.

The following policy question is addressed below: why, despite nearly 15 years of operation, has India's NELP regime produced unclear results ${ }^{2}$, both in terms of a firm indication of the country's resource potential, and of increased domestic production? Can the reason be pinned down to prospectivity, ${ }^{3}$ or is it a combination of factors, including the system of auctions for allocating acreage to firms, and poor contract enforcement ex post? As prospectivity is a dynamic concept that is influenced by technological advancements, it is unlikely to be a primary reason.

This paper argues that a substantial part of the reason for this lack of performance may lie in auctions and market design, and sets this argument out in terms of three separate hypotheses or lines of argument. First, the design of the NELP auctions has led to the unintended consequence of a highly concentrated, arguably even duopsonistic, market in upstream acreages where a small number of firms hold the largest amounts of acreage. Second, the NELP auctions and market design have led to a 'holdup' problem that may be attributed to an asymmetry of information and incentives between the government and bidders -with the results that firms may not fulfil their work programme commitments within the stipulated timeframe. Third, the lack of a clearer understanding and definition of the objectives of the auctions and of their relative importance, for instance, optimality (the maximization of revenues) versus efficiency (the maximization of gains to trade), has acted as a constraint on the effectiveness of the regime.

We use a dataset of variables for the period 1999-2010, representing nine rounds of auctions (with some missing values) under the NELP to explore these three lines of argument, drawing from conventional methods in existing empirical literature.

\footnotetext{
2 Discussed further in Sections 2 and 4.

${ }^{3} \mathrm{~A}$ term used to describe the likelihood of whether an area contains reasonably recoverable deposits of minerals or hydrocarbons.
} 

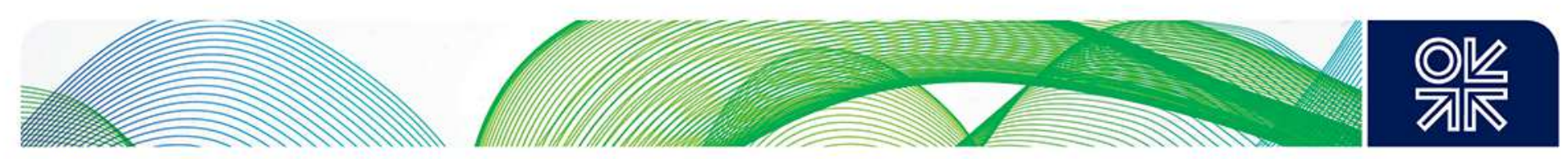

Section 2 summarizes the policy problem and some potential conclusions. Section 3 introduces the use of auctions in resource allocation. Section 4 provides the background and context to the NELP and sets out the main arguments. Section 5 contains a summary of empirical literature. Section 6 begins the empirical work by setting out the characteristics of the market for NELP auctions, followed by analyses of our hypotheses. Section 7 contains a discussion of auction theory which we use to explore the optimality versus efficiency argument. Section 8 contains extended descriptive statistics to explore some of the 'big picture' outcomes of the NELP rounds in terms of the influence of competition, bidder behaviour, geological factors, and economic factors on the value of the high or winning bid. Section 9 contains policy options that begin to address some of the issues discussed in the paper, and Section 10 concludes. 


\section{The Policy Problem}

In 1999, following a period of plateauing domestic production and rising energy demand, the Indian government liberalized its upstream sector for hydrocarbons exploration, stating the need to attract private capital and technology to boost exploration and production (Gol, 1999). The liberalized policy - the New Exploration Licensing Policy (NELP) - had two main components. First, blocks of onshore, shallow-water offshore, and deep-water offshore acreage were to be allocated using a system of first price sealed bid auctions, to domestic and foreign companies, with public and private firms competing on a 'level playing field' for the right to explore and/or develop these acreages within a stipulated time period. And second, once these blocks were auctioned off to the highest bidders, Production Sharing Contracts ${ }^{4}$ were to form the basis of agreements between these companies and the federal government, to ensure compliance ex post.

Under the NELP, substantial quantities of hydrocarbons have been added to India's total 'estimated reserves'. ${ }^{5}$ These reserve estimates by themselves do not count towards domestic production unless they are commercially extractable. Therefore, in terms of its impact on supply, only one 'giant' commercial discovery (of natural gas in 2004) has been brought into production (in 2009), in the deep-water eastern offshore Krishna Godavari basin over a period equivalent to nearly two full exploration cycles since the launch of the NELP ${ }^{6}$, and there are currently just three producing blocks (Nambiar, 2013). Added to this have been other concerns - in 2011, an audit report by the Comptroller and Auditor General of India highlighted inefficiencies in the enforcement of contracts ex post, resulting in the slow relinquishment and turnover of acreage, and allegedly in revenue lost to the exchequer (CAG, 2011). It has been argued that the failure to bring new volumes of production into the market, alongside problems with ex post enforcement, reflects an underperformance by the NELP regime to boost domestic exploration and production, particularly in natural gas.

There is in fact some degree of confusion over what constitutes 'success' under the NELP regime, given that the objectives of the system are not explicit. One view is that success is reflected in the

\footnotetext{
${ }^{4}$ Production Sharing Contracts set out the terms of the agreement between the exploration firm and the government and are based on the premise that profits from any production will be shared with the government according to a pre-agreed formula or percentage. For a detailed explanation, see Johnston (2003). All production under the NELP is subject to a domestic market obligation and hydrocarbons are sold by upstream producers to oil marketing companies within India.

5 Over 700 million metric tonnes.

${ }^{6}$ This too has encountered problems. Although production began in 2009, it has been falling steadily since 2011 and there has been much speculation on the reasons for this drop in production - linking it to the fiscal terms of exploration, to pricing, and to technical difficulties.
} 

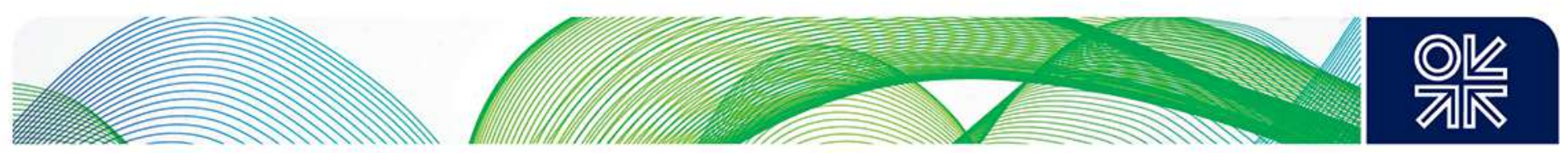

number of companies that decide to participate in the bidding rounds for blocks. ${ }^{7}$ Going further, the types of companies (in terms of size, scale, ownership, and reputation) may also be considered important. Under NELP, for instance, very few of the international majors have participated in bidding rounds. A second view focuses on the amounts of money that are committed for spending on exploration ex ante - as we later show, these investment commitments have often not been fulfilled. A third view focuses on the ex post results of these bidding rounds, and on whether contracts are implemented to deadline, acreage is 'turned over' quickly, and any discoveries are brought into production within reasonable timeframes - all of which have been contested by the 2011 audit report.

A fourth view relates to the firm establishment of 'prospectivity' - the availability of sufficient information to credibly determine the likelihood of the country containing areas with reasonably (commercially) recoverable deposits of minerals or hydrocarbons. Arguably, the last of these four criteria - prospectivity - influences the other three. It can be argued that the non-participation of international majors, who otherwise operate in some of the world's most hostile regions, may simply signal inadequate resource potential. There are however two factors which challenge this potential conclusion: first, examples exist in India where areas initially perceived to have low or no prospectivity have later yielded large amounts of hydrocarbons ${ }^{8}$, and second, given the role of technology in exploration, prospectivity is a dynamic concept and is hence unlikely to be the primary cause of underperformance of a country's exploration regime in the long term. Although India lies lower down the league of the world's resource-rich countries, its 'prospectivity' thus remains ambiguous. ${ }^{9}$

Related to prospectivity, there is a perceived lack of updated, published databases of geological and other relevant information, the building up of which has been one of the implicit objectives of the NELP regime. This is in contrast with other developing economies, for instance, Brazil - which launched its bidding regime for exploration in the same year as India, but has arguably been more successful in data gathering and sharing.

The central research question posed in this paper is therefore: why, despite nearly 15 years of operation, has the NELP regime yielded inconclusive or ambiguous results, in terms of participation in the auctions, a firm indication of India's resource potential, and increased domestic production? In answering this question and in evaluating the effectiveness (or 'success') of the NELP, we need to take a step back to consider three related questions: what were the original objectives of Indian

\footnotetext{
Going purely by auction theory in economics, participation is indeed a primary indicator of the success of an auction. ${ }^{8}$ Royal Dutch Shell entered into a Production Sharing Contract with ONGC in 1992 to explore for hydrocarbons in Rajasthan. Although Shell carried out exploratory drilling, it exited the operation without making any commercial discoveries. The block was then acquired by Cairn Energy in 1998, which eventually (in 2004) made India's largest onshore oil discovery which included 3.6 billion barrels of oil in one oilfield alone.

${ }^{9}$ Prospectivity may also be influenced by resource price movements.
} 
policymakers when the NELP was first implemented? Second, what was the purpose of using first price sealed bid auctions, as opposed to other methods, to allocate blocks (apart from the fact that auctioning systems were being used in many other developing nations at the time)? And third, was market design carefully considered in the policy formulation process?

These questions bring us to the intricacies of the 'policy problem' being explored in this paper. Although neither the original policy directive on the NELP ${ }^{10}$ nor the announcements ('Notices Inviting Offers') preceding each of the nine auction rounds contained an explicit statement of objectives (with a relative order of importance), the implicit goals for the NELP at the time of launch were a) to facilitate deep-water offshore exploration and production through private capital and technology as most onshore areas had been explored by the National Oil Companies (NOCs), b) to respond to pressures from within both the private and public sectors to allow competition for acreages on a 'level playing field', and c) to create a regime that would serve as a bridge to an 'Open Acreage Licensing Policy', by facilitating data collection and the build-up of a geological database..$^{11}$ In the absence of an explicit set of objectives, it is admittedly difficult to measure the performance of the regime, but in this paper we show that these implicit objectives have not been fully met.

There are arguably different ways to analyse this policy problem - specifically, as auctions comprise the main element of the NELP, auction theory from the discipline of economics provides us with a set of tools for understanding the suitability of auctions to resource allocation, the types of outcomes in auctions, and generally lends itself to practical application. We therefore use auction theory combined with some empirics to investigate our research questions. The NELP uses first price sealed bid auctions which are carried out in the presence of significant information asymmetries amongst bidders and the auctioneer (government), with no reserve prices. It must however be noted that auctions form one part of a larger picture in the study of the NELP regime. Another part of the picture relates to market design, which we explore to a lesser extent in this paper.

Our empirical results and theoretical analysis confirm a set of observed phenomena: first, that the majority of acreage that has been auctioned (specifically for deepwater blocks) is split between a small number of the largest exploration companies, effectively representing a duopsony (or highly concentrated market) in upstream acreage. Second, there are some indications of firms putting in winning bids in excess of their actual valuations of blocks, which may imply 'overbidding' for

\footnotetext{
10 This can be accessed at http://petroleum.nic.in/newgazette/goi1.pdf

${ }^{11}$ An Open Acreage Licensing Policy represents a liberalized regime where bidding rounds can be conducted year-round upon the nomination of prospective acreages by exploration companies themselves. A database of geological and other information is viewed in India as a prerequisite to the implementation of such a regime. In other words, 'prospectivity' requires to be established to a reasonable degree.
} 
deepwater blocks (attributable to a phenomenon called 'the winner's curse' in auction theory) or 'speculative bidding' for onshore blocks - where firms may view a block of acreage as adding value to their asset portfolios for a specific time period. This is perceived to have lead to a situation that we refer to as the 'holdup' problem ${ }^{12}$. Third, there has been a lack of clear objectives under the auctions, particularly with respect to optimality (the maximization of auctioneer revenues, or of producer surplus) versus efficiency (the maximization of the gains to trade, or of producer and consumer surpluses) - leading to questions over whether success in the auctions is represented by the maximization of revenues to the government or by the maximization of efficiency in the exploration and development of acreages, and whether the two are mutually exclusive. This lack of clarity has acted as a constraint on the effectiveness of the bidding regime ex post.

The results also point to the 'big' conclusion that there is a dichotomy in the auction outcomes for onshore (and shallow water) blocks and for deep-water offshore blocks, indicating that bidders for these different geologies have different elasticities of demand. This, in turn, supports our argument that policymakers may be attempting to achieve different objectives in relation to different geologies, and could therefore be attempting to use the same system to achieve different goals. Potential answers may therefore lie outside the question of 'what system' should be used and be found instead in the question of 'what goals' might policymakers in India want to achieve through allocating blocks for exploration using auctions.

Our logical understanding is that as onshore areas are relatively well explored in comparison with deep-water offshore areas, the goal in allocating licenses for onshore areas is justifiably the maximization of revenues to the auctioneer (government). The theory shows that first price sealed bid auctions can be optimal (revenue maximizing for the government as auctioneer) as well as efficient only in situations where the bidder bids his true value for the block. ${ }^{13}$ We therefore conclude that onshore acreages could continue to be auctioned using first price sealed bid procedures, but these should necessarily be combined with a reserve price ${ }^{14}$, and substantially higher penalties for default or large upfront payments (through bonuses), to deal with the issue of 'speculative bidding' particularly for smaller onshore blocks. ${ }^{15}$

\footnotetext{
${ }^{12}$ Note that this is different from the standard holdup problem in microeconomics. It refers specifically to a situation where acreages that have been auctioned are then not developed within stipulated timeframes, thus 'holding up' progress under the NELP regime.

${ }^{13}$ They are efficient as they maximize the sum of seller and buyer surplus, although the seller (government) captures the entire surplus.

${ }^{14}$ Setting reserve prices for onshore blocks may be easier than for offshore blocks, as onshore areas have been relatively well explored and reserve prices could be based on expected volumes of production valued at the international price of oil, for instance.

${ }^{15}$ Auctions broadly allocate objects to bidders with the highest values. If the source of high bids/ high valuations by firms is speculation, but the objective of the auctioneer is purely to maximize revenues, then first price sealed bid auctions with upfront
} 

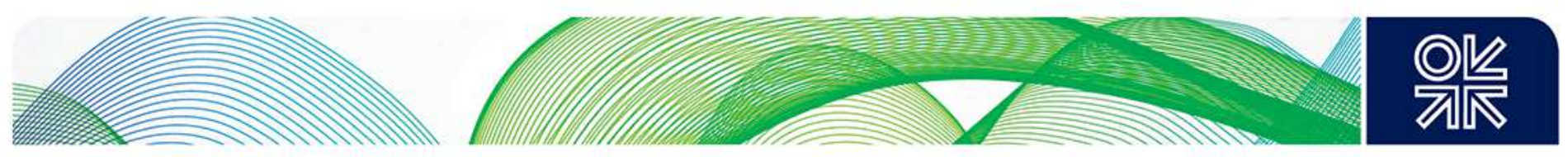

Deep-water offshore areas on the other hand are different. Thought to hold greater resource potential and seen as relatively less-explored, as discussed earlier, the original (implicit) objectives under the NELP were to facilitate the capital and technology investments that would enable both NOCs and private firms to move into deep-water offshore exploration and production, and to enable the building up of data on geological and other information. In terms of these dual goals, the theory shows that first price sealed bid auctions are not efficient, as they may maximize revenues for the auctioneer (the auctioneer captures both seller and buyer surplus) but do not maximize bidder (or consumer / buyer) surplus or the gains to trade, and therefore system welfare. ${ }^{16}$

There is therefore a paradox of outcomes in using first price sealed bid auctions under the NELP first price sealed bid auctions can lead to optimal and efficient outcomes for onshore blocks under conditions where bidders bid their true values for blocks. However, they do not necessarily lead to efficient outcomes for deep-water offshore blocks - which presumably hold greater resource potential and also require the largest amounts of capital investment, and towards which the regime was originally targeted. In looking for policy solutions on deepwater blocks, we suggest considering the problem in two stages: the first stage relates to exploration and production of deepwater blocks per se, and the second stage relates to the problem of data.

Taking the first stage - there are two areas in which explanations and policy solutions may lie for our findings on deepwater blocks. The first concerns the auction design: undesirable auction outcomes, such as the holdup problem, could be attributed to weaknesses that are endemic in the auction format per se which we outline later in this paper. A solution would be to use different auction formats for different geologies, and to replace the first price sealed bid auction format for deepwater blocks with a dynamic auction format - for instance a second price sealed bid auction, in which (as we show later in this paper) a bidder's dominant strategy is to submit a bid equal to his true value. As second price sealed bid auctions result in the winning bidder paying an amount equal to the second highest bid, this could ensure that the block is awarded to the bidder with the highest value, and that the gains to trade (and hence efficiency) are maximized. Dynamic or hybrid auction formats could also be considered. 
The second area relates to market design - ex post inefficiencies in the pace of exploration and production could be attributed to two factors. The first is that while auctions broadly allocate acreages to the bidders that value them the most, they do not validate the source of these valuations. If the source of the higher valuation is the desire to maintain market power ${ }^{17}$, then potential solutions lie not just in the auction format, but in the design of the market. In this case it may be effective to introduce market design elements such as the reservation of a certain number and/or type of tracts for new entrants.

Another factor in market design is that while auctions broadly allocate blocks of acreage to firms with the highest valuations for them, these firms may update their information on the acreage ex post. In some scenarios, the firm may conclude that it is inefficient to continue with exploration and production. Hotelling (1931) describes this in terms of a firm's optimal rate of extraction - a firm finds it efficient to produce only when price or marginal revenue equals the cost of extraction plus the opportunity cost, where the opportunity cost (also called the shadow price or the scarcity rent), grows at a rate equal to the rate of interest. ${ }^{18}$ Therefore, while it may be inefficient under some circumstances for a firm to continue exploring, it may be considered inefficient from a government's point of view, for the firm not to engage in exploration and production, given the government's short term economic and wider social objectives relating to energy supply, and given contractual arrangements. This reflects a misalignment of objectives between the firm and the government, and a subsequent 'commitment problem'. Policy solutions to this commitment problem again lie in ascertaining what the objectives of the regime are, and in using elements of market design to orient the regime towards these objectives.

The second stage of the policy problem relating to deepwater blocks is the building up of data, which was seen as one of the implicit objectives of the NELP regime in aiding the move to an Open Acreage Licensing Policy. Data is essentially a public good as it is shared, and hence no private party has an incentive to provide it. It therefore needs to be provided by the government - and the policy problem here is essentially a public good problem, with associated solutions in the determination of ways in which the government can facilitate the building up of a database. First, the government could undertake this exercise itself; in practice, governments of developing countries may not have the technical capabilities to do so. Second, the government could procure this data - essentially making data a public procurement issue rather than something that is directly concerned with the auction of acreages. Solutions may lie in designing separate procurement auctions for data. The winner of a

\footnotetext{
${ }^{17}$ This is particularly relevant when domestic market obligations exist and firms are required to sell all production within the domestic market.

${ }^{18}$ This indicates the return on capital in alternative uses. Efficiency may be achieved in this situation when the private discount rate of the firm equals the social discount rate.
} 

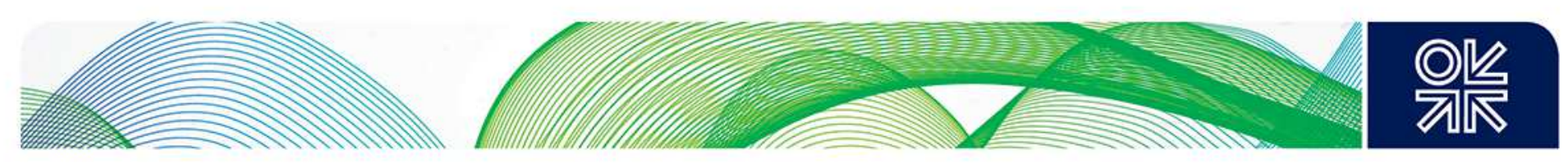

data contract should ideally not participate in the bidding rounds for acreages, as this is likely to deter participation in the auction from other bidders. Some countries (e.g. United Kingdom) have also mandated the sharing of data through legislation.

This two-stage approach separates the issues of 'prospectivity' and 'efficiency' in the allocation of deep-water offshore blocks. We explore some policy options further in Section 9, although the focus of much the paper is on assessing past outcomes. In the remainder of this paper, we proceed to demonstrate the main arguments aired in this section in greater detail. 


\section{Auctions in Resource Allocation}

In most countries in the world the ownership of natural resources is vested in sovereign states, with national governments acting as custodians. ${ }^{19}$ In India, the regulation and development of national resources lies constitutionally with the sovereign state. ${ }^{20}$ Governments around the world have relied upon various methods to allocate the rights to develop natural resources. Generally, methods for resource allocation are classified into 'open door systems' if they involve agreement primarily through negotiation, and into 'licensing round systems' if they involve structured procedures with qualifying criteria (Tordo and Johnston, 2009). Specifically, the four most common procedures are administrative processes, lotteries, first-come-first-served, and auctions (Afualo and McMillan, 1996). A question that frequently arises in resource allocation, is: why use auctions (over other allocation methods)?

The central problem in resource allocation is information revelation. Governments need to know how highly each firm values a resource in order to allocate it efficiently (which usually implies maximizing social welfare, or maximizing the gains to trade for consumers and producers through their respective surpluses) amongst a set of firms.

To demonstrate this problem, in one of the seminal papers on auction theory, Vickrey (1961) explored whether efficient allocation could be achieved through the establishment of an exclusive public marketing agency, to which all sales of a commodity must be made, and from which all supplies of the commodity must be bought. A simple solution to the allocation problem could be achieved if the agency could determine with confidence what the equilibrium competitive price would be and could then establish this price for its purchases and sales, in such a way that neither buyers nor sellers could expect to have any influence over it. This price would then be a fixed datum to buyers and sellers, and competitive behaviour be expected (Vickrey, 1961).

The trouble with this solution is that much of the information that the agency would need in order to determine the competitive equilibrium would have to come from buyers and sellers, who would then have an incentive to understate prospective demands and supplies, or to curtail their actual sales and

\footnotetext{
${ }^{19}$ With some exceptions; for example, the US Constitution grants ownership rights to private landowners.

${ }^{20}$ In the Indian Constitution (Schedule 7) the regulation and development of oil and gas resources has been granted to the Government of India. In the Oilfields (Regulation and Development) Act, 1948, the regulation of onshore resources lies with the state governments, while that for offshore resources lies with the federal government. All royalty revenues from offshore resources flow to the federal government, and all royalty revenues from onshore resources flow to the state governments. The division of other resource-related revenues is also set out according to the federal fiscal system.
} 
purchases, in the hope of inducing the agency to change the price in their favour (Vickrey, 1961). Although hard to see, it can be argued that in a static situation, the agency might conceivably manage not to be misled by such information. However, in a more realistic dynamic situation, where the equilibrium price is continuously changing, it would be much more difficult to ascertain the equilibrium price, keep the price at this level, and simultaneously persuade buyers and sellers that future changes in the published price will not be influenced by tactical deviations on their part (Vickrey, 1961).

This reasoning also relates to arguments debating central planning versus market allocation. Although the 'perfect planner' and the 'perfect market' could theoretically both achieve equilibrium price and allocation, in practice the perfect planner has to work out this equilibrium through the gathering of relevant information, whereas the perfect market shows us what the equilibrium is through providing incentives to market participants to reveal this information. This leads to the conclusion that markets in general may be relatively better placed to achieve 'efficient ${ }^{21}$ allocation.

In theory, a government's choice of allocation method matters less if it permits resale than if it does not. With a perfectly operating secondary market, the resource would eventually find its way into the hands of the firm best able to use it, so an efficient allocation would eventually emerge (Afualo and McMillan, 1996). In practice, the government's allocation method does matter; first, giving a resource away, as opposed to auctioning it, could lead to a potential loss of revenue for governments (Afualo and McMillan, 1996). Second, secondary markets for resources are typically 'thin' markets ${ }^{22}$ with significant transaction costs, so an efficient allocation from the beginning would better ensure the capturing of gains (Afualo and McMillan, 1996).

Vickrey's exploration of the presence of information asymmetry between governments (or public agencies) and firms in resource allocation makes a strong case for the use of auctions over other procedures. Empirical evidence tends to support this; Binmore and Klemperer (2002), for instance, show that firms ranked licences differently from government expectations in the UK $3 G$ spectrum auctions, whilst McAfee et al. (2009) show that while the US Federal Communications Commission had long attempted to achieve efficient spectrum allocations through the use of both administrative procedures and lotteries, it failed to achieve an allocation as efficient as it did through the use of auctions, beginning in $1994{ }^{23}$

\footnotetext{
21 'Efficient allocation' generally refers to a result where the resource is allocated to the user who places the highest value on it, such that the total gains to trade, or total surplus, is maximized. We discuss efficiency further in Section 7.

${ }^{22}$ With a small number of buyers and sellers.

${ }^{23}$ The 1994 auction used methods that were later replicated around the world to sell radio spectrum licences to the value of over US\$100 billion (McAfee et al., 2009).
} 

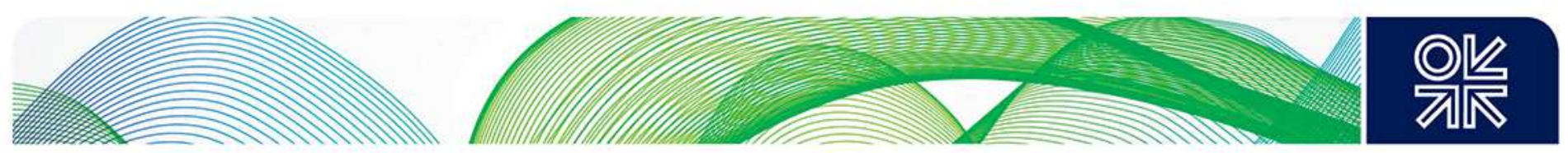

Amongst the other allocation methods, administrative processes, although globally the most commonly used, are susceptible to corruption, and risk assigning valuable public resources for less than their full value (Afualo and McMillan, 1996). Lotteries, which involve the assignment of public resources through random drawing, speed up the process - as seen in the US lottery for the allocation of cellular telephone licences in the 1980s (Afualo and McMillan, 1996). However, in the case of lotteries, it is difficult to discern serious bidders from speculative bidders, as was the case with the US cellular lottery. Again, assigning public property at random does not ensure that the property is placed into the hands of parties who are able to make the best use of it (Afualo and McMillan, 1996).

'First come first served' or 'queuing' procedures are arguably the closest to auctions, in the sense of placing an object in the hands of the bidder that has the highest value and use for it, since applicants most willing to stand in line are typically those who have the lowest opportunity costs - or, queuing favours those with access to few alternative resources (Afualo and McMillan, 1996). However, it has been argued that queuing can also be susceptible to the same random character and inefficient outcomes as a lottery (Afualo and McMillan, 1996).

Auctions are thus meant to reveal information about the value placed on the resource by the bidders, and consequently which bidder values it the highest (Afualo and McMillan, 1996). In a regulated industry, auction prices can also be used to give governments an estimate of the costs of regulation (Afualo and McMillan, 1996). For example, in the USA, when electricity prices were set by public commissions, utility firms had an incentive to overestimate the costs of environmental standards. But when the US Environmental Protection Agency introduced an auction of 'allowances to pollute' (giving industry the option of either installing mandated equipment or purchasing rights to pollute) bid prices of the pollution permits were lower than predicted, indicating that compliance costs were lower than originally claimed by industry during the setting of prices by public commissions (Afualo and McMillan, 1996).

An advantage of auctions is that they are transparent and minimize discretion, as they require the rules to be stated in advance (Afualo and McMillan, 1996). Auctions with carefully designed rules can be used to meet a variety of policy goals that may be different from pure revenue maximization, such as incentivizing technological innovation, or guarding against market dominance by imposing rules on how much of the resource can be controlled by a single firm (Afualo and McMillan, 1996). Governments could also attach conditions that successful bidders must meet in order to exploit the public resource; for example, the 'use it or lose it' provision in the US and Mexican spectrum licence auctions, designed to impose a pre-specified time limit within which to begin offering telecommunications services to the public (Afualo and McMillan, 1996). 
However, this ex ante requirement of auction design also implies that governments need to be very clear about auction objectives, and about the desired structure of the market ex post (Boue, 2002). ${ }^{24}$

\subsection{Types of Auctions}

Auction theory defines four basic auction types. In the ascending auction, the price is successively raised by the auctioneer until only one bidder remains; that bidder wins the object at the price at which the second highest bidder dropped out (Klemperer, 2004). The ascending auction is also known as the 'English auction'. In the descending auction, the auctioneer begins at a very high price, which is then lowered continuously. The first bidder to accept the price then wins the object at that price (Klemperer, 2004). This method is used in flower auctions in the Netherlands, and is therefore also referred to as the 'Dutch auction' (Klemperer, 2004). In the first price sealed bid auction, each bidder independently submits a single bid, without knowing his competitors' bids, and the object is sold to the highest bidder (Klemperer, 2004). These auctions have been used in the allocation of leases for the US Outer Continental Shelf (OCS). In the second price sealed bid auction, the highest bidder wins the auction but pays a price equal to the second-highest bid. The second price sealed bid auction is also referred to as a 'Vickrey auction' (Vickrey, 1961).

The Dutch auction and the first price sealed bid auction are strategically equivalent, as in each case the bidder's strategy involves determining, in advance, a single price at which he is willing to bid (Klemperer, 2004). Similarly, the English auction and the second price sealed bid auction are strategically equivalent, as in each case the winning bidder pays a price equal to the value of the second-highest bidder (Klemperer, 2004). Thus, for instance, in the ascending auction and the second price sealed bid auction, the optimal strategy for a bidder would be to submit a bid equal to his true value for the object; if he wins he always makes a surplus, as he pays a price equal to the value of the second-highest bidder - and from the auctioneer's point of view, this would ensure that the resource is allocated to the bidder that values it most (Klemperer, 2004). However, bidders are able to observe the bids of their competitors in the ascending auction, which is not always the case for the second price sealed bid auctions. ${ }^{25}$

In practice, governments have used a combination of different auction types in the auctioning of oil and gas leases, mineral leases, and telecommunications spectrum licences. Governments also have

\footnotetext{
${ }^{24}$ For example, the creation of monopsonistic or duopsonistic market structures where a single or a pair of bidders controls the market is not usually desirable.

${ }^{25}$ This depends on whether the government chooses to reveal all bids, or only the highest and second-highest bids. The strategic equivalence between the main auction types has led to auctions being modelled as strategic form games using solution concepts such as the Nash equilibrium.
} 

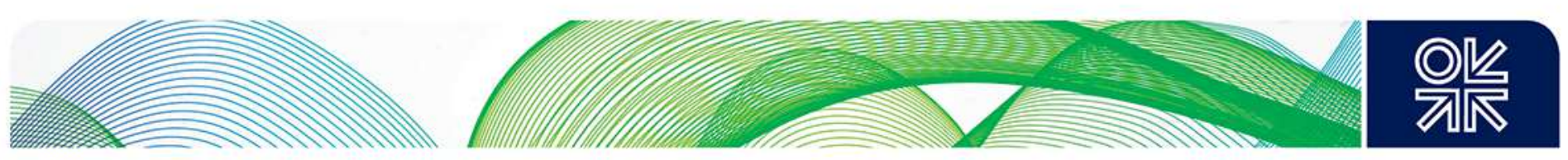

the option of designing either simultaneous auctions, where all items are auctioned at one time, or sequential auctions where objects are auctioned in sequence. But while auctions are economically superior to the alternatives, they may not always be preferred politically, and they may face resistance from incumbents (Afualo and McMillan, 1996). First, auctions may reveal information about bidders' valuations that governments may prefer not to disclose to the public. ${ }^{26}$ And second, a common fear expressed by critics of auctions is that firms' costs in auctions may be passed on to consumers in the form of higher prices (Afualo and McMillan, 1996). In the past two decades, growing public awareness of the need for transparency has been a predominant factor leading democratic governments to choose auctions as a method of resource allocation (Afualo and McMillan, 1996).

In India, the auctioning of oil and gas exploration leases has been pursued as part of a wider effort to reorient the economy from a centrally planned to an increasingly market oriented system. The next section discusses this context further, and sets out the main hypotheses of this paper.

\footnotetext{
${ }^{26}$ For example, if trade quotas were auctioned, then voters in democratic systems would gain some estimate of how much they were losing through trade restrictions (Afualo and McMillan, 1996).
} 


\section{Auctions for Oil and Gas Exploration Licences in India}

The allocation and use of licences (leases) for oil and gas exploration in India has followed a trajectory which mirrors the evolution of the wider economy. Originally, India's economy had limited private sector activity, moving later to a nationalized, centrally planned and administered postindependence operation primarily aimed at extending the benefits of economic development to the vast majority of the population. This was followed by a transition period, beginning in the early $1990 \mathrm{~s}$ but which is still underway, where mixed (increasingly private, alongside public) operation was encouraged (Jain, 2011; Jain and Sen, 2011). ${ }^{27}$ The underlying problem throughout this process of evolution has remained the question of how to continue to meet urgent objectives related to distribution, poverty alleviation, and affordable access, in an economically sustainable manner.

\subsection{Background and Context}

In the early 20th century, just two private companies operated in India's petroleum and natural gas sector. ${ }^{28}$ After India gained its independence in 1947, a period of expansion and nationalization took shape in the sector, beginning with the establishment of the Oil and Natural Gas Directorate (later Commission) (ONGC) in 1955, and eventually resulting in the existence of two large National Oil Companies (NOCs) - ONGC and Oil India Limited (OIL) by 1981. Petrofed (2005) details the evolution of this post-independence exploration regime. Jain $(2011,26)$ provides a summary of early exploration activities and major discoveries.

ONGC and OIL dominated the exploration sector from the 1950s to the late 1970s, and exploration activity was, by extension, conducted entirely within the domain of the government. The federal government allocated oil and gas leases through administrative procedures carried out within the public sector - the NOCs were required to 'nominate' areas of acreage believed to contain resource potential, and were awarded licences to explore these areas.

Although early discoveries by the NOCs sustained production up to the 1990s, reserve accumulation targets, set by the federal government under each of the Five Year Plans, consistently failed to be met. In response to this, the earliest bidding round for exploration licences, allowing partial private sector participation, was carried out in 1980; this was followed by two more rounds, in 1982 and 1986. However, the impact of declining reserve accumulation began to be seriously felt in the early 1990s,

\footnotetext{
${ }^{27}$ The Indian economy began liberalizing in 1991.

${ }^{28}$ Assam Oil Company and Burmah Oil Company.
} 

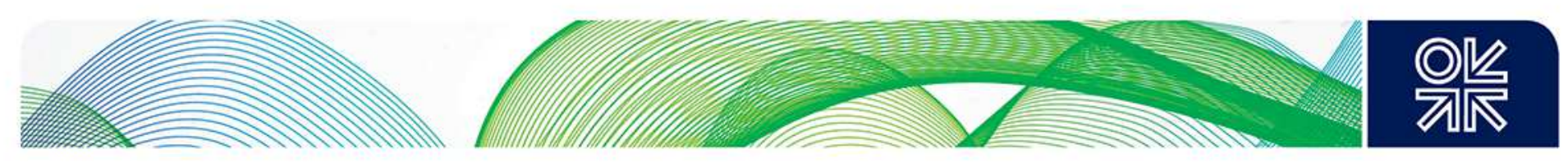

when it was clear that production from ONGC's largest offshore discovery (made in 1974), the Bombay High field, was beginning to plateau, and no significant new discoveries had been made. ${ }^{29}$

This spurred renewed efforts to attract private capital and technology into the sector and six more bidding rounds for exploration acreage took place between 1991 and 1995. Additionally, as part of the Structural Adjustment Programme attached to a World Bank loan at the time of India's 1991 financial crisis and subsequent economic liberalization, the federal government held two bidding rounds for the development of 'discovered fields' or acreages. These had been previously held by NOCs, and had been proven to contain substantial quantities of hydrocarbons. Tables $4.1 \mathrm{a}$ and $4.1 \mathrm{~b}$ summarize the responses to these eleven rounds of auctions in total.

\footnotetext{
${ }^{29}$ Proved oil reserves steadily declined from 6.1 billion barrels to 5 billion barrels between 1991 and 1999 , and oil production declined from 720,000 bopd to 590,000 bopd from 1989 to 1993 , after which it rose again to roughly 770,000 bopd in 1995, and then appeared to plateau (BP, 2011).
} 


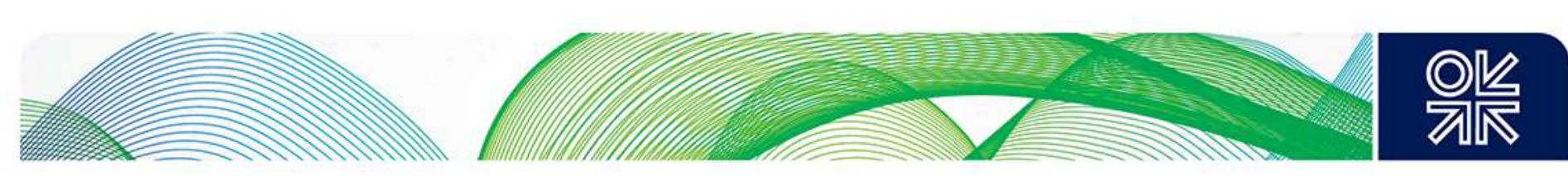

Table 4.1a: Bidding Rounds for exploration licences, 1991-5

\begin{tabular}{|c|c|c|c|c|c|c|c|c|}
\hline \multirow[t]{2}{*}{ Year } & \multirow[t]{2}{*}{ Round } & \multicolumn{3}{|c|}{ Number of Blocks Offered } & \multirow[t]{2}{*}{ Bids Received } & \multicolumn{3}{|c|}{ Contracts Signed } \\
\hline & & Offshore & Onshore & Total & & Offshore & Onshore & Total \\
\hline 1980 & 1 & 17 & 15 & 32 & 4 & 1 & 0 & 1 \\
\hline 1982 & 2 & 42 & 8 & 50 & 0 & 0 & 0 & 0 \\
\hline 1986 & 3 & 27 & 0 & 27 & 13 & 4 & 0 & 4 \\
\hline 1991 & 4 & 39 & 33 & 72 & 24 & 2 & 3 & 5 \\
\hline 1993 & 5 & 29 & 16 & 45 & 15 & 4 & 2 & 6 \\
\hline 1993 & 6 & 17 & 29 & 46 & 20 & 2 & 3 & 5 \\
\hline 1994 & 7 & 17 & 28 & 45 & 12 & 2 & 3 & 5 \\
\hline 1994 & 8 & 15 & 19 & 34 & 38 & 1 & 3 & 4 \\
\hline 1995 & 9 & 10 & 18 & 28 & 22 & 1 & 1 & 2 \\
\hline
\end{tabular}

Source: Petroleum Federation of India (Petrofed, 2005, 87)

Table 4.1b Bidding Rounds for developing discovered fields (reserves), 1992-3

\begin{tabular}{|c|c|c|c|c|c|c|c|}
\hline \multirow[t]{2}{*}{ Year } & \multirow[t]{2}{*}{ Round } & \multirow{2}{*}{$\begin{array}{c}\text { Medium Sized } \\
\text { Fields } \\
\text { Offshore }\end{array}$} & & \multicolumn{2}{|l|}{$\begin{array}{c}\text { Small Sized } \\
\text { Fields }\end{array}$} & \multirow[t]{2}{*}{ Bids Received } & \multirow{2}{*}{$\begin{array}{c}\text { Number of fields } \\
\text { for which } \\
\text { contracts signec }\end{array}$} \\
\hline & & & Onshore & Offshore & Onshore & & \\
\hline 1992 & 1 & 6 & 6 & 10 & 21 & 117 & 18 \\
\hline 1993 & 2 & 2 & 6 & 4 & 29 & 54 & 12 \\
\hline
\end{tabular}

Source: Petroleum Federation of India (Petrofed, 2005, 92) 

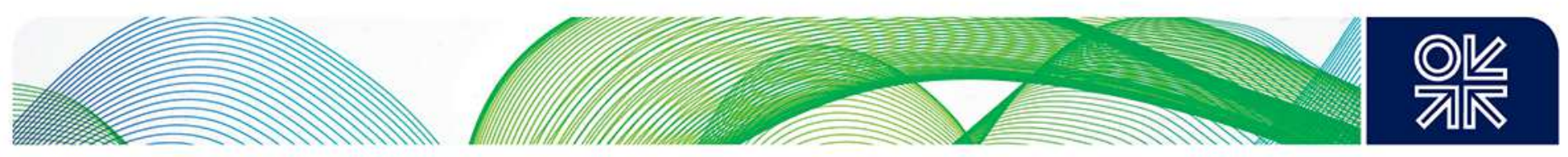

As the tables suggest, responses to the bidding rounds for the development of reserves discovered by the NOCs were far more favourable than responses to the bidding rounds for exploration licences. The bidding rounds for exploration licences attracted responses ranging from a high of 38 bids for one round to no bids for another; this variance can be attributed partially to international factors (such as the discovery of non OPEC supply sources, and competition for investment from other developing nations) and partially due to investors' perceptions of prospectivity at the time (Petrofed, 2005). ${ }^{30}$

The defining characteristic of the bidding rounds between1980-95 was the extent of involvement of the NOCs, which operated as extensions of the government. NOCs were involved in the selections of acreage and publishing of geological data, right through to the evaluation of bids; they also had a stake in the Production Sharing Contracts signed with private companies - in the first seven rounds through a 30 per cent carried interest and in the last two rounds through a joint venture with between 25 and 40 per cent working interest. Despite the relatively positive response to the last two bidding rounds, the number of contracts that were actually signed was very small. This was partially due to inefficient ex post procedures, where some contracts were signed nearly two years after the bids were awarded.

By the mid 1990s, there was increasing pressure to review the procedure for allocation of exploration licences. Part of this came from within the government and its desire to address a slowdown in the rate of reserve accumulation; it was felt that deep-water exploration would be enabled by attracting capital and technology. Another part of the pressure came from the private sector, which argued that the incentive structure in the existing regime was flawed; given their independent exploration activity alongside their role in the bidding rounds, NOCs had an incentive to not fully reveal geological and other information on prospectivity - and therefore, the selection of acreage for the bidding rounds, carried out by NOCs, was subject to moral hazard. A similar argument was made in relation to the fiscal terms relating to the NOCs' carried and working interest shares. In the event of a discovery, NOCs were liable for all royalty payments for contracts signed in the 1994 and 1995 bidding rounds for exploration - it was argued that this created disincentives for NOCs, leading to inefficiencies in the operation of joint ventures.

A review of the allocation procedure for exploration licences was carried out in 1995, resulting in the 1999 launch of a new regime for auctioning exploration acreage, the New Exploration Licensing Policy (NELP). The move to the NELP involved two components of reform; first, addressing concerns over the need to separate the NOCs from administrative and regulatory functions during the allocation

${ }^{30}$ Global oil price movements may also have played a role. 
of acreages, and second, reviewing the fiscal regime and reducing the royalty rate from its pre-NELP level of 20 per cent, to attract greater private investment.

The first component was addressed by appointing a separate body, the Directorate General of Hydrocarbons, in 1993 under the purview of the Ministry of Petroleum and Natural Gas, to take over all administration and oversight of the bidding rounds, freeing the NOCs to compete on a level playing field' with private companies in the bidding rounds. ${ }^{31}$ The second aspect required obtaining consensus from, first, the Ministry of Finance, which wanted to ensure that the new regime would allow for an early flow of revenues to the exchequer, and second, from the state governments, for whom royalties from onshore resources constituted a potentially crucial source of revenue. The federal government faced particular resistance from states in lowering the royalty rates. Eventually, a consensus was achieved and the rates were reduced to 10 per cent for offshore and 12.5 per cent for onshore discoveries under a Production Sharing Contract model. The NELP at the time was meant to be an intermediate arrangement in the transition from state control to an 'Open Acreage Licensing Policy (Jain, 2011); however, it continued to be pursued over the following 14 years, during which nine bidding rounds for exploration were carried out.

\subsection{India's New Exploration Licensing Policy (NELP)}

The NELP was announced in a federal government resolution on 10 February $1999 .{ }^{32}$ The main statement of the resolution read:

In order to attract private investment in [the] oil sector, [the] Government of India had been offering exploration blocks to private companies from time to time. There have so far been nine rounds of exploration bidding and [the] Government of India has entered into contracts for exploration by private companies through Joint venture arrangements. The demand for petroleum is expected to rise rapidly and it is necessary to step up the level of investment in exploration to hasten the pace of reserve accretion, which can serve as a base for higher levels of domestic production. (Gol, 1999).

The NELP contained two sets of significant reforms. The first applied to the fiscal terms of the regime, which was based on a Production Sharing Contract between the federal government and Exploration Company or consortium. ${ }^{33}$ These fiscal terms were 'progressive' under the common classification for fiscal systems (Johnston, 2003), in that the system was not front-loaded from the investor's point of

\footnotetext{
${ }^{31}$ This did not resolve the regulatory concern, as in practice the Directorate General of Hydrocarbons continues to be staffed by employees seconded from ONGC and OIL, in roughly a 75:25 ratio of representation.

${ }^{32}$ Available at http://petroleum.nic.in/newgazette/goi1.pdf

${ }^{33}$ Joint ventures and consortiums required each participating company to hold a minimum of $10 \%$ of the equity.
} 
view, and revenue (from the sharing of profits from production between the government and exploration company) began flowing to the government in proportion to the volume of cash flow, with profits beginning to be shared only after companies had recovered their capital costs of exploration.

Royalty rates for crude oil were set at 12.5 per cent for onshore and 10 per cent for offshore areas. Royalty for natural gas was set at 10 per cent. To encourage deep-water exploration, royalty was charged at 5 per cent for the first seven years of deep-water production. Companies were not required to pay signature, discovery, or production bonuses. Profits from production were to be shared with the federal government on the basis of a 'pre tax investment multiple' (similar to an R factor scale in the literature on fiscal design) ${ }^{34}$ Companies were allowed to claim back 100 per cent of exploration (capital) costs prior to sharing their profits from production with the federal government. A seven year tax holiday was granted from the start of production. ${ }^{35}$ Fiscal stability was guaranteed during the contract period and contracts were subject to the Conciliation and Arbitration Act (1996). Companies, including the NOCs, were to be paid international prices for crude oil. ${ }^{36}$ They were also given the contractual 'freedom to market' their production within the domestic (Indian) market, although this provision has been controversial in practice. ${ }^{37}$ There was no mandatory state participation and no carried interest of the state.

The second set of reforms under the NELP pertained to the procedure for allocating exploration acreage: a system of first price sealed bid auctions was introduced, which continues to be used to date. Acreages are identified and carved into onshore, offshore shallow-water, and offshore deepwater 'blocks' by the Directorate General of Hydrocarbons, which announces bidding rounds and makes data packages (with estimated production profiles and price estimates on these blocks) available for purchase to potential bidders. These packages are used, along with their own estimates on geology and operating and capital expenditure, by potential bidders to prepare their bids. A first price sealed bid auction is conducted in which bidders typically submit their sealed bids (simultaneously) for individual blocks within a deadline four or five months after the bidding round is announced. Bids are publicly opened within a few hours of the submission deadline. The system aims to minimize discretion in the identification of the winning bids. The time period taken to the actual

\footnotetext{
${ }^{34}$ This investment multiple was defined as the ratio of cumulative cash flow to cumulative capital expenditure. Companies were required to share a percentage of profits with the government at each of six tiers of this investment multiple: 1.5 and below, 1.5 to 2, 2 to 2.5, 2.5 to 3,3 to 3.5 and 3.5 and above. Typically, a higher share of profits would be shared at higher tiers of the investment multiple, or as the company's production (and therefore cash flow) grew in proportion to its capital expenditure.

${ }^{35}$ This was applied differently for oil and natural gas, as there were debates over the definition of 'mineral oil' in Production Sharing Contracts (Jain, 2011).

${ }^{36}$ There was a separate price discovery mechanism for gas. Jain (2011) and Sen (2012) provide an analysis of gas pricing in India.

${ }^{37}$ Jain (2011) provides a detailed analysis of the government's 'Gas Utilisation Policy'.
} 

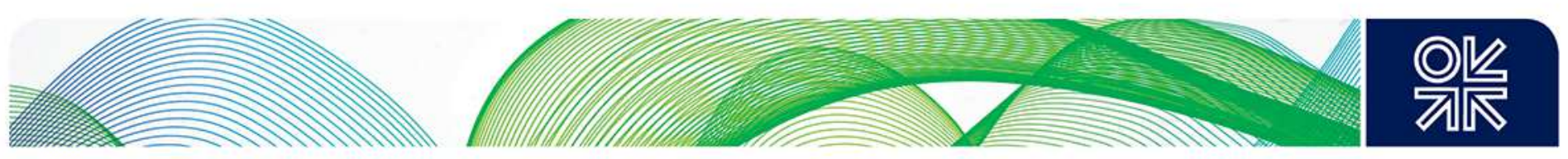

signing of contracts has then varied, often taking several months. Nine bidding rounds have been conducted under the NELP since 1999.

\subsubsection{Evaluation of Bids and Changes to the NELP Terms}

As there were no upfront monetary bonuses involved (in contrast to, for instance, the first price sealed bid auctions for leases on the US Outer Continental Shelf), the evaluation of bids under the NELP was carried out according to a set of predefined criteria. These criteria were: financial, technical, fiscal, and physical (work programmes) and each was assigned a maximum weight or score out of 100. Bids submitted for blocks were marked against these four parameters, and the bidder with the highest composite score (out of 100) awarded the licence to explore the block. There were no reserve prices, and bids were evaluated relative to each other.

Within the four main criteria, the scores were split into further sub-parameters, which have been occasionally modified across the nine rounds. Thus, the assessment for the technical criterion included the amount of acreage already held by the bidder, previous reserve accumulation and production, and previous experience of operatorship for deep-water blocks. ${ }^{38}$

For the financial criterion, the assessment included the net worth, debt-equity ratio, and profit before tax of bidders. The fiscal criterion required bidders to bid a maximum percentage of costs recoverable by the company in each year of production (bidders offering a lower maximum percentage were scored higher as this allowed profits from production to be shared with the government earlier on in the production phase), and the percentage of profits to be shared with the government at each tier of the investment multiple. The physical criterion pertained to the proposed work programme and related minimum expenditure commitment over the exploration period, which consisted of either seven or eight years, split into either two or three phases. Sub-criteria included the number of line kilometres of 2D seismic surveys, square kilometres of 3D seismic surveys, and wells (the depth of wells was also taken into account in later NELP rounds).

The weights assigned to the four main criteria were frequently modified to reflect the relative priorities of the federal government (as the auctioneer). Table 4.2 below shows how these weights varied across the nine bidding rounds.

\footnotetext{
${ }^{38}$ Although arguably, firms which had those advantages would in any case have been more likely to win the auctions. This assignment of extra credit therefore looks ambiguous - although it may have been meant to attract specific types of firms at the time.
} 

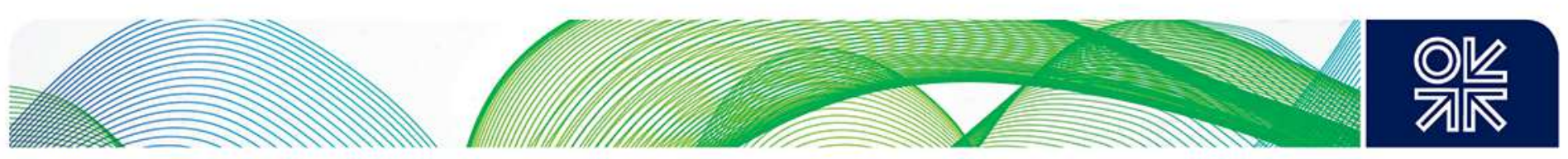

Whilst the first five rounds had higher weights allotted to the work programme (physical) relative to fiscal terms, this was reversed in the sixth round, reflecting a change in the government's objectives from encouraging exploration activity to ensuring rent extraction. This change followed the 2004 discovery of India's largest gas field in the Krishna Godavari basin (KG-D6) by Reliance Industries Limited (RIL), under the NELP. This approach was maintained until the eighth round when weights for the two criteria were equalized for all but deep-water blocks, emphasizing a focus on deep-water exploration.

Within the fiscal criterion, the six-tier investment multiple was replaced with a two-tier system in the seventh bidding round: 1.5 and below, and 3.5 and above, with shares in-between worked out on the basis of a linear sliding scale. This was to address concerns over companies inflating their capital costs to remain within the lower bounds of the investment multiple, in order to share a lower percentage of their profits. The change was meant to ensure the government a share of profits from production at every increment of the investment multiple.

The financial criterion was removed from the total score from the sixth round onwards, being replaced with a requirement that bidders met a basic qualifying standard (which generally proved that their net worth was greater than the total value of the work programme). Similarly, the technical score for onshore and shallow-water blocks was replaced with a qualifying standard (based on previous experience in operatorship or production, or both, depending on the geological complexity of the block) from the seventh round onwards. Therefore, in later rounds of the NELP, the fiscal terms and work programme alone accounted for the main parameters upon which the winning bids were determined.

Another significant amendment was the categorization of the resource potential of blocks, introduced in the sixth bidding round, based on existing data, where 'A' blocks were deemed more favourable than 'B' blocks (this categorization was rescinded in the eighth round). Additionally, ' $S$ ' type blocks (smaller onshore blocks under 200 square $\mathrm{km}$ in area) were introduced in the seventh round. The entry barriers to bidders for ' $S$ ' blocks were very low, presumably to encourage participation from small- and medium-sized companies, and to encourage exploration in marginal fields which did not meet the economic thresholds set by larger companies. 


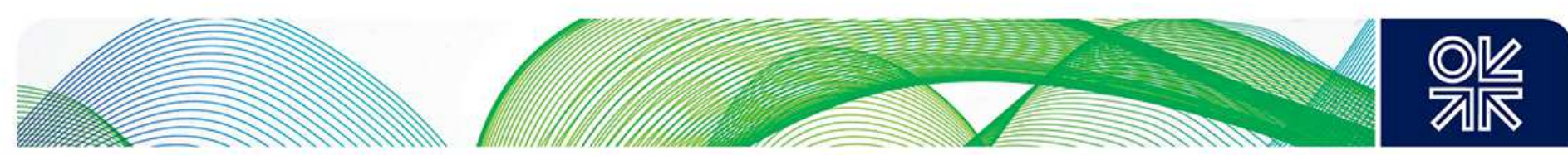

Table 4.2: Bid Evaluation Criteria, NELP Auction Rounds I-IX

\begin{tabular}{|c|c|c|c|c|c|c|c|c|c|c|c|c|c|c|c|c|}
\hline \multirow{3}{*}{$\begin{array}{l}\text { Criterion/ } \\
\text { Points }\end{array}$} & I & II \& III & \multicolumn{2}{|c|}{ IV \& V } & \multicolumn{4}{|c|}{ VI } & \multicolumn{5}{|c|}{ VII } & \multicolumn{3}{|c|}{ VIII \& IX } \\
\hline & (1999) & $(2000$ & (2003 & 2005) & \multicolumn{4}{|c|}{ (2006) } & \multicolumn{5}{|c|}{ (2007) } & \multicolumn{3}{|c|}{$(2009 \& 2010)$} \\
\hline & & & $\begin{array}{c}\text { onshore } \\
\text { \& } \\
\text { shallow- } \\
\text { water }\end{array}$ & $\begin{array}{l}\text { deep- } \\
\text { water }\end{array}$ & \multicolumn{2}{|c|}{$\begin{array}{c}\text { onshore \& } \\
\text { shallow- } \\
\text { water }\end{array}$} & \multicolumn{2}{|c|}{ deep-water } & \multicolumn{3}{|c|}{$\begin{array}{c}\text { onshore \& } \\
\text { shallow-water }\end{array}$} & \multicolumn{2}{|c|}{ deep-water } & $\begin{array}{c}\text { onshore } \\
\text { S-Type }\end{array}$ & $\begin{array}{l}\text { onshore } \\
\text { \& } \\
\text { shallow- } \\
\text { water }\end{array}$ & $\begin{array}{l}\text { deep- } \\
\text { water }\end{array}$ \\
\hline Type & & \multicolumn{3}{|c|}{ No Categorization } & A & B & A & B & $A$ & B & $\begin{array}{c}\text { S- } \\
\text { Type }\end{array}$ & $A$ & B & S-Type & \multicolumn{2}{|c|}{ No Categorization } \\
\hline Technical & & 6 & 6 & 9 & 15 & 15 & 20 & 20 & \multicolumn{2}{|c|}{ Qualifying } & None & 30 & 30 & None & Qualifying & 25 \\
\hline Financial & disclosed & 4 & 4 & 6 & \multicolumn{4}{|c|}{ Qualifying } & \multicolumn{5}{|c|}{ Qualifying } & \multicolumn{3}{|c|}{ Qualifying } \\
\hline $\begin{array}{c}\text { Work } \\
\text { Programme }\end{array}$ & & 60 & 60 & 55 & 25 & 35 & 20 & 30 & 40 & 50 & 40 & 15 & 25 & 50 & 50 & 25 \\
\hline Fiscal & & 30 & 30 & 30 & 60 & 50 & 60 & 50 & 60 & 50 & 60 & 55 & 45 & 50 & 50 & 50 \\
\hline Total & & 100 & 100 & 100 & 100 & 100 & 100 & 100 & 100 & 100 & 100 & 100 & 100 & 100 & 100 & 100 \\
\hline
\end{tabular}

Source: Ministry of Petroleum and Natural Gas 
One aspect of the NELP which also underwent frequent adjustment, but which is not captured in Table 4.2, relates to the government's efforts to discourage 'speculative' bidders and ensure the enforcement of work programme commitments ex post. This was carried out through rules for the relinquishment of acreage, financial guarantees and penalties for unfinished work programmes, and the introduction of mandatory work programmes. Typically, companies have been required to relinquish a certain percentage of the area of the block upon completion of the first phase of the exploration period, and the entire area upon completion of the remainder (apart from areas where discoveries have been made). Relinquishment at the end of the first phase was first set at 25 per cent; this was increased to 40 per cent in the seventh round, and then made optional in the eighth round on the condition that a stipulated number of wells were drilled by companies opting to retain the block area within the remainder of the exploration period. In practice, the government has been criticized for failing to enforce relinquishment rules stringently and for permitting extensions (CAG, 2011). ${ }^{39}$

Financial guarantees, amounting to a specified percentage of the value of the annual work programme, were introduced in the sixth bidding round. Mandatory work programmes, acting as an implicit reserve price, were also brought in during the sixth NELP round; winning bidders were required to commit to these in addition to the work programme in the bid. An additional measure to discourage 'speculative bidders', introduced in the eighth round, was the requirement for a 'bid bond' to be paid by bidders, valid for a one year period, which would be released upon the signing of the Production Sharing Contract. ${ }^{40}$ Financial penalties for unfinished work programmes were also introduced in the eighth round; companies were required to pay 'liquidated damages' which were fixed per line kilometre or square kilometre of $2 \mathrm{D}$ and $3 \mathrm{D}$ seismic surveys, and per well. ${ }^{41}$ The amounts of these penalties comprised a fraction of overall expenditure commitments.

The basic terms of the NELP auctions system, therefore, remained largely unchanged over the period 1999-2010.

\footnotetext{
${ }^{39}$ Relinquishment, or 'use it or lose it' provisions are controversial. For instance, if a firm reduces exploration because of a fall in the long run price of oil, or information discovered early on in the process, then continuing exploration may be inefficient and a 'use it or lose it' provision could encourage waste - feeding into the cost recovery process. At the same time, stopping exploration may be in violation of contractual agreements.

${ }^{40}$ The amounts of the bid bond were: Rs. $2 \mathrm{~m}$ for deep-water blocks, Rs. $1.5 \mathrm{~m}$ for shallow-water blocks, Rs. $1 \mathrm{~m}$ for onshore blocks and Rs.500,000 for onshore 'S' type blocks.

${ }^{41}$ For onshore work programmes, the fines were US $\$ 1 \mathrm{~m}$ per well, US $\$ 5,000$ per square $\mathrm{km}$ of $3 \mathrm{D}$ seismic, and US $\$ 2,500$ per line $\mathrm{km}$ of $2 \mathrm{D}$ seismic surveys. For shallow-water programmes, the corresponding amounts were US $\$ 3 \mathrm{~m}$, US $\$ 1,500$, and US $\$ 1,000$. For deep-water programmes, the corresponding amounts were US $\$ 6 \mathrm{~m}$, US $\$ 1,500$, and US $\$ 1,000$.
} 


\subsection{Main Hypotheses}

Roughly 250 production sharing contracts have been signed, US $\$ 16$ billion of investments committed, and reserves of 700 million metric tonnes of oil and oil-equivalent gas accumulated under NELP. However, looking closely at ex post outcomes, there are indications that the regime has not fulfilled its implicit objectives.

First, data on exploration coverage implies that the NELP auctions may not always have allocated blocks efficiently, that is, to bidders who placed the highest value on them, or that the market design has not ensured that the source of wining bidders' valuations is to explore for hydrocarbons. ${ }^{42}$ Figure 4.1 shows progress in exploration across India's 26 sedimentary basins - which constitute a total area of 3.14 million square $\mathrm{km}$.

Figure 4.1: Progress in Exploration, 1995-2011

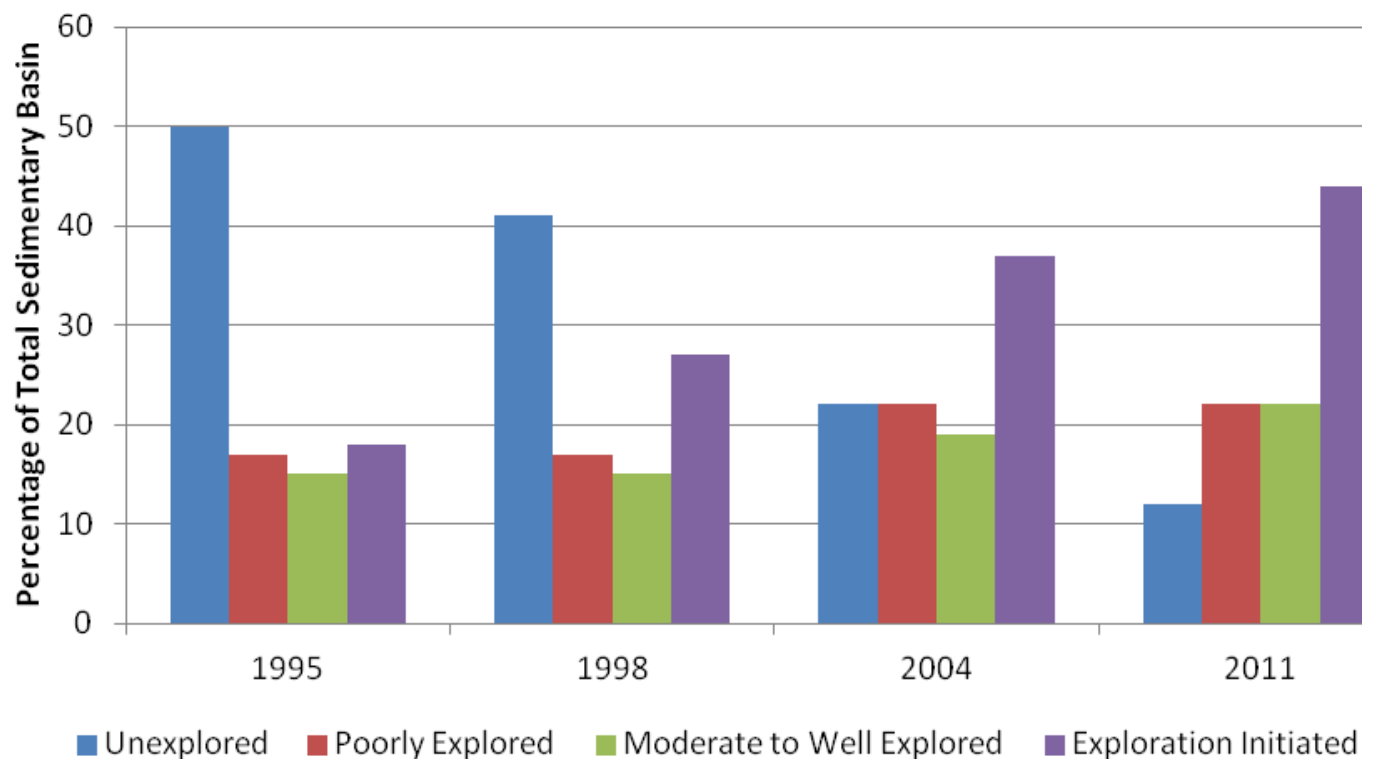

Source: Directorate General of Hydrocarbons (2011)

Between 1995 and 2011, while the percentage of 'unexplored' area has been steadily decreasing (from 50 to 12 per cent) and the percentage where 'exploration has been initiated' has been simultaneously increasing (from 18 to 44 per cent), the percentages of 'poorly explored' and 'moderate to well-explored' areas have remained largely unchanged over the period of the NELP.

\footnotetext{
${ }^{42}$ Bidders may value blocks based on other objectives (sources of valuation), such as increasing an asset portfolio in the short term, or maintaining market share.
} 
This indicates a potential holdup problem - large swathes of acreage have been auctioned and exploration initiated in these, but very little or no progress appears to have been made in determining and developing their resource potential. This is supported by the fact that over a period of nearly two exploration cycles, the NELP resulted in just one 'giant' discovery of gas (the KG-D6 field by Reliance Industries Limited) being brought into production. ${ }^{43}$

The holdup problem could signify two underlying issues; (1) ex ante problems with ensuring that the auction process allocates blocks to bidders that will make the best use of them, and (2) ex post problems with contractual enforcement or contractual incompleteness, where the winning bidder (company or consortium) does not, or is unable to, fulfil its work programme commitments - or essentially, problems with market design.

Second, it follows from the above that auction design plays an important role in the allocation of acreage, particularly with respect to its role in information revelation and in the removal of information asymmetry between auctioneer and bidder. A pertinent example of the impact of information asymmetry can be seen in the seventh bidding round, where a consortium comprising BHP Billiton and GVK Industries placed bids for seven deep-water blocks, and were awarded all seven, but consequently could not meet their investment commitments, leading to a holdup in exploration. Reports suggest that the companies discovered ex post that they were the sole bidders on all of these blocks. ${ }^{44}$ This example suggests that BHPB-GVK may have in aggregate submitted a bid higher than their actual value for the blocks, a situation commonly referred to as the 'winner's curse' in auctions literature; the same literature suggests this can be avoided through the ex ante reduction of information asymmetry - via the publishing of geological databases, or through the use of reserve prices. Another possibility is that the consortium may have discovered information ex post which made it inefficient to continue exploration - in this case, the objectives of the firm were not in alignment with those of the government, and market design could have played in important role in ensuring that the objectives of the regime were met. ${ }^{45}$

Figure 4.2 shows that the percentage of blocks for which bidding companies (consortiums) were unable to fully meet their committed investments on exploration has been relatively high for each NELP round.

\footnotetext{
${ }^{43}$ The initial volumes of expected production from this discovery were also revised downwards.

${ }^{44}$ Media reports indicated that this had been unanticipated by both BHP and GVK, who later struggled to meet their capital outlay commitments, leading to delays in exploration. See 'GVK, BHP likely to sell part of stake in blocks', Livemint - Wall Street Journal, 5 August 2011. Available at http://www.livemint.com/2011/08/05010243/GVK-BHP-likely-to-sell-part-o.html In October 2013, BHP announced its intentions to exit from all its deepwater acreages.

${ }^{45}$ In other words, the 'rules of the game' could be designed to take into account this situation.
} 

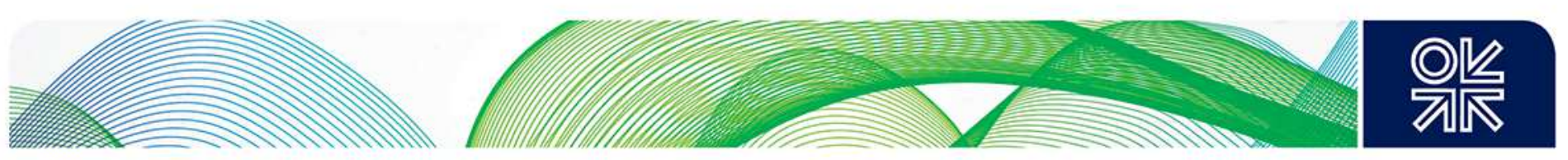

Although financial penalties were introduced to enforce work programme commitments in the seventh round, the literature on auctions suggests that if penalties are not set substantially high, bidders may simply adjust their bids to include these costs as sunk costs; thus if the costs of defaulting on commitments is small, bidders end up bidding (and paying for) 'options on prizes rather than the prizes themselves' (Klemperer, 2004). This would hold true for the amounts of liquidated damages, for instance, per well, under the NELP, which formed a fraction of the total cost of drilling a well.

\section{Figure 4.2: Percentage of Blocks for which Investment Commitments Not Met}

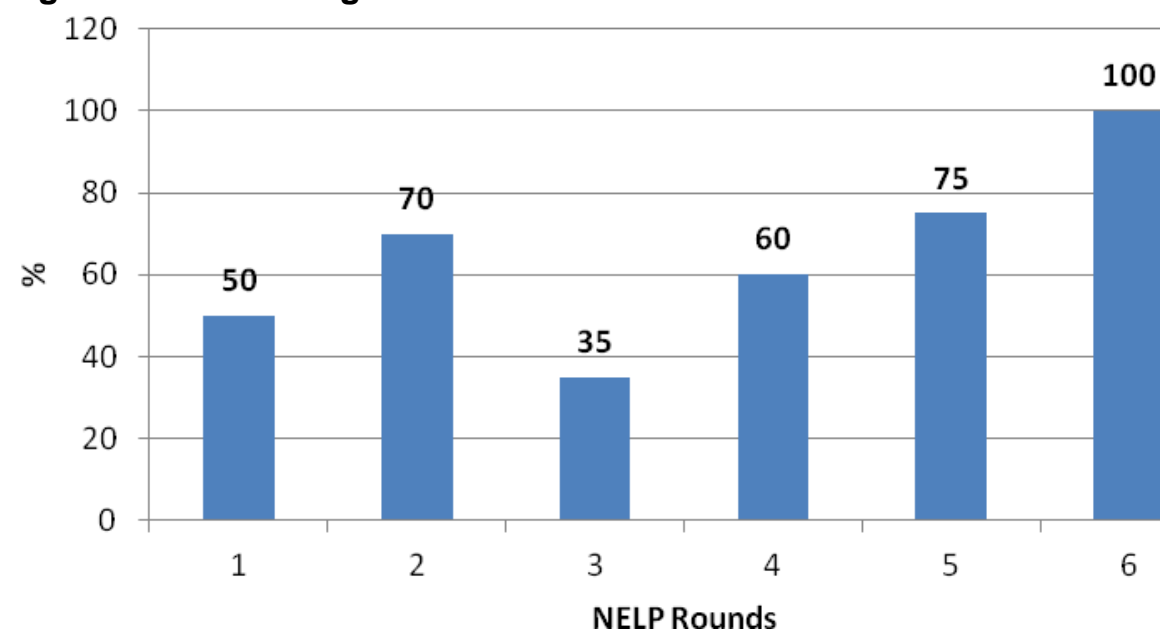

Source: Ashok Chawla Committee Report on Natural Resource Allocation (2011) Note: Data not available for $7^{\text {th }}, 8^{\text {th }}$ and $9^{\text {th }}$ rounds.

It can be argued that this failure to fulfil exploration commitments has, in turn, led to a proliferation of insufficient information, as new geological information fails to be made available. This is reflected in the ambiguous perceptions of India's resource potential, or prospectivity, by potential investors.

A third indication that the NELP auctions have had unintended consequences is reflected in the wider issue of the extent of participation from different types of bidders. Notably, few of the international oil and gas majors - important in facilitating the capital and technology injections required for development of deep-water reserves - have participated in the NELP rounds. Table 4.3 compares the participation of major international companies in India with participation in bidding rounds in Brazil (another large developing country with a similar economic and political system) which were also launched in 1999, at the same time as the NELP. 
Table 4.3 Participation of International Majors in Bidding Rounds, India vs Brazil

\begin{tabular}{|l|c|c|}
\hline & India (NELP) Auctions & Brazil Bidding Rounds \\
\hline Anadarko & & $\sqrt{ }$ \\
\hline BG & $\sqrt{ }$ & $\sqrt{ }$ \\
\hline BHP Billiton & $\sqrt{ }$ & $\sqrt{ }$ \\
\hline BP & & $\sqrt{ }$ \\
\hline Chevron & & $\sqrt{ }$ \\
\hline ConocoPhillips & & $\sqrt{ }$ \\
\hline ExxonMobil & $\sqrt{ }$ \\
\hline ENI & $\sqrt{ }$ & $\sqrt{ }$ \\
\hline Gazprom & $\sqrt{ }$ \\
\hline Petrobras & & $\sqrt{ }$ \\
\hline Royal Dutch Shell & & \\
\hline Statoil & & \\
\hline Total & & \\
\hline Soure: Compled
\end{tabular}

Source: Compiled by Authors

Participation from Indian companies, on the other hand, has been much more forthcoming, although there are some interesting patterns within this participation. The NOCs have, for instance, continued to account for the majority of winning bidders under the NELP, particularly for deep-water acreage - a close replication of market structure under the pre-NELP era.

Further, the response to auctions for smaller 'S' type blocks has been overwhelmingly higher than for deep-water blocks, and has involved non specialist companies rushing to participate in exploration through partnerships with smaller domestic exploration companies. However, although the objectives of bidders for different geological types are presumably different (smaller bidders may view the NELP in terms of medium-term investment opportunities, whereas large bidders take a longer term view, possibly linking into opportunities in the downstream sector), the same auction format is used for all geological types.

A final indication of problems with the NELP regime lies in debates within the federal government over its effectiveness in (a) the extraction of revenues and (b) the pace of exploration of acreages by companies. The Comptroller and Auditor General of India (CAG) published an audit of 22 NELP Production Sharing Contracts in August 2011 in which it was claimed that large amounts of revenue had been potentially lost to the exchequer due to poor ex post enforcement, particularly in relation to the monitoring of capital costs and profit sharing. The report also criticized the Directorate General of Hydrocarbons for not stringently enforcing relinquishment rules, which may have slowed the pace of 

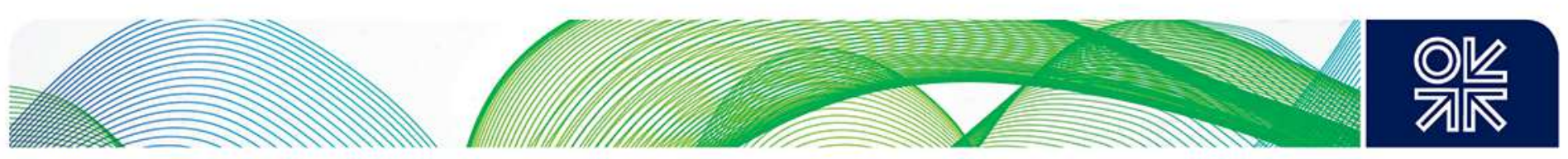

exploration $^{46}$ (CAG, 2011). Whilst these concerns are partially attributable to enforcement issues, it can also be argued that the original NELP resolution does not clearly state the objectives of the auctioneer (government) in terms of their relative importance. This is significant as there are some debates in auction design literature on whether optimality (the maximization of the auctioneer's revenues) and efficiency (the maximization of social welfare, via both consumer and producer surpluses) are conflicting objectives. ${ }^{47}$

Based on these initial observations, and on the empirical literature review which follows, this paper proposes to explore the outcomes of the NELP regime by analysing the following main hypotheses, or lines of argument:

1. The Ex Post Market Structure: The NELP auctions have led to an unintended ex post market structure (in terms of company sizes, ownership, and capabilities) resembling a highly concentrated market, in which few companies have tended to dominate bidding rounds, as opposed to a more diversified one.

2. The Holdup Problem: The NELP auctions have led to a 'holdup' problem, where blocks have been awarded to bidders who have not developed them within the contractual exploration period. Potential reasons for this could be that winning bidders have over-bid for blocks ex ante and are unable to fulfil their investment commitments; or insufficient attention has been given to market design to deal with the misalignment between firm and government incentives ex post in instances where firms may discover information that makes it inefficient for them to continue with exploration. This paper argues that there is some evidence of both.

3. The Objectives of the Auctioneer - Optimality versus Efficiency: The objectives of the government (as auctioneer) in auction design remain ambiguous in the NELP auctions, in terms of their relative importance; for instance, the optimality (maximizing revenue) versus efficiency (maximizing the gains to trade) issue. This lack of policy clarity has arguably led to some of the unintended outcomes of the NELP, acting as a constraint on its effectiveness.

In the remainder of this paper we investigate the above hypotheses using a combination of empirics and economic theory. We also explore the dynamics of the auction rounds using a simple

\footnotetext{
${ }^{46}$ On the basis that large areas of auctioned acreage continued to be held but not developed by exploration companies. However, as discussed in Section 4.2, 'use it or lose it' provisions or relinquishment may not necessarily be effective and could lead to inefficiencies.

${ }^{47}$ This is discussed further in Section 7.2.
} 

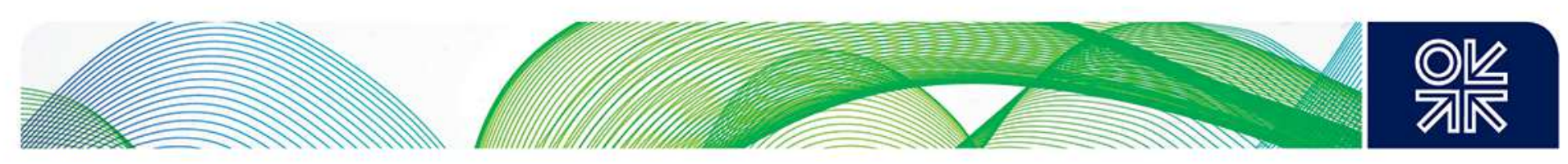

econometric model which analyses the correlates of successful bids, based on an empirical approach from lledare et al. (2004).

The next section reviews the main empirical studies of lease auctions, focusing on the types of outcomes observed, and the methods used. 


\section{Summary of Empirical Literature}

The most frequently studied auctions in the world have been the US auctions for drilling leases, primarily due to an abundant availability of data - we therefore focus on these in developing our methodology. Lease auctions in the USA began in 1954, where leases granting the right to explore and develop a particular tract for five years were auctioned. ${ }^{48}$ If oil is found and developed, the lease is renewed for a nominal fee as long as production continues (Cramton, 2007). Oil companies nominate tracts for auction, and the government then shortlists tracts for auctioning. The auction is a simultaneous first price sealed bid auction using cash bonuses; each bidder simultaneously submits a bid - which must meet or exceed the minimum bid (a reserve price) stated in US\$ per acre - on each of the tracts it desires (Cramton, 2007). A tract is either awarded to the high bidder, or all bids on the tract are rejected; the reserve price is undisclosed during the process. A winning bidder pays its cash bonus and also pays a royalty of one-sixth of revenues for any oil subsequently produced (Cramton, 2007). Lease sales are categorized into three types: wildcat tracts, which are relatively unexplored; drainage tracts, areas that lie adjacent to proven or producing tracts; and developmental tracts, which are re-offerings of previously sold tracts that were relinquished without any exploratory drilling, or reofferings of tracts where previous bids were rejected. Cramton notes that the differences in information asymmetry between the three types of lease could have been more successfully used by the auctioneer to maximize revenues by tailoring auction design to each type of lease - a simultaneous ascending auction for wildcat tracts and a simultaneous sealed bid auction for drainage and developmental tracts. ${ }^{49}$ However, auctions for all three different geologies have been carried out using the same method; Cramton (2007) attributes this to 'reasons of inertia'.

Mead et al. (1984) on the other hand argue against the use of different auction formats. They analyse bidding behaviour for wildcat leases in comparison with that for drainage leases, and although they find a large difference in the aggregate after tax Internal Rate of Return (IRR) of bidders for the two types of sale, they argue that wildcat and drainage leases should not be treated as different with regard to the amount of rent extracted by the auctioneer (government). Their study explains the lower IRR on wildcat investments by suggesting that buyers of wildcat tracts are investing in both the option to produce oil and gas from a wildcat lease and in the opportunity to obtain information from the lease which could be of value in bidding for an adjacent tract (Mead et al., 1984). They argue that if bidders on drainage leases are expected to achieve superior results in future lease auctions, it does not

\footnotetext{
${ }^{48}$ US auctions use the terms 'tract' and 'lease' instead of 'block' and 'licence'.

${ }^{49}$ Wildcat tracts are unexplored areas, and ascending auctions, with their repeated interactions, allow the revelation of information which alleviates asymmetries of information amongst the auctioneer and bidders. Drainage and developmental tracts are those in which resource potential has been reasonably determined, and hence information asymmetry is low as both auctioneer and bidders have access to this information.
} 

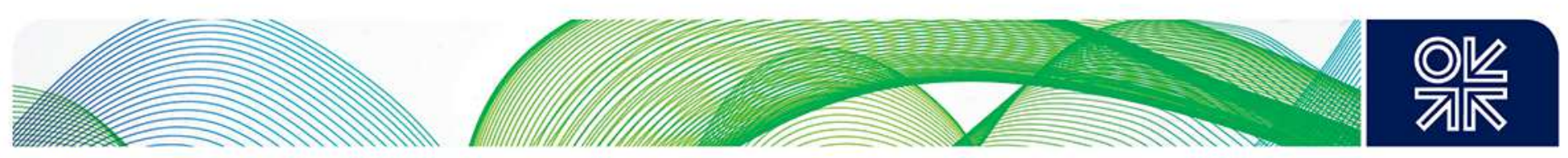

necessarily follow that the federal government should eliminate their bidding advantage - the superior information position of bidders on drainage tracts is ultimately derived from leasing and exploring wildcat tracts. Given effective competition, the government will capture the net expected value of drainage prospects in the leasing of wildcat tracts (Mead et al., 1984). However, the level of competition required to assure this is unspecified, and may not exist in developing countries such as India.

In discussing different auction formats for different geologies, parallels can be drawn with the US Forest Service Timber auctions. The Forest Service identifies tracts of timber for auction and announces the details (including estimates of available timber, logging costs, tract characteristics, and a reserve price). ${ }^{50}$ The auctions are conducted in two formats - open (ascending) auctions and sealed bids - depending on the characteristics of nearby markets. If the market has a high volume of sales, low inventory, and high economic 'dependence' on Forest Service timber, open auctions are used (Hansen, 1986). Bidders are either 'loggers' or 'mills'; mills have the manufacturing capacity to process timber and thus an ex ante advantage - thus, mills are the 'stronger' bidders (Athey et al., 2004). Athey et al. use data from these timber auctions, assuming asymmetry and heterogeneous value distributions amongst bidders (by distinguishing between loggers and mills), and the fact that it is costly to acquire information and bid in the auction. The results show that sealed bid auctions attract more loggers and result in slightly higher revenues to the auctioneer than open auctions (which attract more mills); but they also distort the efficient allocation towards loggers (that is, loggers tend to win sealed bid auctions). The implicit conclusion is that open auctions attract stronger bidders but are perceived as less competitive (in terms of participants) whereas sealed bid auctions attract greater competition but do not always result in the allocation of timber to bidders that are able to make the best use of it.

Porter (1995) analyses the role of information in the US oil and gas offshore auctions, testing separate models for wildcat and drainage tracts. The findings suggest that joint bidding - which gives firms the incentive to communicate and coordinate - has had an impact on the structure of the market ex post. Porter also questions the goals of the auction and what should be 'maximized'; much of the literature on optimal auction design assumes that government revenue maximization is the goal. However, the expeditious exploration and development of supplies is an alternative goal, and this study poses the question of whether the two are mutually exclusive (Porter, 1995).

\footnotetext{
${ }^{50}$ Reserve prices are set by the auctioneer, but take into account estimates submitted by the industry and potential bidders.
} 

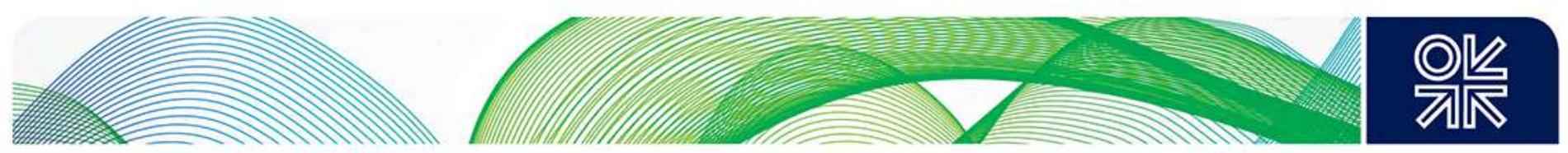

Smith (1982) studies the economic determinants of bidding behaviour in petroleum lease sales on the US Outer Continental Shelf (OCS) and classifies the factors which condition the magnitude of a firm's bid as including: the expected economic value of the potential resource, the degree of uncertainty which surrounds this value, the anticipated degree of competition to acquire the tract in question, and the bidding firm's capacity to bear financial risks. The study uses multiple regression analysis to measure the explanatory influence and statistical significance of these factors. It also investigates the prevalence of joint bidding, which became a concern for the federal licensing authority, which eventually banned eight of the largest firms from submitting joint bids on certain tracts to avoid problems of collusion.

Iledare et al. (2004) review, evaluate, and analyse bidding behaviour and performance for leases awarded in the Gulf of Mexico, off the Texas and Louisiana coasts, from 1983 to 1999, in terms of the responsiveness of the value of the high (winning) bids to: the number of bids, the perceived quality of the lease, the size of the firms bidding for leases, the bidding methods (solo or joint), and the bidding structure (multiple bids as compared to single bids). They conclude that neither aggregate measures used to analyse concentrated market and industry structures, nor patterns of joint bidding among firms active in the offshore Gulf of Mexico suggest either a decrease or a deficiency in the competitiveness of the lease sales. Their empirical results show that the relative change in the mean value of the winning bonus bid for leases with multiple bids (competitive leases) is greater than the change in the mean value of single-bid leases. Further, the mean value of the winning bonus bid for deep-water leases is also found to be significantly higher than that for shallow-water leases. The results also suggest that variation in crude petroleum prices may lead to a higher mean value of bonus bids, ceteris paribus.

Other relevant empirical work on the US auctions includes Gilley and Karels (1981), which shows that the number of individual bids decreases as the number of bidders increases; Hughart (1975), which shows that optimal allocation (to the highest bidder) does not take place when one bidder has superior information; Reece (1978), which shows that the value of bids decreases as the number of bidders decreases, along with uncertainty about the value of tracts; and Ramsey (1980), which argues that the number of licences should be limited when the number of bidders is less than three or four, as the lack of competition reduces government revenue.

Besides the US auctions, Maritz (2003) analyses the determinants of bidding for offshore petroleum exploration permits in Australia, where bids are assessed primarily on the basis of a work programme proposed for the first three years, as the auctioning authority awards exploration permits to the bid that is most likely to further the potential of the area. If a discovery is made, the company can apply 

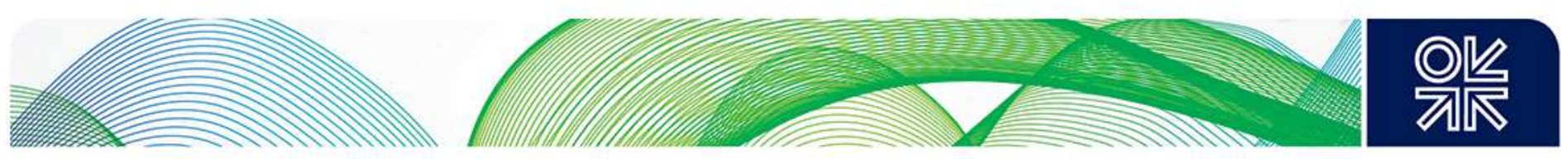

for a production licence and is entitled to all profits (after taxes and royalties) from production. In the event of a discovery of non-commercial reserves that are likely to become commercial within 15 years, the permit holder may postpone development and production under a retention lease that is reassessed every five years (Maritz, 2003). The study investigates the factors that determine the size of work programme bids and the functional relationship between the bids and these factors, and the factors that are most important in explaining the observed variability in the size of work programme bids. Maritz uses bivariate data analysis and regressions to examine these questions for factors such as: the oil price, prospectivity, competitiveness, economic environment (GDP), foreign participation, and the sizes of bidders and joint ventures. Out of these factors, competitiveness emerges as a major determinant of the size of bid. Maritz highlights the fact that more research is required into auction designs that meet the dual goals of optimal bids and an appropriate spread of productive exploration in more and less mature areas.

The academic literature on the Indian NELP auctions is scant, in part due to difficulties with obtaining data. This paper therefore contributes significantly by analysing a dataset of variables covering the nine NELP auction rounds, for the period 1999-2010. Data was collected on fieldwork, which also included interviews with roughly 40 individuals and organizations in the oil and gas sector. Data is analysed in this paper primarily through extended descriptive statistics and regression analysis. 


\section{Empirical Analysis}

\subsection{Characteristics of the Market for NELP Auctions}

This section presents a descriptive analysis of the structure, conduct, and performance of the market for oil and gas exploration leases under the NELP auctions from 1999-2010, based on the approach in lledare et al. (2004). We begin by setting out a broad picture of the performance of the auctions at an aggregate level, using standard performance indicators described in the literature - the number of blocks on offer, the number of blocks for which bids were received, the number of blocks which were awarded (to the highest bidder), and the number of contracts signed (assuming one contract signed per block).

Figure 6.1: Aggregate Trends Over Nine NELP Auction Rounds: I

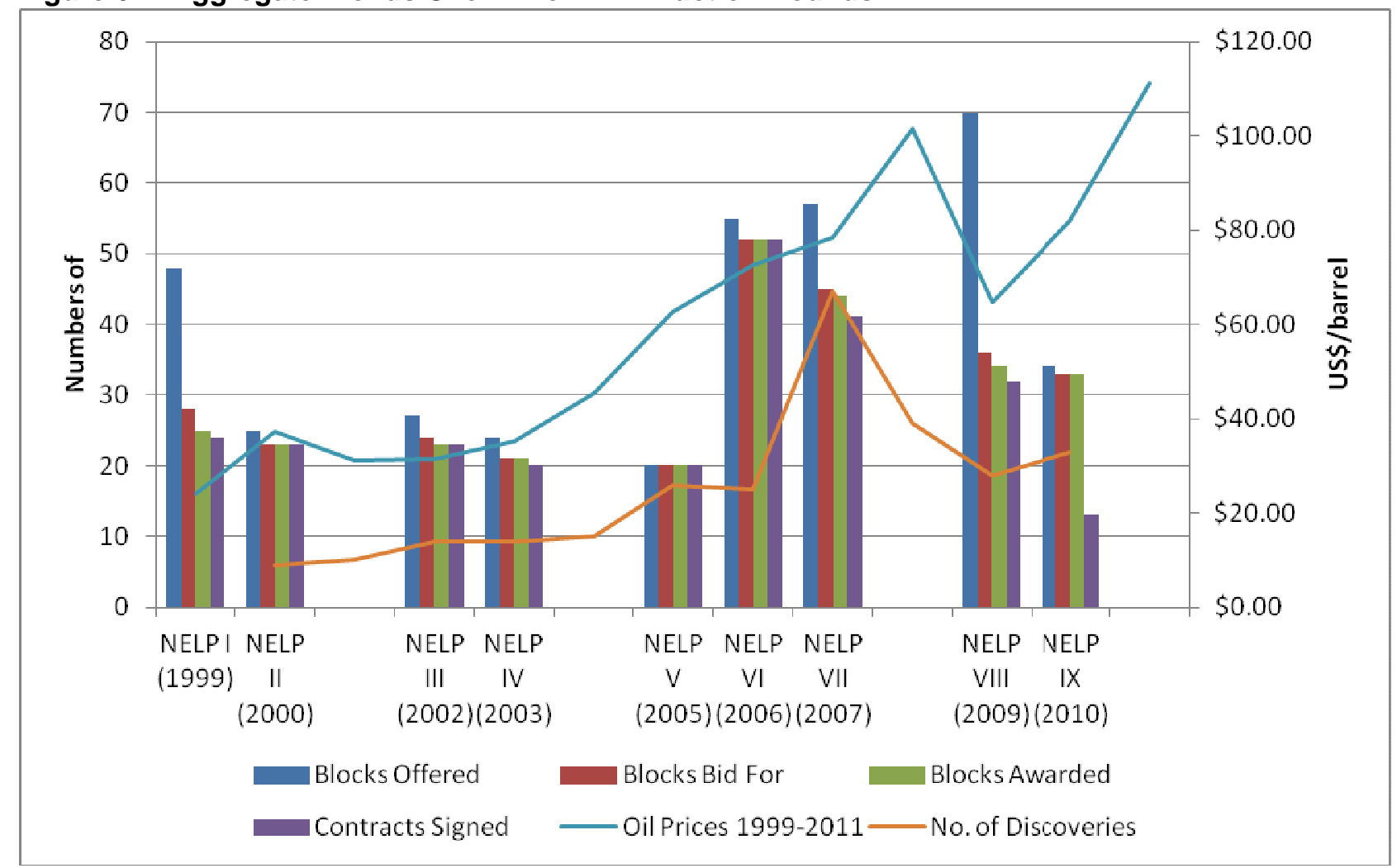

Source: Directorate General of Hydrocarbons (2010); US Energy Information Agency (2012); MoPNG (2010; 2009; 2007; 2006; 2005; 2003; 2002; 2000; 1999); World Bank World Development Indicators (2012); BP (2012)

In Figure 6.1, we graph these variables against world oil prices and against the number of existing discoveries at the time; and in Figure 6.2, we graph these variables against the world economic growth rate, and the rate of growth of the Indian economy. ${ }^{51}$ The expectation is that auctions would be

${ }^{51}$ World oil prices and world economic growth rates were identified by interviewees as important factors affecting the outcomes of bidding rounds. 
more successful during periods of favourable (high) oil prices and higher growth rates; similarly, responses to auction rounds are expected to be greater when perceptions of prospectivity or resource potential (in this case represented by the number of existing discoveries) are favourable. Figures 6.1 and 6.2 show that aggregate trends generally conform to this expectation.

\section{Figure 6.2: Aggregate Trends over Nine NELP Auction Rounds - II}

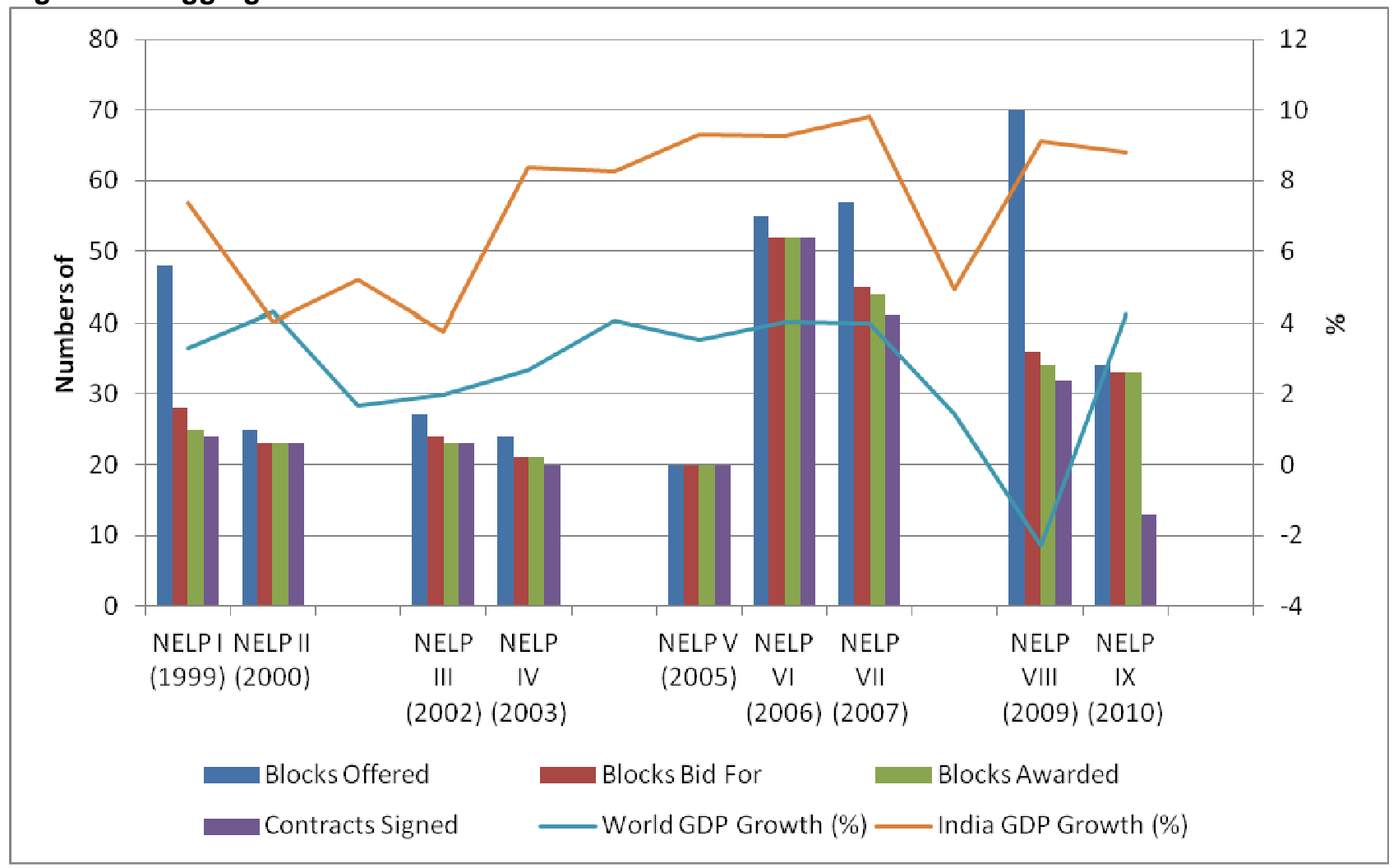

Source: Directorate General of Hydrocarbons (2010); US Energy Information Agency (2012); MoPNG (2010; 2009; 2007; 2006; 2005; 2003; 2002; 2000; 1999); World Bank World Development Indicators (2012); BP (2012)

Two attributes commonly used to describe the degree of competition in lease auction markets are: the percentage of blocks attracting bids, indicative of bidder participation; and the number of bids per block, indicative of competitiveness (Iledare et al., 2004). On the surface, bidder participation for the NELP auctions appears reasonable, given India's position on the scale of 'prospective' countries; ${ }^{52}$ on average, roughly 80 per cent of blocks offered for auction have attracted bids. ${ }^{53}$ Whilst the first round had a bidder participation rate of 60 per cent, this gradually increased. The fifth round of the NELP appears to have been the most successful, with all the blocks on offer attracting bids. Bidder participation began declining again from the sixth round onwards, despite a trend of rising oil prices and a peak in the number of discoveries during the seventh round. The sixth round also saw the

\footnotetext{
${ }^{52}$ India can be perceived as being on the lower end of the scale when compared with resource-rich countries, as it has been found to contain only $0.6 \%$ of world gas reserves, $0.4 \%$ of world oil reserves, and $7.1 \%$ of world coal reserves (Jain, 2011, 15).

${ }^{53}$ An extremely successful auction would arguably attract far more bids - in excess of the number of blocks for auction.
} 
beginning of several changes to the NELP regime, as described in Section 4 . The sixth and seventh rounds also coincided with a period of low economic growth.

Bidder participation was at its lowest (50 per cent) during the eighth round. This coincided with a crash in world oil prices, a drop in the number of discoveries, and the onset of economic recession (although the Indian economy continued to support a positive growth rate). The eighth round, held in 2009 , also took place during a court dispute over the pricing of natural gas produced under the NELP regime. It has been argued that the uncertainty engendered by the dispute may have contributed adversely to perceptions of risk amongst potential bidders. ${ }^{54}$ Bidder participation improved in the ninth round, as oil prices and economic growth began to pick up once again.

Figures 6.3 and 6.4 graph the number of bids per block against world oil prices, the number of discoveries at the time of the bidding round (representing 'prospectivity'), and world and Indian economic growth, and show that competition in the bidding rounds tended to correspond more closely with factors related to the energy sector specifically, rather than to world or Indian economic conditions.

Figure 6.3: Aggregate Trends - Bids per Block: I

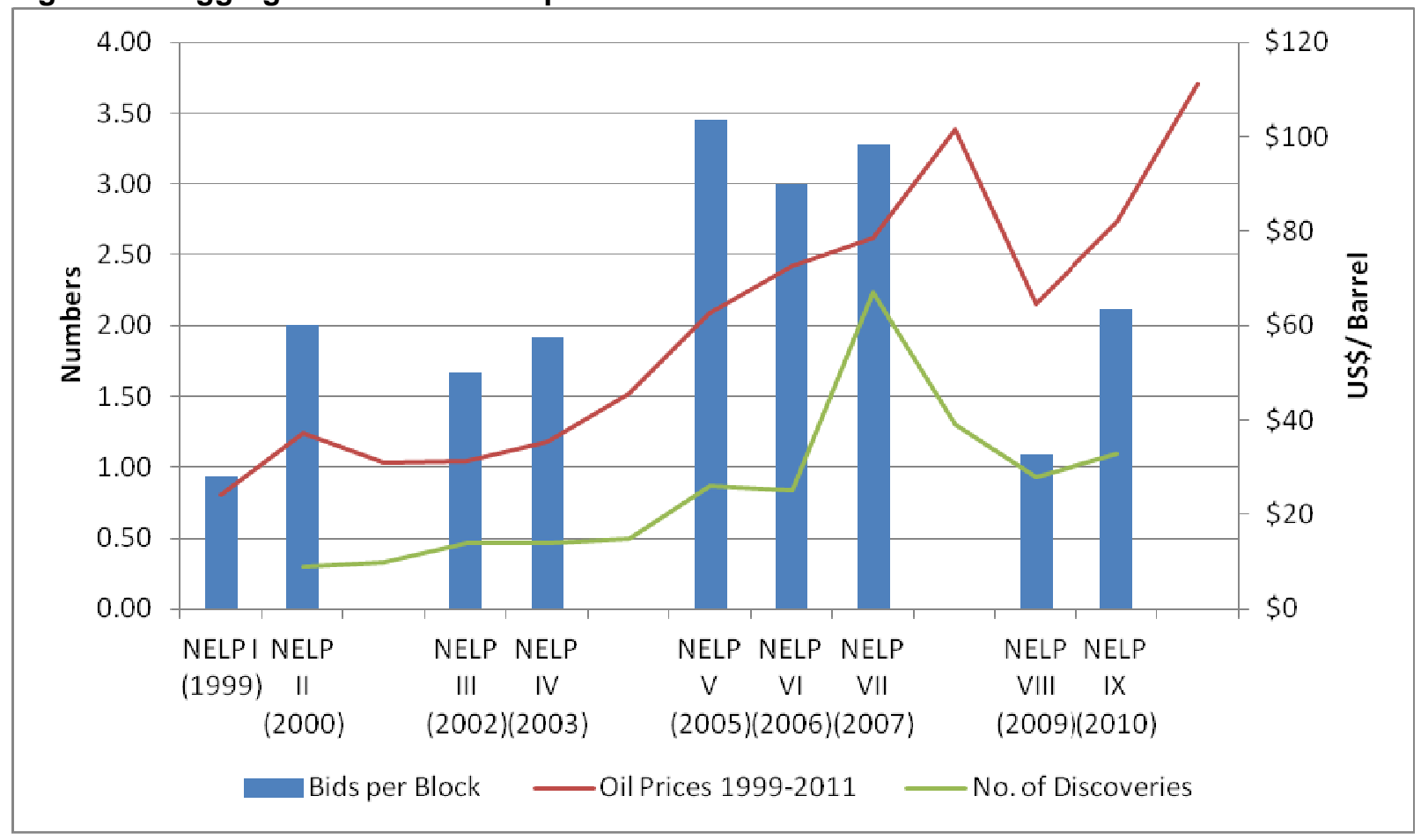

Source: Directorate General of Hydrocarbons (2010); US Energy Information Agency (2012); MoPNG (19902010 - Notices Inviting Offers); World Bank World Development Indicators (2012); BP (2012) 
Figure 6.4: Aggregate Trends - Bids per Block: II

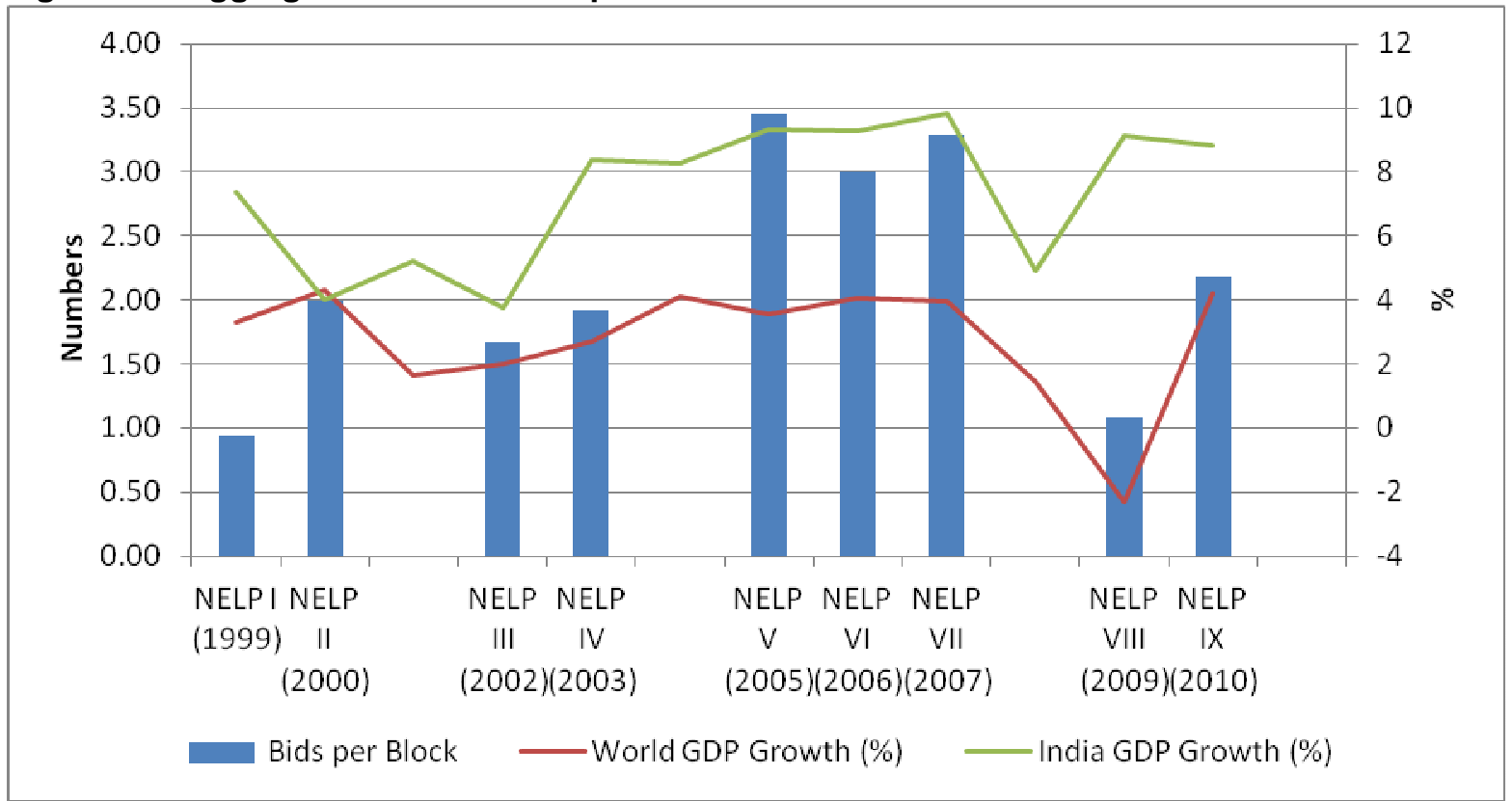

Source: Directorate General of Hydrocarbons (2010); US Energy Information Agency (2012); MoPNG (19902010 - Notices Inviting Offers); World Bank World Development Indicators (2012); BP (2012)

Although there are no clear international benchmarks for the number of bids per block, we refer to the US auctions for leases on the Outer Continental Shelf (OCS) as these have generated sufficient data to allow for reasonable observation. Iledare et al. (2004) show that during the period 1954-99, average numbers of bids per block in the US OCS auctions ranged from a minimum of 2.66 to a maximum of 3.96. By these standards, the NELP auctions lie in the lower range - with the exception of the fifth, sixth, and seventh rounds, which appear to have been relatively more successful, based on this parameter.

The data on the progress or 'coverage' of exploration suggests that offshore deep-water areas hold greater opportunities for resource potential than onshore and shallow-water areas (Directorate General of Hydrocarbons, 2011). Based on an approach set out in lledare et al. (2004), Table 6.1 analyses participation in bidding rounds in greater detail using the measure of the number of bids per block, and accounting for geological and other differences, by breaking this data down by:

- geological type: onshore and shallow-water versus deep-water,

- competitiveness: blocks that attracted multiple bids (competitive) as opposed to single bids (noncompetitive), and

- bidding behaviour: bids that were submitted through joint ventures as opposed to solo ventures. 

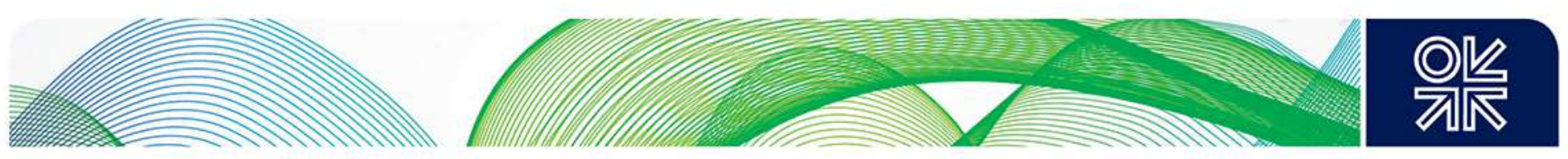

Additionally, it groups these attributes into two separate policy periods - the first covers the period up to NELP $V^{55}$ while the second period (2006-10) covers the sixth to the ninth bidding rounds. This grouping is based on the premise that significant policy changes began to be brought in from NELP $\mathrm{VI}$, including the introduction of mandatory work programmes, the categorization of blocks based on perceived resource potential (' $A$ ' and ' $B$ ' type blocks) according to available data, and the revision in the six-tier (R Factor based) investment multiple in NELP VII.

In offshore (particularly deep-water) operations, joint venturing provides the means of facilitating the entry of a relatively small operator into a risky and capital-intensive market; it also allows for the pooling of resources to meet the minimum capital requirements for bidding, and allows risk sharing between firms (Iledare, et al., 2004, 246). It has been argued that the incidence of joint ventures and the number of bidders or bids should therefore be positively correlated (Iledare et al., 2004; Markham, 1970; Saidi and Marsden, 1992). ${ }^{56}$

During the NELP rounds, the percentage of joint bids for competitive leases (attracting more than one bidder) declined from 61 per cent in the period 2001-5 to 53 per cent in 2006-10; the percentages of joint bids for all leases (competitive and non competitive), however, remained virtually the same, at 64 per cent, for both periods. Further investigation shows that the percentage of joint bids for competitive deep-water leases declined from 21 to 8 per cent between the two policy periods, whereas the percentage of joint bids for competitive onshore and shallow-water leases increased from 17 to 25 per cent between the two periods. Similarly, the percentage of joint bids for all deep-water leases declined from 23 to 12 per cent between the two policy periods, while the number of joint bids for all onshore and shallow-water leases increased from 42 to 52 per cent.

\footnotetext{
${ }^{55}$ Data for the first and second bidding rounds was unavailable; however, this inadvertently equalizes the length of each policy period (4 years).

${ }^{56}$ Alternatively, joint bidding may occur when the underlying risk is highest and hence there are fewer bidders.
} 
Table 6.1: An Analysis of Participation in Bidding Rounds over Two Policy Periods

\begin{tabular}{lccccc}
\hline & \multicolumn{4}{c}{ 2001-5 } & \multicolumn{3}{c}{$\begin{array}{c}\text { 2006-10 } \\
\text { onshore \& shallow- } \\
\text { water }\end{array}$} & $\begin{array}{c}\text { deep- } \\
\text { water }\end{array}$ & $\begin{array}{c}\text { onshore \& shallow- } \\
\text { water }\end{array}$ & $\begin{array}{c}\text { deep- } \\
\text { water }\end{array}$ \\
& Joint & 1.43 & 1.26 & 1.65 & 0.52 \\
$\begin{array}{l}\text { Competitive } \\
\text { (blocks attracting multiple } \\
\text { bids) }\end{array}$ & Solo & 0.61 & 0.81 & 0.92 & 0.28 \\
& All & 2.05 & 2.07 & 2.57 & 0.80 \\
Aggregate & & & & & 0.84 \\
& Joint & 1.52 & 1.33 & 1.87 & 0.31 \\
\hline & Solo & 0.73 & 0.93 & 1.06 & 1.15 \\
\hline
\end{tabular}

Source: Calculated by authors using data from Directorate General of Hydrocarbons (2005-2010); Press Information Bureau of India (various releases) and www.dghindia.org

Table 6.1 shows that the number of bids per block for deep-water blocks declined for both competitive and non competitive leases after the introduction of policy changes in the sixth bidding round, whilst they generally increased for shallow-water and onshore blocks.

This data implies that the bidding rounds for deep-water blocks, generally considered as holding greater resource potential than onshore blocks, have not been competitive in later NELP rounds. This corroborates with the widely held view amongst stakeholders ${ }^{57}$ that a dichotomy exists in the bidding process under the NELP rounds, where onshore and shallow-water blocks attract a rush of smaller, often non-specialist, companies through joint ventures, whereas deep-water blocks, which require highly specialized companies, struggle to attract qualified bidders. This also implies that the incentives to bid relating to smaller bidders/non specialist firms are different from those which apply to larger, more specialized firms, whilst the NELP regime does not clearly differentiate between them - at least with regards to the type of auction (first price sealed bid) that is used for both. This also fits with an observation from the empirical literature reviewed in Section 5, where Cramton (2007) argues that the differences in information asymmetry between different types of leases could be more successfully exploited by the auctioneer to maximize its revenues, by tailoring auction design to each type of lease.

In the next section, we explore in further detail the first hypothesis set out in Section 4, relating to the market structure and composition of the winning bids across the NELP rounds in greater detail.

${ }^{57}$ This was corroborated by stakeholder discussions conducted during fieldwork. 

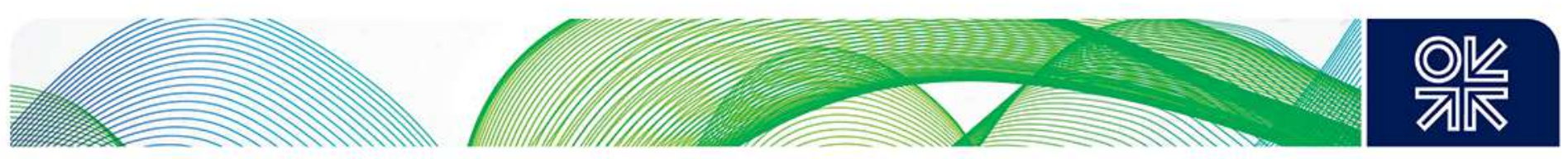

\subsection{The Ex Post Market Structure}

Section 4.3 argued that the NELP regime has led to an ex post market structure that does not entirely reflect the intended objective of the regime (that is, to attract diversified investments). A conventional measure used to study trends in industrial organization looks at the share of the industry owned by the largest four or eight firms (lledare et al., 2004). However, these 'concentration ratios' by themselves do not reveal the relative sizes of the firms within the groups, nor within the rest of the market (lledare et al., 2004). Instead, the Herfindahl Index, a commonly accepted measure of absolute and relative concentration of market shares, which has been used in the study of markets for oil and gas leases (lledare et al., 2004), is used here. It is defined as the sum of the squares of the market share of all participating firms in the lease auction market in a given period; it therefore considers the size of all the participants, not just the largest four or eight and it is expressed as follows:

$$
H I=\sum_{i=1}^{n}\left(s_{i}\right)^{2}
$$

where $s_{i}$ is firm is market share.

Industry or market competitiveness is broadly characterized using the magnitude of the Herfindahl Index. A market with an Index of less than 1000 is less concentrated and can be described as being 'competitive' (Iledare et al., 2004). A market is moderately concentrated if the Index lies between 1000 and 1800, and highly concentrated when the Index is greater than 1800 (lledare et al., 2004).

The Herfindahl Index was calculated for each of the nine NELP rounds. The results are presented in Figure 6.5. 


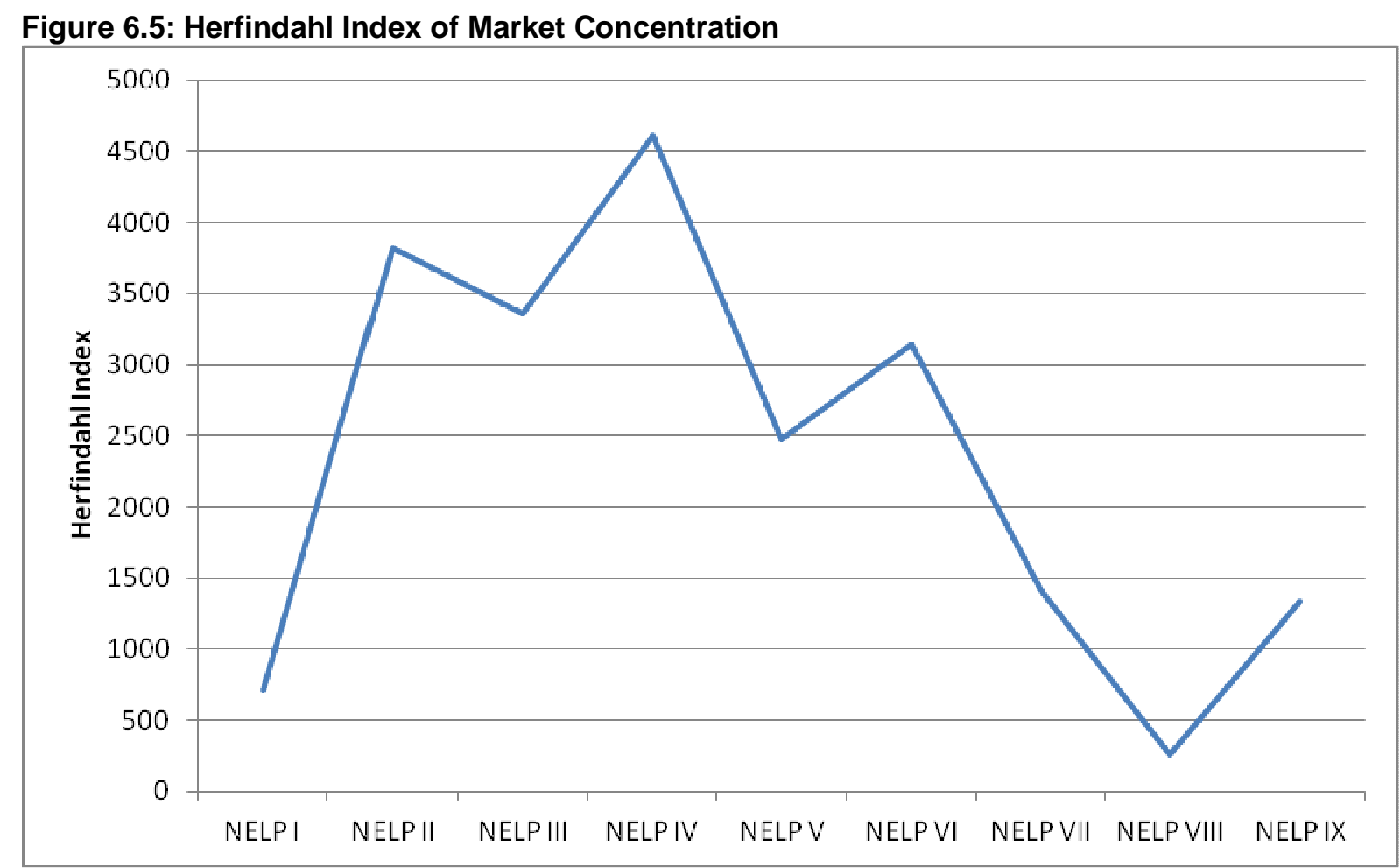

Source: Calculated from MoPNG (1999-2010); Directorate General of Hydrocarbons (2005-11); www.dghindia.org.

Market shares in the Indian upstream hydrocarbons sector are extremely difficult to analyse over time, as accurate data on the turnover of acreage ${ }^{58}$ is unavailable. In order to obtain as accurate an Index as possible, the Herfindahl Index for each NELP round was calculated by looking at the winning bids in blocks for each NELP round, and using the participating share in a block (measured by the percentage ownership in the total area of the block) of each company in any winning bid, to work out its total share of acreage won in each NELP round (hence, if the bid was won by a single company, the acreage of the entire block was included in the calculation of its 'market share'). To overcome problems with the lack of data on the turnover of acreage, a static Herfindahl Index was calculated. The Index therefore reflects the market concentration resulting from each auction round at that point in time without taking into account the acreage won by companies from previous years or previous auctions. In a sense, a 'static' Herfindahl Index helps to identify ex post market concentration of each auction round separately.

Using the benchmarks set out in lledare et al. (2004), it is evident that although the first round of NELP contained a low level of market concentration, it soared under the second round and peaked in the fourth round. Market concentration reduced in the fifth round (but remained high) before rising

\footnotetext{
${ }^{58}$ Or the regular relinquishment of acreage, as per the terms of Production Sharing Contracts.
} 

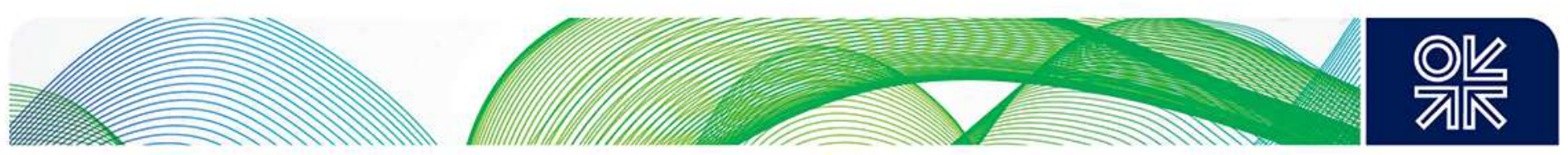

again in the sixth round. It fell in the seventh round and was at its lowest in the eighth round. It rose again in the ninth round to a moderately concentrated level.

These changes in the levels of market concentration, and their true impact, are better understood by looking in more detail at data from each round; this reveals underlying patterns. Appendix $A$ of this paper contains graphs for each of the nine rounds of the NELP.

The low market concentration in NELP I could be a result of the fact that 50 per cent of the acreage on auction did not attract any bids. Amongst the remainder, ONGC and Reliance Industries Limited (RIL) won the majority of acreage, with almost equal amounts. Other winning bidders included Oil India Limited (OIL) and Indian Oil Corporation Limited (IOCL) - the two large NOCs - as well as Hindustan Oil Exploration Company Limited (HOEC), Cairn, and Niko Resources.

The high market concentration in NELP II could be a result of ONGC winning a majority (60 per cent) of the share of acreage on auction. Market concentration fell marginally under the third round, but still remained very high compared with the benchmark; ONGC and RIL each won roughly 40 per cent of the acreage on auction, and 15 per cent of acreage did not attract any bids.

The Herfindahl Index peaked under NELP IV; ONGC won over 60 per cent of the acreage on auction, whilst the amount of acreage attracting no bids was simultaneously at its lowest level since NELP I. Under the fifth round, also considered the most successful, the Index remained high compared with the benchmark, but the distribution of acreage arguably improved. Although RIL (roughly 40 per cent of acreage) and ONGC (roughly 25 per cent) won the majority of acreage, other companies such as Cairn, ENI, and Geoglobal Resources (GGR) won higher amounts of acreage relative to the market structures of previous rounds.

The Index rose again under the sixth round, when ONGC won over 50 per cent of the acreage on auction, and roughly 10 per cent of acreage did not attract bids. It fell to roughly 1000 in the seventh round, indicating moderate to low levels of market concentration; ONGC won roughly 30 per cent of the acreage, but the second largest winner was a private Indian company, GVK Oil and Gas (GVKOG), which also had a significant presence in other infrastructure sectors. Other winners included BHP Billiton (BHPB), Geoglobal Resources (GGR), and Gujarat State Petroleum Corporation Limited (GSPC). Roughly 25 per cent of the acreage on auction did not attract bids. 

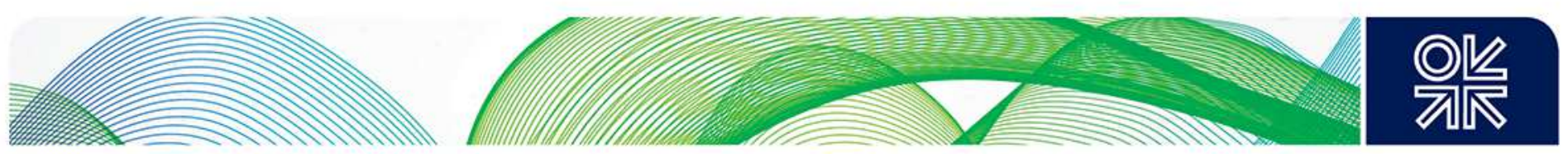

The Index was at its lowest level in the eighth round, indicating a low level of concentration or an ex post 'competitive' outcome. However, over 60 per cent of acreage did not in fact receive any bids. ONGC emerged the highest winner, with approximately 15 per cent of the bids, followed by OIL, BHP Billiton, and Cairn. The eighth round has also been considered by some as the most unsuccessful NELP round; whilst this has largely been attributed to the global recession, a dispute over the pricing of natural gas under the NELP was in the courts at the time, and this may have contributed to uncertainty in the business environment. The Herfindahl Index increased under the ninth round indicating a moderately concentrated market. The distribution of acreage improved; although ONGC won the highest amount of acreage (over 25 per cent), other companies such as OIL, BG India (BGEPIL), BHPB, and Bharat Petro Resources Limited (BPRL) won significant amounts of acreage. RIL won roughly 10 per cent of acreage, and less than 5 per cent of the acreage on auction received no bids. ${ }^{59}$

The analysis above shows that whilst at an aggregate level the NELP auctions appear to have performed reasonably well, with 'low' periods coinciding with adverse changes in external factors such as world economic growth, the underlying impacts suggest, on the other hand, that they have led to an ex post duopsonistic market structure. One reason for this occurrence in the bidding rounds up to NELP VIII could have been that the amount of acreage held by bidders from previous exploration was one of the criteria upon which the NELP bids were evaluated. Some companies could arguably have had an ex ante advantage in this regard, for instance. ${ }^{60}$ It is also apparent that in most rounds, a proportion of the acreage on auction has attracted no bidders.

These findings support our hypothesis in Section 4.3, which states that the NELP auctions have led to an unintended ex post market structure, in terms of company sizes, ownership, and capabilities, resembling a highly concentrated market in which a small number of companies have tended to dominate bidding rounds, as opposed to a highly diversified one.

\subsection{The 'Holdup’ Problem}

The holdup problem is related to both auction design and market design. A situation that is frequently encountered in auctions is where the winner of the auction discovers that it may have overpaid or overbid for an object. This is popularly referred to as the winner's curse (Capen et al, 2971; Klemperer, 2004). The theoretical literature on auctions shows that this situation arises due to

\footnotetext{
${ }^{59}$ As Figures 6.1 and 6.2 earlier in this section have shown, contracts were signed for only around half of the blocks awarded under NELP IX, as the Government appeared to apply a reserve price to bids.

60 This was recognized in NELP VIII, and technical criteria relating to the holding of acreages were revised.
} 
information asymmetry, and auction formats which permit a limited amount of information revelation during the auction process - notably first price sealed bid auctions - are particularly susceptible to it. Thus, the winner of the auction discovers that he may have overpaid for a lease when the secondhighest bid is revealed to be relatively low. The difference between the winning bid and secondhighest bid is an indicative measure of the extent of overbidding.

For oil and gas auctions that are based almost entirely on cash bonuses or upfront payments - for example, the US OCS auctions which do not have a mandatory requirement for the winning bidder to carry out any drilling during the period of the lease - the ex post consequences of overbidding may not be as serious as those for auctions where winning bids are based on the work programmes that are committed by winning bidders. In the case of the latter, overbidding may lead to a situation where the winning bidder is unable to fulfil exploration commitments; the tract (or block) then has to be 'recycled' in a future auction round. This creates a 'holdup' problem which has a potential knock-on effect, with wider consequences for the pace of exploration. ${ }^{61}$

Overbidding, could also be indicative of 'speculative bidding' - or bids made with the main intention of increasing the value of the portfolio of a bidder, particularly during times of high international oil prices. This has been a concern in the Indian hydrocarbons sector, particularly with respect to 'aggressive' bidding by non specialist firms for smaller exploration blocks. ${ }^{62}$ It was, for instance, alleged by some large international firms that in the bidding rounds for NELP VI, some bidders offered speculative bids on fiscal terms which in theory would have led to returns that were lower than those from 'risk free' investments, such as government bonds. It was also argued that some of these fiscal bids may have been made merely to win fields, with the intention of renegotiating terms ex post (FE, 2006). One of the challenges in practical auction design is therefore to create an auction format that encourages competitiveness and entry, but prevents exaggerated bidding.

Attempts have been made in the empirical literature to quantify the winner's curse, and the extent of overbidding, using the dispersion in bid levels between auction rounds - also referred to as 'money left on the table' - which could be conceived as the percentage difference between the high bid and the second-highest bid on a lease (Haile et al., 2010). In the case of the NELP auctions, data on the monetary value of bids is unavailable; it is, however, reasonable to use the differences in the total

\footnotetext{
${ }^{61}$ Section 4 contained an illustration of a possible holdup scenario in the seventh NELP bidding round, where BHP Billiton and GVK Industries were the sole bidders on seven deep-water exploration blocks; they later struggled to meet their investment commitments, leading to delays in exploration. BHP Billiton announced in 2013 that it would give up nine exploration blocks. Other factors contributing to this may have been difficulties in obtaining clearances from other Ministries such as Defence and Environment.

${ }^{62}$ Bidding behaviour on smaller blocks has been described as aggressive by industry stakeholders. For instance, in the eighth round a very high number of wells in proportion to the area of the block was bid for several 'S' type blocks - examples include 10 wells for a block with an area of 68 square kilometres and 12 wells for a block which was 90 square kilometres. Discussions with industry experts suggest that these bids are extremely high.
} 

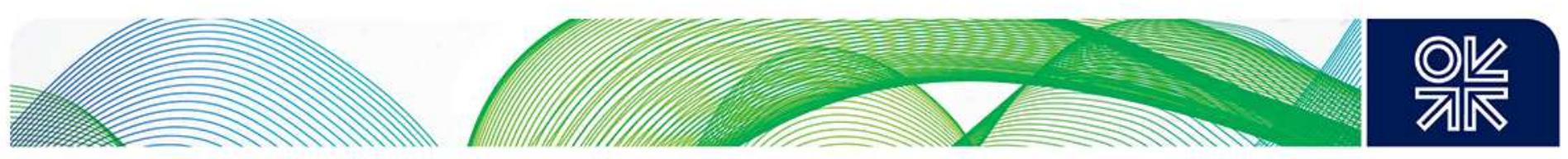

scores awarded to the highest and second-highest bids on blocks as a notional measure of this dispersion. Data was available for five of the eight rounds. ${ }^{63}$ Table 6.2 shows the percentage of blocks receiving more than one bid, and the average (median) difference between the highest and secondhighest bid (scores).

The second row of Table 6.2 (median overbid) implies that half of the winning bidders on blocks with multiple bids bid at least 46 per cent more than the second-highest bid in the second round of the NELP; the amounts for the fourth, sixth, seventh, and eighth rounds are 27 per cent, 16 per cent, 8 per cent and 11 per cent, respectively. Although there are no benchmarks to determine the extent of overbidding in the NELP rounds, authors of empirical studies have considered levels ranging from as low as 9 per cent to as high as 60 per cent to be indicative of overbidding (Jayasena and Uhanowitage, 2008; Haile et al., 2010; Klemperer, 2004).

Haile et al. (2010) consider data on the US OCS auctions in a different way; they note that the amounts of 'money left on the table' are fairly constant (within a narrow range) over time, not just for tracts which received more than one bid, but also in the cases of tracts which received more than 10 bids - thus, these amounts do not vary significantly with changes in the number of bids received for blocks. This lack of variation for the US OCS rounds, combined with the fact that the US OCS auctions used reserve prices in the award of winning bids, could suggest that the dispersion between the highest and second-highest bids for the OCS auctions was attributable to differences in bidders' values, rather than to overbidding. A similar pattern cannot be conclusively discerned for the NELP rounds ${ }^{64}$ although the median overbid does appear to have reduced over time.

\footnotetext{
${ }^{63}$ Data was available for the second, fourth, sixth, seventh, and eighth rounds.

${ }^{64}$ This could be due to insufficient data.
} 
Table 6.2: 'Money Left on the Table' - Notional Indicators

\begin{tabular}{|c|c|c|c|c|c|}
\hline & NELP II & NELP IV & NELP VI & NELP VII & NELP VIII \\
\hline $\begin{array}{l}\text { Blocks with } \\
\text { multiple bids } \\
(\%)\end{array}$ & 42 & 65.38 & 68.52 & 47.37 & 44.44 \\
\hline $\begin{array}{l}\text { Median } \\
\text { Overbid (\%) }\end{array}$ & 46.38 & 27.21 & 15.99 & 7.77 & 11.14 \\
\hline
\end{tabular}

Source: Compiled by authors; using data from Press Information Bureau of India (various releases) and Directorate General of Hydrocarbons.

In the second and fourth bidding rounds, the majority of multiple bids were placed on deep-water blocks; in the sixth, seventh, and eighth bidding rounds, the majority of multiple bids were placed on onshore blocks. In fact, in the seventh and eighth rounds, almost all the deep-water blocks attracted single bids. In contrast, the number of multiple bids received on onshore blocks (particularly $S$ type blocks) was as high as 19 (in the seventh round). This suggests, as argued earlier in this section, that as measures were adopted to increase competition, the bidding on onshore blocks saw the highest number of new entrants, whereas the bidding on deep-water blocks saw relatively fewer new entrants, across the different rounds.

The holdup problem may be partially attributable to market design, particularly in relation to the alignment of firm objectives with the government's wider goals. The discovery of information ex post (once a firm has won an auction) may lead to a situation where it is inefficient or wasteful for the firm to explore. Hotelling (1931) famously sets this out in an analysis of the optimal rate of extraction of a firm, namely the point where price or marginal revenue equals the cost of extraction plus an opportunity cost. The consequences of holdup on wider government goals on exploration are arguably greater when auctions are based on notional investment commitments rather than upfront bonus payments. ${ }^{65}$ The holdup problem could be addressed in these circumstance by designing markets or the 'rules of the game' to take into account the potential misalignment between firm and government objectives.

In the next section we use some fundamental concepts from the theoretical literature on auctions to place these results in context, and to set out our final hypothesis relating to whether optimality and efficiency are mutually exclusive objectives in auction design.

\footnotetext{
${ }^{65}$ Even with upfront payments, the firm may view these payments as a sunk cost - therefore exploration will only be optimal for a firm in this situation if it is profitable compared to the ongoing costs of exploration.
} 

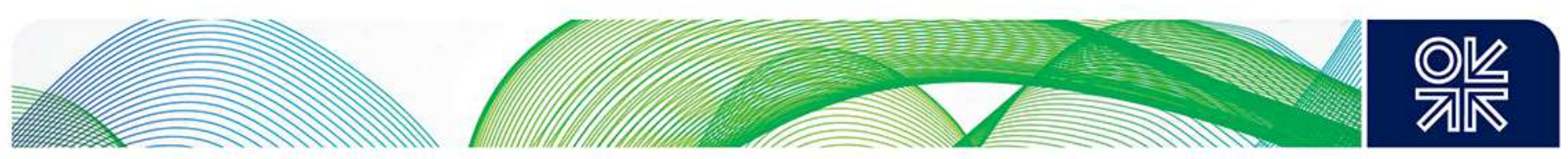

\section{Theory}

The literature on auction theory provides insights into the dynamics of auctions and bidder behaviour in situations of symmetry of information, partial asymmetry, and complete asymmetry of information amongst auctioneers and bidders. This section sets out some important contributions of auction theory in a non-technical manner, and explores the optimality versus efficiency hypothesis set out in Section 4.3.

At the basic conceptual level, for all auction types discussed in Section 3.1, auction theory distinguishes between a bidder's bid, and a bidder's value for an object. A bidder seeks to maximize his profit or surplus from participation in the auction by submitting a bid that is lower than his actual value, subject to the rules of the auction and to expected competition.

An auctioneer on the other hand, attempts to extract from the bidder a bid that is equal to his true value, thereby capturing the entire amount of surplus, as well as achieving an 'efficient' allocation by ensuring that the object is awarded to the bidder that places the highest value on it (Klemperer, 2004). ${ }^{66}$

For instance, in the first price sealed bid auction, a bidder's expected gains can be expressed as follows:

$$
\left(X_{i}^{*} \text { probability of winning }\right)-\text { Expected payments }
$$

Where, $X_{i}$ denotes the bidder's value. Lowering the bid has two opposite effects on the expected gains for the bidder; the probability of winning decreases and the gains from the bid increase. The optimal bid strategy has been described as a bid (b) which balances these two effects, thus maximizing equation (2), as below (Muller, 2001; Levin, 2010).

$$
\max _{b \in B} \text { V.Pr}(\text { Win } \mid b)-E(\text { Payment } \mid b)
$$

Auction theory also classifies the value structures of bidders by distinguishing between private or independent values, and common (or almost common) values. If a bidder has a private value for an object, this implies that his value is determined entirely independently from other bidders' values (this

\footnotetext{
${ }^{66}$ Efficiency, in this sense, equates to optimality or the maximization of the auctioneer's revenues. We discuss the interpretation of efficiency in other contexts in further detail in Section 7.2. A revenue maximizing auctioneer, however, would not care about efficient allocation (except to the extent that it maximizes the price). A revenue maximizing auctioneer may therefore wish to commit to an auction that allows the possibility of inefficient allocation.
} 

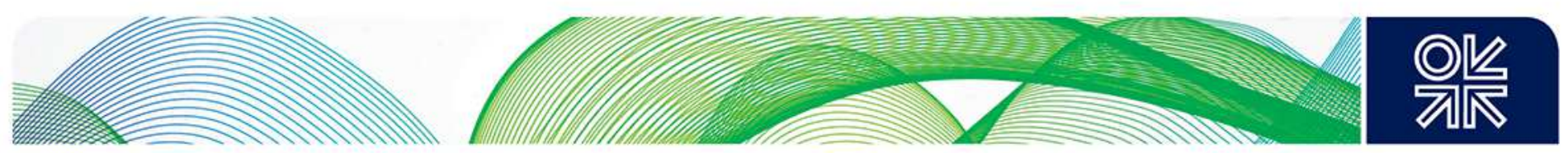

also equates with complete asymmetry of information between bidder and auctioneer). With common (also referred to as 'almost common') values, the implication is that a bidder's value is a function of not just his own value, but also of shared information, reflected in the values of other bidders. This equates with a situation of partial information asymmetry. In auctions of oil and gas exploration licences, for instance, bidders will hold 'almost common' values; that is, the value they place on the object will be based on a mix of their private values (determined, for instance, by their geological expertise), and on shared or common values (such as the expected quantity of production from the exploration area, valued at the international price of oil).

The phenomenon of the 'winner's curse', demonstrated in the previous section is an important feature of auctions with common or 'almost common' value structures - each bidder must recognize that he wins the object only when he has the highest bid (or signal) - this per se constitutes an element of 'bad news' - the failure to take this into account ex ante can lead to the winner paying more, on average, than the object is worth (Klemperer, 2004). As we have illustrated earlier (Section 6.3), in hydrocarbon lease auctions based on work programmes rather than monetary bonuses, this can lead to holdup problems ex post. Making additional information on the 'unknown' part of the common value publicly available is therefore likely to weaken the winner's curse effect (Muller, 2001). For instance, in the hydrocarbons sector this would relate to shared additional seismic or geological information, through a facility such as a common accessible database.

\subsection{Revenue Equivalence}

A fundamental concept in the analysis of auctions is that of 'revenue equivalence' -conditions under which an equivalent amount of revenue can be obtained from auctioning an object under any auction format. Revenue equivalence largely deals with optimality, or the maximization of revenues from the auction as a primary objective, but work on revenue equivalence, and subsequent studies, provides essential insights into the outcomes of auctions under varying assumptions.

The central result in revenue equivalence is the Revenue Equivalence Theorem, proved in Vickrey (1961). The Theorem shows that, subject to a set of assumptions, an auctioneer or seller can expect equal profits, on average, from all standard (and many non-standard) types of auctions, and that buyers are also indifferent amongst them all (Klemperer, 2004). Vickrey also showed the strategic equivalence of different auction types, such as the English ascending auction and the second price sealed bid auction (discussed earlier). The Theorem assumes a fixed number of symmetric, riskneutral bidders, who each want a single unit of the object, have independent information, and bid independently. It also assumes that the bidder values are drawn from the same distribution. Independent of the auction rules (or of the type of auction), a bidder's expected profit depends only on 
his equilibrium probability of winning as a function of his value. Therefore, every auction that allocates goods efficiently and offers no profit to a zero valuation bidder has the same expected profits for every bidder valuation, and thus the same expected revenue to the auctioneer (Milgrom, 1989).

In practice, auctions do not hold to the assumptions of the Revenue Equivalence Theorem, and subsequent work in auction theory tests for such situations, using the assumptions of the Theorem as a starting point.

One stream of theoretical work relaxes the assumption of risk neutrality among bidders. In ascending and second price sealed bid auctions, risk aversion has no effect on a bidder's optimal strategy, which remains to bid (or bid up to) his value (Klemperer, 2004). However, in a first price sealed bid auction, a slight increase in a player's bid slightly increases the probability of winning, at the cost of slightly reducing the surplus from winning, and so would be desirable for a risk-averse bidder if the current bidding level were optimal for a risk neutral bidder (Klemperer, 2004). As the amounts of risk involved are relatively small, auction theory shows that risk-averse bidders tend to bid more aggressively in first price sealed bid auctions (Klemperer, 2004). Consequently, where the primary objective of the auctioneer is to raise revenues, a risk neutral seller faced with risk-averse bidders would prefer a first price sealed bid auction over the other auction types, as this would be the most profitable of all the auction types (Klemperer, 2004; Maskin, 1984). This feature appears to be at least partly responsible for bidding behaviour that has been described as 'aggressive' in the NELP auctions for exploration licences (which use first price sealed bids), particularly by non-specialist firms (Katakey, 2008) which are arguably more risk averse than the more specialist firms that work with international portfolios of managed risk.

A second stream of theoretical work on revenue equivalence relaxes the assumption that each bidder's private information is independent of competitors' private information (Klemperer, 2004). Intuitively, given the 'open' nature of the English ascending auction in particular, information is more likely to be affiliated or correlated. This work also shows that when the bidders' costs or valuations depend on some common random factors, so that all the bidders are estimating the same variables, their estimates will be positively correlated even if their estimation errors are independent (Milgrom, 1989). Milgrom and Weber (1982) develop a model for 'affiliated values', which they define as a situation where a high value of one bidder's signal makes high values of other bidders' signals more likely. They conclude that auctions where bidders' values depend at least partially on other bidders' information would lead to higher revenues on average; the intuition is that the winning bidder's surplus is due to his private information. Thus the more the price paid depends on others' information, the more closely the price is related to the winner's information (since information is affiliated), the lower 
is the winner's information rent (and hence his expected surplus), and therefore the higher the expected revenue (Milgrom, 1989).

In the ascending auction, the winning bidder's value is a function of all the other bidders' values, whereas in the second price sealed bid auction, it is a function of only one other bidder's value. According to Milgrom and Weber (1982), the ascending auction raises the largest amount of revenue in a situation where bidders' signals are affiliated (followed by the second price auction). This general principle - that expected revenue is raised by linking the winner's payment to information that is affiliated with the winner's information - is known as the Linkage Principle. ${ }^{67}$ Based on this principle, the optimal policy for an auctioneer who has access to any private or exogenous information is to precommit to revealing it honestly, as this information 'links' all the bidders and can raise a higher amount of revenue from the auction. Arguably, one of the main weaknesses of the NELP auctions has been inadequacies in the availability and quality of information. Milgrom and Weber (1982), however, caution against adopting ascending auctions in situations where there are affiliated signals, as ascending auctions are susceptible to collusion ${ }^{68}$ if improperly designed.

A third assumption of the Theorem is that of 'symmetry', or (statistically) that all bidders are drawn from the same distribution and no one bidder has any inherent advantage over the other (such as reputational advantages). In practice, there are often asymmetries of information present amongst bidders, and bidders may be drawn from different ('stronger' and 'weaker') distributions (Klemperer, 2004). Asymmetries have somewhat ambiguous effects - they are determined by the structure of values (private or common) amongst bidders, and by the type of auction being used. These (particularly the structure of values) are in turn determined by the precise nature of information (amount, quality, and access) that is available to the bidders ex ante. The results from auction theory show that in a situation where bidders' values are drawn from 'strong' and 'weak' distributions and are hence asymmetrical, with private values, weaker bidders tend to bid more aggressively in first price auctions; first price auctions also tend to discriminate in favour of weaker bidders as compared to second price and ascending auctions (Klemperer, 2004).

Therefore, first price auctions may result in raising higher revenues for the auctioneer, but may not necessarily lead to an 'efficient' allocation. ${ }^{69}$ Maskin and Riley (2000) show that in the presence of asymmetry with private values, weaker bidders tend to prefer first price auctions, and stronger bidders, second price auctions. This may be important when the attraction of bidders to enter the

\footnotetext{
${ }^{67}$ For a mathematical explanation, see Milgrom and Weber (1982).

${ }^{68}$ Or manipulation of the auction due to collusive behaviour by bidders.

${ }^{69} \mathrm{Here}$, the definition of efficiency relates to the allocation of an object to the bidder which makes the best use of that object.
} 

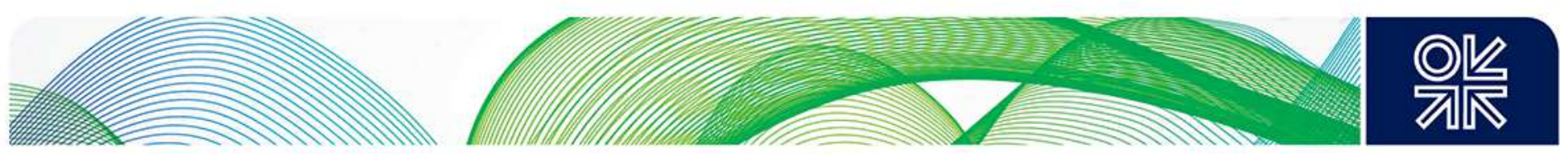

auction is an important consideration (Klemperer, 2004). When bidders share 'almost common' values but information is asymmetric, a bidder with a small ex ante advantage will bid more aggressively in an ascending auction. This strengthens the other bidders' winner's curse (since winning against an aggressive competitor is perceived as an element of 'bad news' about the actual value of the object), and they will tend to bid conservatively. In ascending auctions particularly, this effect is magnified due to the repeated interaction between bidders; a small advantage thus translates into a very large competitive advantage, and a resultant inefficient allocation, in an ascending auction (Klemperer, 2004; 1998).

\subsection{Auction Objectives: Optimality versus Efficiency, and Parallels with Third Degree Price Discrimination}

A concern which frequently emerges in government policy on the auctioning of natural resources relates to the objectives of the auctioneer - namely, whether to focus on raising high amounts of revenue from the auction, or to ensure that the resource is allocated to the bidder that makes the most 'efficient' use of it ex post. One way in which governments have dealt with this has been to clearly rank, ex ante, the relative importance of different objectives of the auction. For instance, the British $3 G$ spectrum auctions had three objectives - to assign the spectrum 'efficiently', to promote competition, and to realize their 'full economic value' - however, the efficiency considerations were given clear priority over revenue considerations (Binmore and Klemperer, 2002).$^{70}$ In India, the Comptroller and Auditor General (CAG) published an audit of 22 Production Sharing Contracts in 2011; this expressed serious concerns regarding the probability that large amounts of revenues had potentially been lost to the exchequer. Whilst this was primarily attributed to poor ex post enforcement of contracts in relation to the granting of extensions for completion of the work programme, one could also argue that it may have been due to the design of auctions, as well as market design.

Although in practical auction design some governments, as well as designers of auctions, see the optimality versus efficiency objectives as mutually exclusive, or as requiring some sort of ordering of priorities, the literature is in fact ambiguous on this. We argue in this section that the optimality versus efficiency conflict holds for some cases but not for others, based on the type of auction that is used.

'Optimality' here is defined as maximizing the revenues of the seller. 'Efficiency' on the other hand is defined as maximizing the gains from trade or maximizing welfare, which is the sum of consumer and

\footnotetext{
Similarly, in the US spectrum auctions, the Chairman of the US Federal Communications Commission stated that he was 'confident' that the auction method he had chosen would 'put the spectrum in the hands of those who most highly value it and who have the best ideas for its use.' In the law authorizing the spectrum auctions, efficiency was explicitly stipulated by the US Congress to be the main goal (Morgan, 2000).
} 
producer surpluses. Optimality, however, equates with efficiency (the sum of consumer and producer surpluses) in situations where the producer is able to capture the entire amount of consumer surplus (that is, when consumer surplus is zero). Bulow and Roberts (1989) in fact show that a seller's problem in devising an optimal auction is similar to a monopolist practicing third degree price discrimination. ${ }^{71}$

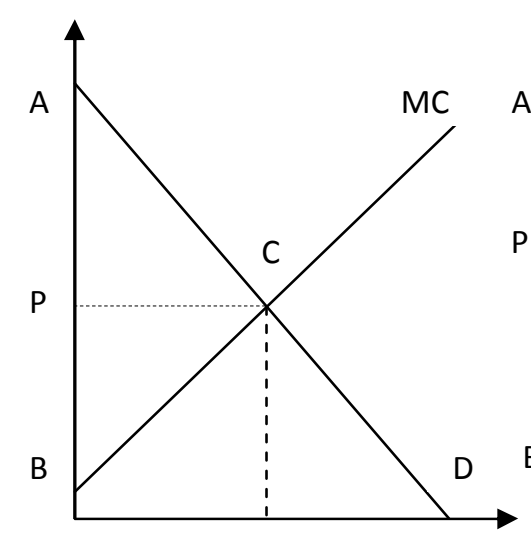

Q

Fig. 7.1 Perfect Competition

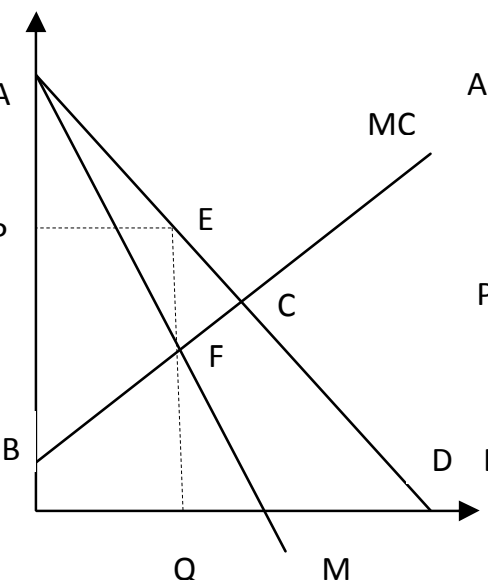

Fig. 7.2 Monopoly
Fig. 7.3 'Direct' Price Discrimination

$$
C S=A P C ; P S=P B C
$$

$C S=A P E ; P S=B P E F$
Deadweight LosS $=E F C$

$$
C S=0 ; P S=A P C+P B C
$$

Figures 7.1 to 7.3 graph the concepts of Consumer Surplus (CS) and Producer Surplus (PS) under perfect competition, monopoly, and price discrimination under standard economic analysis. Figure 7.3 shows the outcome for an auctioneer facing a single bidder. It shows that whilst the total gains from trade $(A P C+P B C)$ are maximized, the producer also captures the entire consumer surplus, thereby demonstrating that optimality equates with efficiency in this case. Essentially, the outcome in Figure 7.3 equates with the outcome in Figure 7.1, apart from the fact that the producer (or monopolist) captures the entire surplus.

'Efficiency' is arguably contingent on the objectives of the seller. We can argue that whilst a seller in general may be interested in maximizing its revenues, in the case of oil and gas lease auctions (where the seller or auctioneer is a government) the seller may be interested in maximizing both individual producer (government/auctioneer) and consumer (winning bidder) surpluses (representing the gains to trade) as a form of incentive to encourage the winning bidder to fulfil ex post

\footnotetext{
${ }^{71}$ Price discrimination is possible when three conditions are met. First, consumers differ in their demands for a given good or service; second, the seller has market power; and third, the firm can prevent or limit arbitrage (or resale) in a secondary market (McAfee, 2008). First degree price discrimination is when every buyer pays $100 \%$ of his or her subjective value of the good, second degree price discrimination is when a monopolist offers a 'menu' of goods, and consumers self-select into groups, and third degree price discrimination is when the monopolist extracts a different price from different consumers, or from consumers in different markets (which is an imperfect form of first degree price discrimination). First and third degree price discrimination have also been classified as 'direct' and second degree as 'indirect' price discrimination (McAfee, 2008).
} 

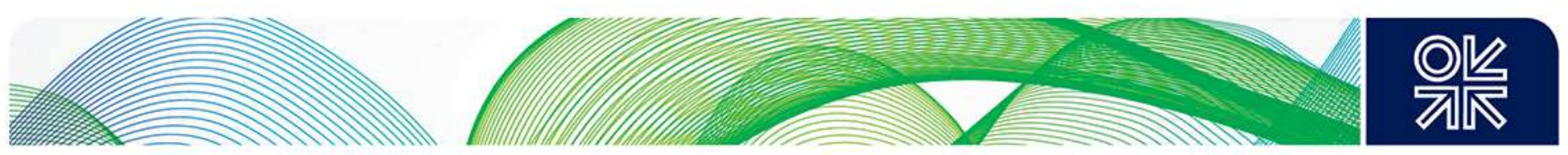

commitments on work programmes, in order to prevent problems of holdup. Yet in practice governments often treat efficiency and revenue maximization as mutually exclusive, or do not explicitly include either in their statement of objectives. ${ }^{72}$

Under third degree price discrimination, there are two instances when both optimality and efficiency can be achieved without losing consumer surplus (social welfare). First, the literature on asymptotic properties of auctions shows that when the number of bidders becomes very large, most standard auctions approach a position of optimality and efficiency simultaneously (Zhan, 2008; Fibich et al., 2004). Second, Aguirre (2011) shows that third degree price discrimination between two markets, one with inelastic demand (and a concave demand curve) and the other with elastic demand (and a convex demand curve) leads to a change in welfare which can be analysed in terms of two effects:

- a misallocation effect - a transfer of quantity from the less elastic (concave demand curve) market to the more elastic (convex demand curve) market, which lowers social welfare (consumer surplus) in the less elastic market, and

- an output effect, or an increase in consumer surplus through an increase in output in the more elastic market.

In situations where the output effect is large enough to offset the misallocation effect, social welfare is maximized through third degree price discrimination. Social welfare is also maximized when third degree price discrimination opens up new markets (Aguirre, 2011).

These scenarios are difficult to illustrate in practical terms, and hence we stay with a simple illustration of the problem of optimality and efficiency in auctions, continued below.

Using microeconomic theory:

$C S=W_{p}-P$

where $W_{p}$ is the willingness to pay, $P$ is the price paid by the consumer and CS is Consumer Surplus. and:

$P S=P-C$

where $C$ is the cost of providing or manufacturing the good, $P$ is the price paid by the consumer and $P S$ is Producer Surplus.

\footnotetext{
${ }^{72}$ For instance, the 1999 NELP Policy Resolution did not mention either of these objectives (that is, efficiency or revenue maximization). Rather, it focused on 'attracting private capital and investment'.
} 

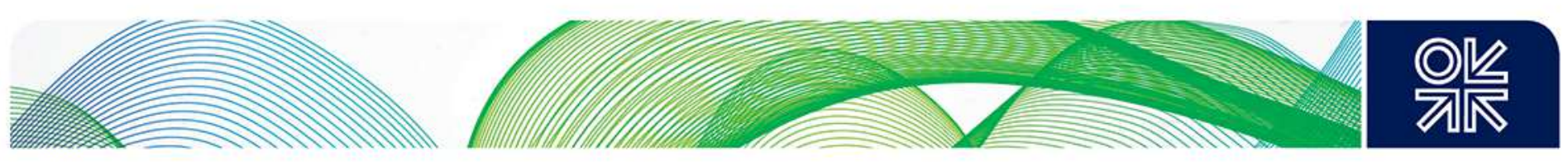

In oil and gas auctions, the value $v_{i}$ for a bidder $i$ represents the bidder's willingness to pay $W_{p}$, whereas the bid $b_{i}$ represents the price paid, $P$. Similarly, the cost of providing the good $C$ can be represented with a reserve price $r$, which reflects the auctioneer's own valuation of the good.

We can therefore rewrite consumer and producer surpluses as:

Consumer surplus: $\mathrm{CS}=\mathrm{vi}-\mathrm{bi}$

Producer surplus: $\quad P S=b i-r$

We can argue that in a second price sealed bid or English (ascending) auction, where the bidder's dominant strategy ${ }^{73}$ is to submit a bid equal to his value (and assuming the bid is accepted only if it is higher than the auctioneer's reserve price $r$ ), then:

$C S=v_{i}-b_{i}=0$.

The auction ensures that the object is awarded to the bidder that places the highest value on it.

However, as the winning bidder pays a price equal to the second highest bid:

$C S>0$ and $P S>0$.

Second price sealed bid auctions are therefore arguably efficient, in theory, as they award the object to the bidder who values it the highest, whilst at the same time maximizing the gains to trade for the auctioneer and the bidder.

First price sealed bid and Dutch (descending) auctions are optimal and efficient only if a bidder's dominant strategy is to submit a bid equal to his value and pay that bid if he wins, (assuming that the bid is accepted only if it matches the auctioneer's reserve price $r$ ). In this situation:

$C S=v_{i}-b_{i}=0$.

Total surplus is maximized but the producer (auctioneer) captures the entire amount of surplus. However, the role of a reserve price would be crucial in designing such an auction.

${ }^{73}$ Strategic equivalences between auction formats were discussed in Section 3.1. 

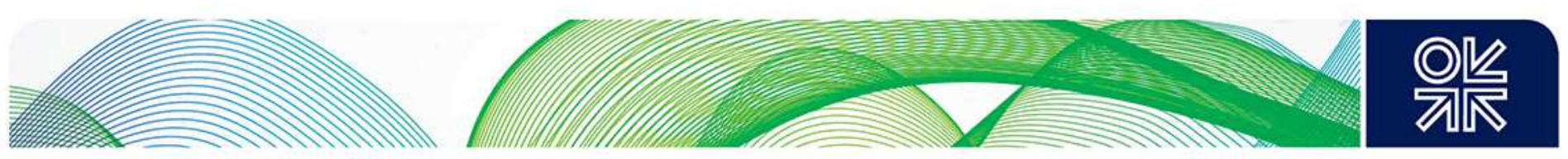

While Figure 7.3 and the illustration above pertain to a single auctioneer facing a single bidder for a single object, a more realistic representation would include multiple bidders and multiple objects. Auction theory shows that most of the basic auction formats can be extended to situations with multiple bidders and multiple objects. ${ }^{74}$ The natural multiunit extension of the first price sealed bid auction is the discriminatory auction (Krishna, 2009). Similarly, an extension of the second price sealed bid auction is the uniform price auction. ${ }^{75}$ The theory also demonstrates that the Dutch multiunit auction is outcome-equivalent to the first price sealed bid auction, and that the English multiunit auction is outcome-equivalent to the ascending auction (Krishna, 2009).

This situation is demonstrated graphically in Figure 7.4. Again, we assume third degree price discrimination - representative of a multiunit discriminatory auction.

Figure 7.4: Multiple Bidders under Third Degree Price Discrimination

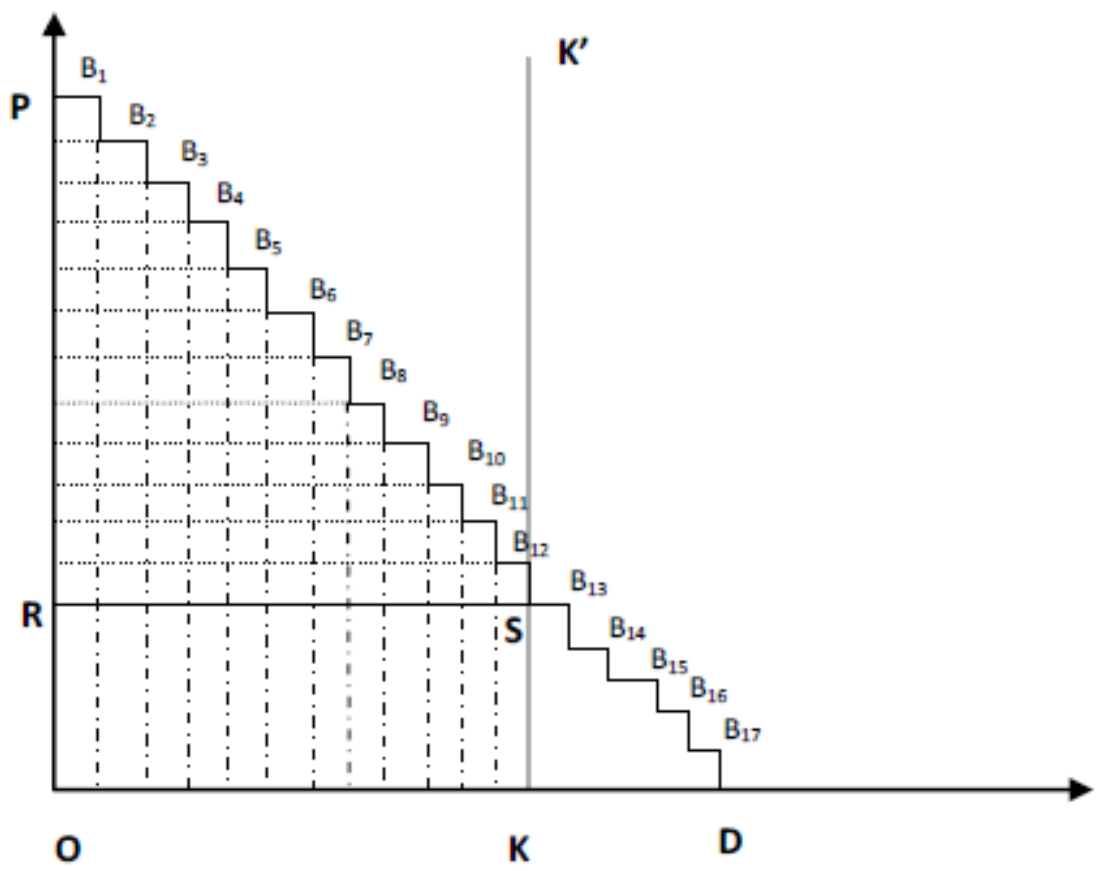

Source: Adapted from Krishna (2009)

Taking each bidder's demand, the step-curve PD represents the aggregate demand of bidders. As the supply of objects is fixed, KK' represents the supply curve. The portion of the triangle POD to the left of the intersection of the aggregate demand and supply functions represents winning bids, and the portion to the right represents losing bids. Each block on the step curve is labelled (' $\mathrm{B}$ ' followed by a

\footnotetext{
${ }^{74}$ Or multiple units of identical or homogenous objects.

${ }^{75}$ The theory is ambiguous on this; some theorists argue that this is an imperfect analogy (Krishna, 2009). Others argue that the Vickrey auction can be extended to multiple objects and bidders.
} 

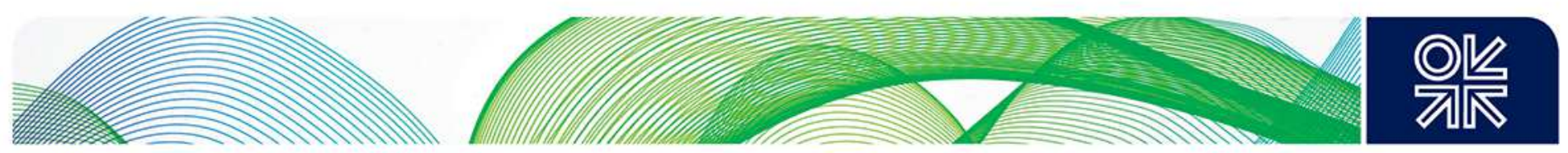

subscript) to represent the identity of the bidder (or the bid). ${ }^{76}$ Bids (prices) can be measured on the $Y$ axis and allocations (quantities) on the $X$ axis. The triangle PRS represents the total surplus; the rectangle RSKO arguably represents a minimum reserve price. For a first price sealed bid auction where all bidders submit their true values as bids, the auctioneer captures the entire surplus (PRS), resulting in an optimal and efficient allocation (this is similar to the single-bidder case).

The implicit assumption in the example in Figure 7.4 is that the objects being auctioned are identical or homogenous. In reality, multiple object auctions often have some degree of heterogeneity among objects. For instance, leases for oil and gas blocks arguably represent heterogeneous objects. The work on auction theory involving multiple heterogeneous objects where bidders have interdependent (common) values is insufficiently developed to allow us to present conclusive results, and this in a sense takes us to the limits of what auction theory can accomplish in this particular policy problem (Krishna, 2009). Nevertheless, Krishna shows that an efficient allocation is attainable under a specific set of assumptions - namely when bidders have additively and informationally separate valuations.

To illustrate, assume that $K$ distinct objects, with no complementarities, labelled $A, B, C$, and so forth, are auctioned. If the value to a bidder of obtaining object $A$ depends on the signals of all buyers pertaining only to object $A$ (informationally separate valuations) and if the value derived from obtaining a bundle of objects is simply the sum of the values of the individual objects (additively separate valuations), then every bidder's dominant strategy is to bid his or her value (Krishna, 2009). In the case of a discriminatory auction, this would lead to an optimal and efficient allocation. In practice, however, for auctions of hydrocarbon exploration leases, there may be complementarities between different leases. For instance, a bidder may wish to obtain leases for two adjacent blocks to take advantage of information synergies between the two.

Nevertheless, based on the discussion in this section, we can argue that conceptually first price sealed bid auctions and Dutch auctions are revenue maximizing (optimal) and also efficient - in the sense that they maximize the total gains to trade (sum of consumer and producer surplus) - only when bidders bid their true values. Second price sealed bid auctions and English auctions may not be optimal (revenue maximizing) but they maximize social welfare, or the gains to trade, and are therefore efficient.

In summary, we can argue that optimality and efficiency vary with the type of auction that is used. We can also argue that an 'inefficient' allocation of a good in an auction occurs when the good is not

\footnotetext{
${ }^{76}$ Hence bidders $B_{1}$ to $B_{12}$ represent winning bids and the rest are losing bids.
} 

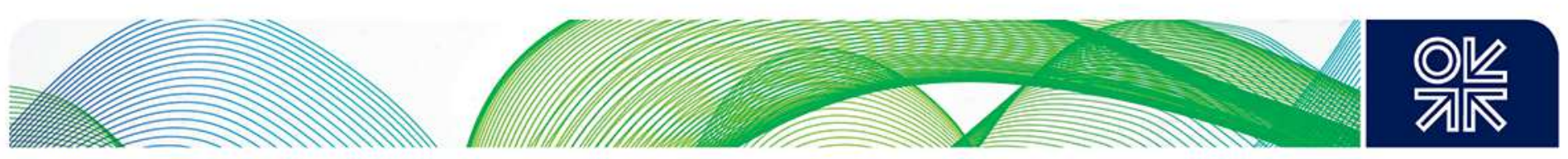

allocated to the bidder who holds the highest value, $v$ (and therefore the highest willingness to pay, $\left.W_{p}\right)$ for it. In this case, therefore, the total gains to trade are not maximized.

\subsubsection{Application to Practical Auction Design}

The practical application of the above theory depends to a great extent on the characteristics of the market being studied, which in turn links with the problems associated with 'real world' auctions. Klemperer (2004) argues that, in practice, the sorts of problems faced by auctioneers are more closely related to conventional problems faced in elementary economics, and these are closely related to market design.

The first is the problem of entry. This relates not only to the types of bidders that the government as auctioneer wishes to attract, but also to the ex post market structure that is created (as discussed in Section 4). The profitability of an auction depends crucially on the number of bidders who participate; as participating in an auction comes at an opportunity cost, bidders will only undertake it if they feel that they have a realistic chance of winning (Klemperer, 2004). An auction with too few bidders risks being unprofitable for the auctioneer, and potentially inefficient (Klemperer, 2004; Bulow and Klemperer, 1996).

It has been argued that ascending auctions favour stronger bidders (such as incumbents) who can outbid their competitors, and hence act as an entry deterrent to new entrants. First price sealed bid auctions, on the other hand, attract more bidders, as the uncertainty of the outcome means that weaker bidders tend to prefer them. However, as argued earlier, weaker bidders with lower values may actually end up winning in first price sealed bid auctions; this leads to an inefficient allocation. Further, if the costs of defaulting on commitments is small, bidders end up bidding on (and paying for) options on prizes rather than the prizes themselves (Klemperer, 2004).

A second problem in practical auction design is that of collusion (Klemperer, 2004). Collusion occurs in auctions characterized by a high degree of transparency, and when there are opportunities for repeated interactions between bidders; therefore ascending (English) auctions and to a lesser extent, second price sealed bid auctions, are said to be susceptible to collusion. The problem of collusion is similar to that of cartel-like behaviour in a market (Klemperer, 2004). Bidders cooperate (or collude) such that one bidder submits an infinitely high bid whilst the others submit very low or zero bids; the 
high bidder wins and the gains are shared according to a predetermined arrangement (Klemperer, 2004).

A third problem in practical auction design relates to political constraints and robustness to political pressures. Experience around the world has shown that different types of auction design that seem similar to economic theorists may seem very different to politicians, bureaucrats, and the public (Klemperer, 2004). The pressures resulting from this should be predicted and planned for in advance - for instance, governments are sometimes resistant to the use of reserve prices, even if they have the information to set them sensibly, as they are reluctant to run even a small risk of not auctioning off all the objects - an outcome that might be regarded as 'failure' (Klemperer, 2004).

Applying the theory to the Indian NELP auctions, it is evident that the types of leases (or blocks) being auctioned - onshore, shallow-water, and offshore deep-water - correspond to different markets with bidders that have differing elasticities of demand. There is therefore a case for using different auction types to allocate different types of leases.

Bidders for onshore blocks are smaller, non specialist firms with a relatively more elastic demand for leases (varying with factors such as the international oil price or macroeconomic environment). We can argue that since onshore areas in India have been relatively well explored in comparison to offshore deep-water areas (where capital and technology requirements are greater and more urgent), the objective of the government as auctioneer for smaller onshore areas is justifiably optimality (or revenue maximization). First price sealed bid auctions are optimal as well as efficient, when bidders bid their true values - implying that the role of a reserve price is crucial ${ }^{77}$. As pointed out earlier, collusion is difficult in sealed bid auctions as they lack repeated interactions. Entry has not been a serious problem under first price sealed bid auctions for smaller onshore blocks under NELP, as the qualification requirements are low.

The case for offshore deep-water blocks, on the other hand, is more complex. As discussed earlier, these areas require large infusions of investment. We have also seen, in Section 6.2, that the ex post market structure has resulted in most deep-water leases being held by a small number of firms (arguably even a duopsony) - this conforms with auction theory, which states that a strong bidder with an ex ante advantage is more likely to win the auction, thereby perpetuating a cycle. Further,

\footnotetext{
${ }^{77}$ Arguably, setting reserve prices for onshore blocks may be easier than for offshore blocks, as onshore areas have been relatively well explored and reserve prices could be based on expected volumes of production valued at the international price of oil, for instance.
} 

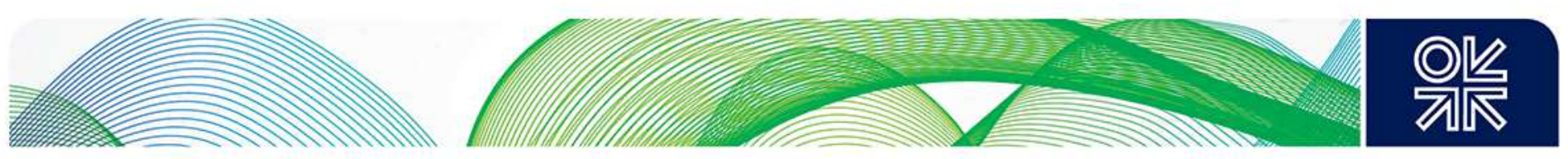

efficiency in this case intuitively implies maximization of the system welfare, whilst also capturing a large amount of surplus.

Offshore deep-water leases could therefore be auctioned using a dynamic auction format - one option would be a second price sealed bid auction, which ensures that the block is auctioned to the bidder with the highest valuation, but also that the gains to trade are maximized.

A second price sealed bid auction implies that the winner, by paying the second highest bid, gains the opportunity cost for the lease - that is, the difference between the maximum total social welfare with and without the winning bidder (Zhan, 2008). ${ }^{78}$ Additionally, market design measures could include the reservation of a certain amount of acreage for new entrants.

Auctions necessarily need to be preceded by the collection (via procurement, if governments lack the resources for data gathering) and release of as much information as possible on each lease. This could reduce any rent that a bidder may obtain from privately held information and hence reduce the bidder's surplus, making it more likely that a bidder will bid his correct value, and that the government will capture a larger amount of rent.

Finally, it may be necessary to increase by a very large amount (for instance a sum much closer to the actual costs of exploration rather than the current fraction of it) ${ }^{79}$ the penalties for defaulting on work programmes, or set them as a proportion of some variable to prevent firms from treating them as sunk costs.

In the next section, we attempt to draw together our observations thus far to lay out some 'big picture' results of the dynamics of the NELP auction rounds using a simple econometric model.

\footnotetext{
${ }^{78}$ In auctions theory, this concept is well demonstrated by the Vickrey-Clark-Groves mechanism (Zhan, 2008).

${ }^{79}$ The cost of a single deep-water well can be as high as US\$150m, whereas the penalty for failing to drill a well under the NELP can be as low as US\$3m.
} 

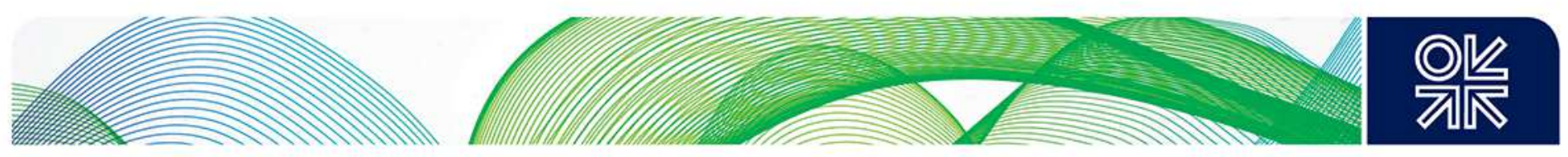

\section{Modelling the NELP Auction Rounds - Extended Descriptive Statistics}

\subsection{Data and Method}

The review of empirical literature in Section 5 summarized a set of conventional techniques used in the analysis of auctions. We adapt a conventional empirical approach for our dataset, based on lledare et al. (2004), which reviews, evaluates, and analyses the bidding behaviour and performance for leases awarded in the Gulf of Mexico OCS off the Texas and Louisiana coasts from 1983 to 1999, in terms of the responsiveness of the value of the high (winning) bids to: the total number of bids, the perceived quality of the lease, the size of the firms bidding for leases, the bidding methods (solo or joint), and the bidding structure (multiple bids or single bids). Their analysis specifically observes - for the effects of bidding behaviour (joint, solo, single, and multiple bidding) - the effects of geological attributes (location and type of lease area) and of other relevant factors - such as the oil price and policy changes - on the value of the high or winning bid.

lledare et al. (2004) apply a simple econometric modelling framework to their data. The basic conceptual framework underlying the analysis specifies that the value of the high or winning bonus bid $(H B)$ is a function of three sets of factors: economics, structure, and conduct. This specification has been used successfully in existing literature to analyse lease auction market performance (Markham, 1970; Gilley and Karels, 1981; Dougher, 1987; Porter, 1995).

The general specification is:

$H B=f(V, S, C, Z)$

Where, as per lledare et al. (2004):

$H B$ represents the magnitude of the high bonus bid for a lease. This is also the dependent variable in the model. It is the highest bid received and accepted by the US Minerals Management Service for the right to develop the lease.

$V \quad$ represents factors which capture the expected gross value of the lease, or the 'economic' factor.

$S$ defines factors that represent the degree of competition in the leasing programme (its 'structure'). A good proxy for the intensity of competition is the number of bids or the number of bidders. It is expected that greater competition, as reflected in more bids per lease, is positively associated with the value of the high (winning) bid per lease.

C is a set of factors that serve as proxies for the behaviour (or 'conduct') of bidders in terms of the types of bids (joint ventures or solo) and whether the bidding was competitive, that is, 
whether more than one bid for the lease was submitted. It is expected that if the incidence of joint ventures is anticompetitive, then its effect on the high (winning) bid will be negative. If it is not negative, then the null hypothesis - that joint venturing is anti competitive - can be rejected. The economic implication for joint venturing is that it is undertaken for information, expertise, or risk sharing purposes.

represents 'other variables' postulated to be relevant to the value of the lease, such as water depth, the size and experience of the firm, as well as time-associated events (in the USA, such an event would constitute something such as the Deepwater Royalty Relief Act the US Congress passed in 1995). For the Indian NELP auctions, it could represent the introduction of changes to the NELP fiscal criteria. More generally, an event could constitute a drop in world oil prices.

We follow a similar conceptual method in the formulation of our regression model, which is presented as an extended descriptive analysis, as it focuses on the correlates of variables rather than causality.

Data was gathered (from a series of visits to the Ministry of Petroleum and Natural Gas and the Directorate General of Hydrocarbons) on variables relating to the winning bid for each block across eight rounds of auctions, although some values were missing (due to difficulties with obtaining a complete dataset). Our complete dataset ${ }^{80}$ contains 29 variables for eight rounds of auctions, representing the period 1999-2010. There are missing years in the panel data, but we think of the irregular years as the periodicity of the underlying stochastic process, and so we consider it to be pseudo-panel data (for example, similar to the waves of the National Longitudinal Survey of Youth or NLSY, which are also not yearly, or do not follow any sort of Gregorian periodicity). These are essentially cross-sections of completed auctions, where the level of the observation is one 'block' (or lease). We stack the data from the different years and track the year effect by including fixed effects for years. We select 12 variables from our dataset to run our model. Table 8.1 shows the variables from the NELP auctions corresponding to the general specification in Equation 4.

The dependent variable is VAL, which represents the score out of 100 awarded on a block by the government (as auctioneer) through the bid evaluation process. In the absence of monetary amounts (such as through bonus bids) we consider this as indicative of the magnitude of the winning bid. This corresponds to $H B$ in lledare et al. (2004).

${ }^{80}$ A description of variables is in Appendix B, and descriptive statistics are in Appendix C. 

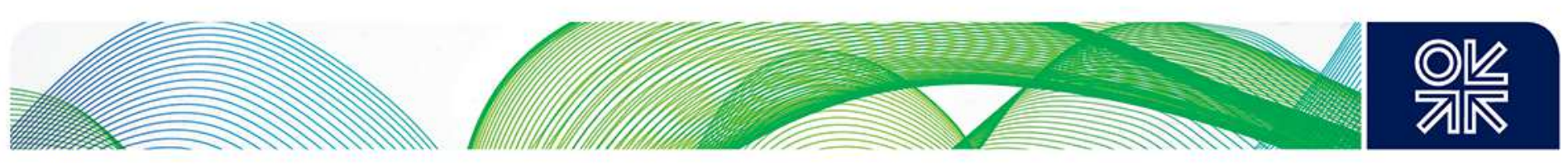

Amongst the independent variables, EXP represents the amount of expenditure committed on work programmes in winning bids, in US\$ millions. This corresponds to $V$ in lledare et al. (2004), as a proxy variable for the expected gross value of the lease or the 'economic' factor.

The variable BIDS represents the number of bids per block, and corresponds to $S$ in lledare et al. (2004), representing the degree of competition in the bidding rounds.

The variables $S J$ (whether the winning bid was a solo or joint bid), SM (whether the block received single or multiple bids, and MS (whether the bidder or consortium includes one of the two companies that held over 50 per cent of the total share of acreage auctioned over the nine rounds), represent bidder behaviour. They correspond to the set of factors $C$ in lledare et al. (2004).

We use six variables to represent $Z$ - or 'other variables' postulated to be relevant to the value of the lease, as in lledare et al. (2004).

First, as it is not possible to distinguish between the equivalents of wildcat, drainage, and developmental leases easily, we use instead a variable PROS as indicative of the value of the lease depending on its perceived prospectivity according to the official categorization of the basin in which it is located. Category 1 and 2 basins are relatively prospective, and Category 3 and 4 basins are less prospective - the variable takes on the score $1 / 0$ accordingly. The differences between these relate to informational advantages or disadvantages possessed by bidders while making their bid (lledare et al., 2004). 


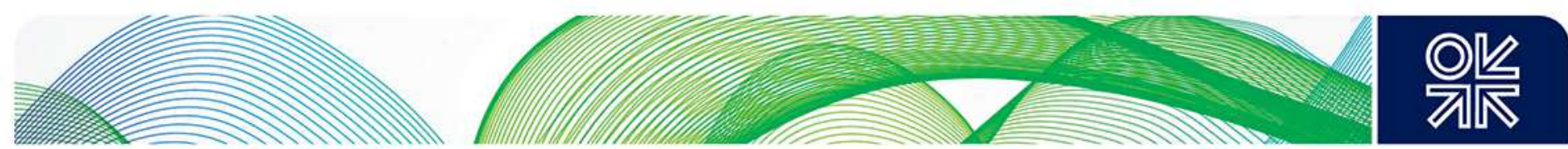

\section{Table 8.1: Description of Variables}

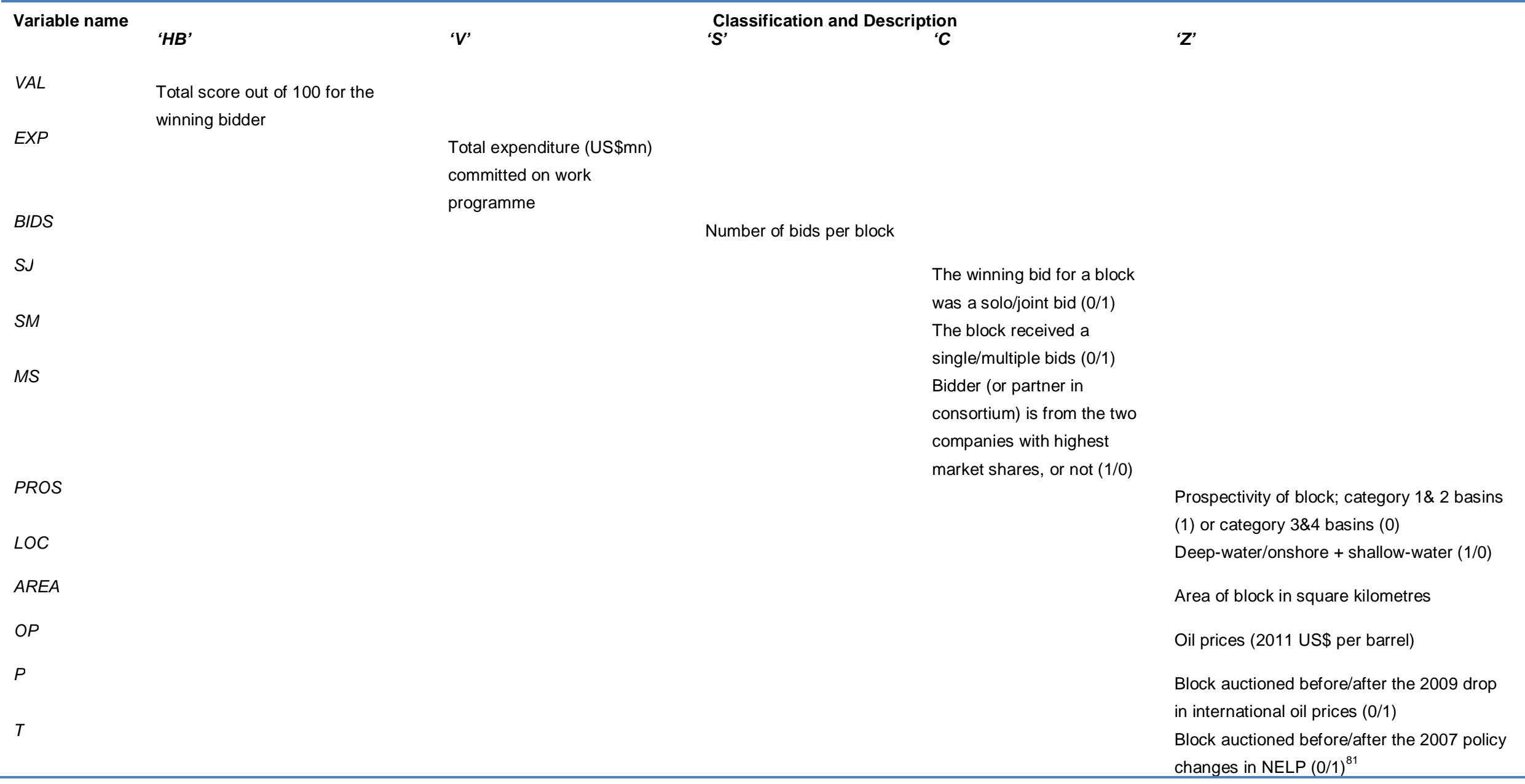

${ }^{81}$ The most significant policy change was brought in for the system of sharing profits from production between the exploration company/consortium and government, as discussed in Section 3. 

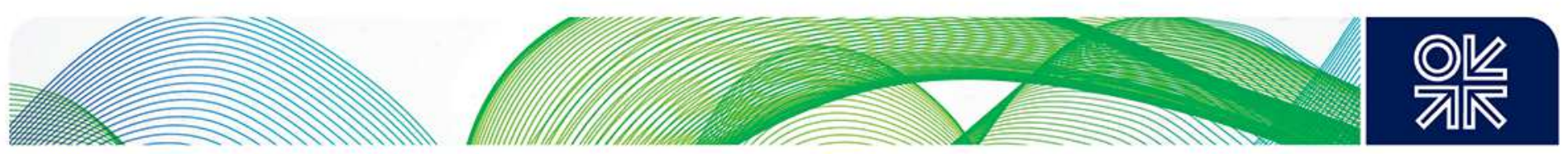

Similarly, we use the variable $\angle O C$ to indicate whether the block is situated in offshore deep water, or in onshore or shallow water, as these differences are also arguably relevant to the value of the block. While lledare et al (2004) use a variable representing average lease water depth to represent costs of exploration and development, as we do not have this data, we use a variable $A R E A$ which represents the size of the block in square kilometres, as being indicative of the costs of exploration. It is expected that the value of the winning bid should decrease with larger areas, due to higher costs of development.

We use the variable OP to represent the crude oil price in 2011 US\$ per barrel, representing a measure of the perceptions or expectations prevailing in the economic environment within which the bidding process operates.

Finally, we use two variables to help identify the relative impact of specific events. First, for the period of our analysis, the only significant drop in oil prices occurred in $2009 ;{ }^{82}$ this effect is therefore represented by the variable $P$ in our dataset, which takes on the score 1 if the block was auctioned after 2009. Second, the only significant policy change in the fiscal terms of the exploration regime occurred in the seventh round of the NELP, when the sliding scale upon which profit sharing with the government was based changed from a six-tier system to two tiers, along with other secondary changes relating to penalties and so forth (described in Section 4). We therefore include the effect of this policy change in the variable $T$, which takes on the score 1 if a block was auctioned after these changes.

The dependent variable in our analysis, which is the total score obtained by the winning bidder, is a bounded value (between 0 and 100). Therefore, rescaled, it is a proportion between 0 and 1 , and we can use a logistic regression (logit) model to analyse our data. ${ }^{83}$ Our methodology is one that is increasing in generality, and we carry out three model estimations to check for consistency. We first estimate a beta regression, followed by a zero-one inflated beta regression, ${ }^{84}$ and a fractional logit regression (Papke and Wooldridge 2008; Calabrese, 2012). Appendix C details the econometric technique further, where we state that the fractional logit regression yields the most efficient

\footnotetext{
${ }^{82}$ This was seen to be an effect of the world recession and contraction in demand, but prices shot up about a year later due to the onset of the uprisings in Egypt, and their proliferation in other gas and oil exporting nations in the Arab world ('Arab Spring').

83 The logit model makes a scale normalization which results in the same marginal effect on regressors with non linearity.

${ }^{84}$ The beta regression does not take into account the extreme $\{0,1\}$ values in the dataset and hence we estimate a zero-one inflated beta regression.
} 
consistent estimator under weaker conditions. ${ }^{85}$ Results are reported from all three models and we discuss economically and statistically significant results. ${ }^{86}$

\subsection{Results}

We report the marginal effects from a beta regression model, zero/one inflated beta regression model, and fractional logit model, in Tables 8.2 and 8.3. The results are consistent across all three models, with an almost equal number of variables showing up as significant in the $0 / 1$ - inflated beta regression than in the fractional logit regression model.

Table 8.2: Marginal effects Beta and 0/1 Inflated Beta Regressions

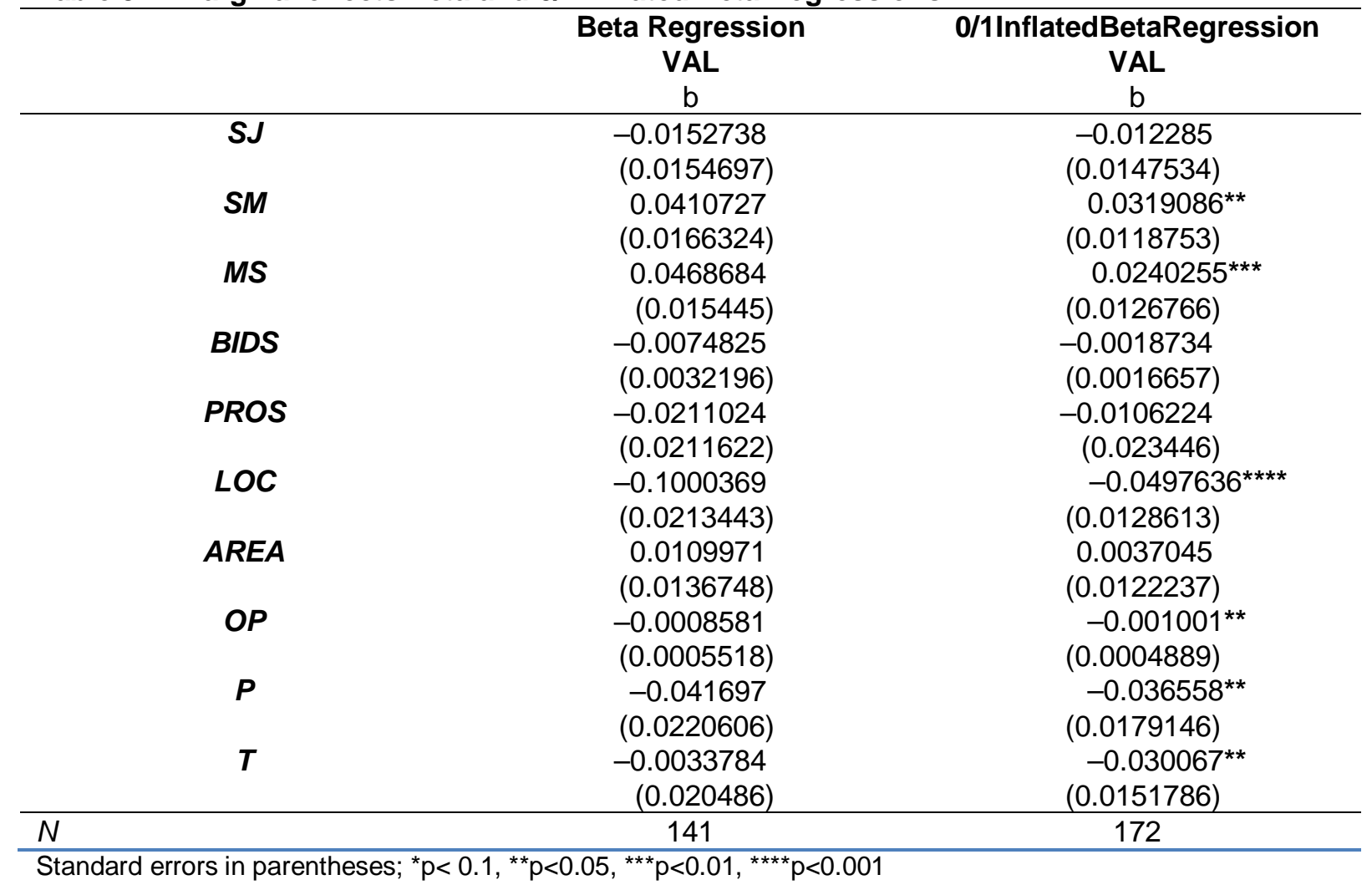

\footnotetext{
${ }^{85}$ In the econometric technique we also apply a transformation using a link function ' $g$ ' which yields a function that is linear in the regressors. The use of cluster-robust standard errors deals with non spherical errors (heteroskedasticity).

${ }^{86}$ A limitation of our method is the possibility of endogeneity, for which we require (a) a precise definition of what constitutes endogeneity in the model, and (b) instruments which are correlated with the endogenous variable(s) but not the error. However, we do not believe that this limitation invalidates our results, first, due to the difficulty of obtaining good instruments for this particular research problem and specification, and second, as we have presented the modelling as an extension of a larger, descriptive analysis, the results of which are largely consistent with each other. We avoid the use of more sophisticated modelling techniques as we believe that endogeneity is primarily not a question of specification, but of the selection of good instruments.
} 


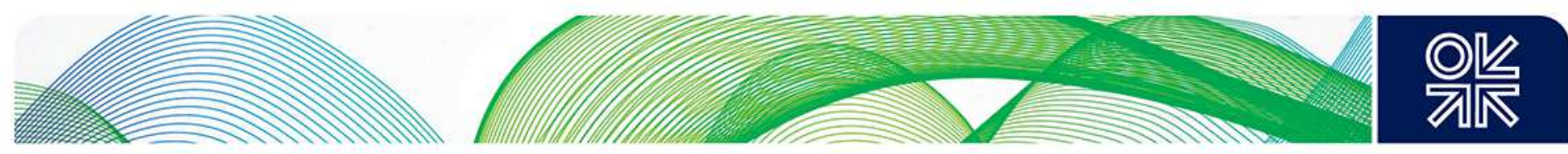

Table 8.3: Marginal Effects - Fractional Logit Models

\begin{tabular}{|c|c|c|c|c|}
\hline & (1) & (2) & (3) & (4) \\
\hline & VAL & VAL & VAL & VAL \\
\hline & $\mathrm{b}$ & $\mathrm{b}$ & $b$ & $b$ \\
\hline SM & -0.0052085 & - & 0.0195704 & 0.7842311 \\
\hline MS & $0.0394212^{* *}$ & $0.0396862^{\star \star}$ & $0.0462084^{\star \star \star}$ & $0.0395333^{\star \star *}$ \\
\hline BIDS & -0.0012935 & -0.0015925 & $-0.0038774^{\star \star}$ & - \\
\hline LOC & $-0.105768^{\star \star \star}$ & $-0.1037908^{\star *}$ & $-0.0898022^{\star \star *}$ & $-0.1046421^{\star * *}$ \\
\hline AREA & 0.0017938 & 0.0013646 & 0.0095167 & 0.0018675 \\
\hline EXP & 0.0003192 & 0.000302 & - & 0.3068286 \\
\hline OP & 0.0219914 & 0.0218935 & $-0.0013571^{\star \star \star \star}$ & 0.0218222 \\
\hline $\mathbf{P}$ & 0.2724784 & 0.2714358 & -0.0523815 & 0.27221 \\
\hline
\end{tabular}

${ }^{*} \mathrm{p}<0.1,{ }^{* *} \mathrm{p}<0.05,{ }^{* * *} \mathrm{p}<0.01,{ }^{* * * *} \mathrm{p}<0.001$ 

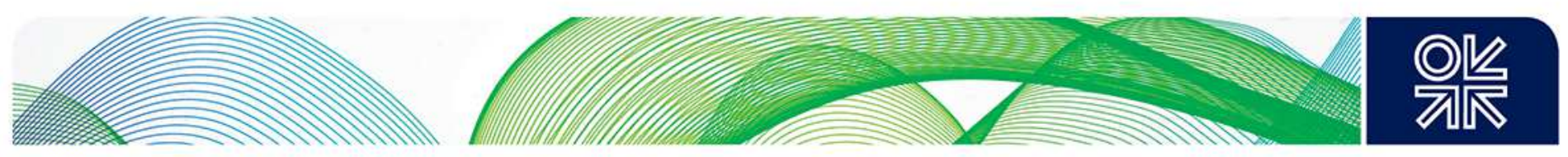

Within the fractional logit model we estimate four sets (or combinations) of results, and we interpret results from the third set (Column (3) in Table 8.3) as it uses the largest number of observations.

The marginal effects coefficients reported in the models provide information about the probability of a change in the dependent variable from a unit change in the independent or explanatory variable. The purpose of the model is to allow us to reasonably observe for these probabilities in relation to the dependent variable VAL (representing the high score or the winning bid). The model can thus be considered as an extended analysis of correlates, and the results should be interpreted with this in mind. ${ }^{87}$ The signs of the beta coefficients are largely consistent across all our estimations, as are the variables that show up as significant.

Amongst variables representing bidder behaviour, $S M$ is positive and significant, indicating that blocks receiving more than one bid were more likely to have a higher winning score than blocks receiving single bids. This is an expected result. However, MS on the other hand is also positive and significant, implying that a high or winning bid involving one of the two firms that control the largest shares of acreage in the lease auction market is likely to lead to a higher winning score than if these firms are not involved. Although other empirical studies focus on whether firms with market power tend to submit and win bids with lower amounts on average (lledare et al., 2004) the result obtained here may be indicative of overbidding (demonstrated by the data in Section 6.3).

Although we obtain the expected sign for $S J$ - indicating that joint bids are likely to lead to a lower winning score - the variable is not significant, which prevents us from making conclusive observations about the effects of joint bidding.

A counterintuitive result is obtained for BIDS or the number of bids per block, indicative of the competitiveness of the auction rounds. The result implies that a higher number of bids per block is likely to lead to a lower score on the winning bid. This is opposed to the theoretical expectation that a competitive bidding round leads to higher winning bids on average. However, we could argue here that this result on its own is inconclusive without relation to an analysis of leases broken down by geological type (onshore, shallow-water, and deep-water). We have attempted to present such an analysis earlier, in Section 6 (Table 6.1), arguing that a dichotomy in bidder behaviour has resulted in

${ }^{87}$ Papke and Wooldridge (2008) discuss more sophisticated models which incorporate endogeneity. 

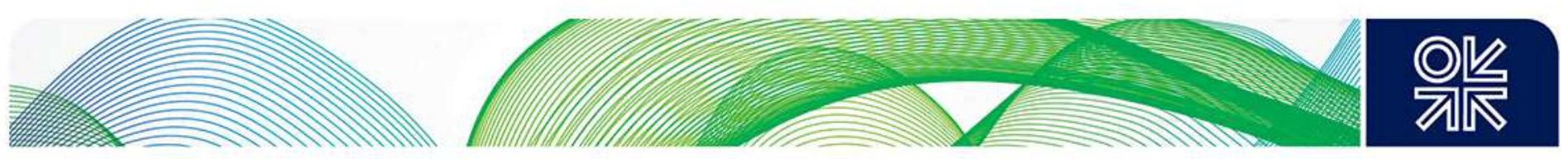

large numbers of bids for onshore and shallow-water blocks and very few or no bids for deep-water blocks.

Amongst geological attributes of leases, $\angle O C$ is negative and significant; implying that a block located in deep-water offshore areas is likely to have a lower score on the winning bid in comparison with onshore and shallow-water blocks - by itself an expected result given that deep-water blocks have struggled to attract qualified bidders.

We also obtain a counterintuitive result for $O P$ or the international oil price. This is negative and significant, implying that a higher oil price is likely to occur alongside a lower total score on the winning bid.

Amongst variables representing policy changes, the coefficient on $P$ is negative and significant, implying that a block auctioned after the drop in oil prices in 2009 was more likely to have a lower score on the winning bid than blocks auctioned prior to the drop. This could indicate the effect on bidder perceptions of volatility in international oil prices. Further, the variable $O P$ has a high standard deviation, lending support to this observation.

Finally, we obtain a negative and significant result for the variable $T$. This indicates that a block auctioned after the changes brought into the NELP regime from the seventh round onwards was likely to have lower score on the winning bid than a block auctioned before the change. This result could also be partially attributable to the general environment of policy uncertainty over pricing and fiscal terms that arose at the time and has persisted ever since. ${ }^{88}$

In summary, these results provide some insight into the 'big picture' dynamics of the auction rounds but they are subject to limitations. ${ }^{89}$ As our dependent variable is a score rather than an absolute value, it is interpreted with caution. Further, as our coefficients represent probabilities rather than absolute changes, it is difficult to determine the effects of independent variables relative to each other. There is scope for taking this analysis further in a separate study. In the next section we discuss policy options, as a way of beginning to think about the issues highlighted in the empirical analyses in Sections 6-8.

\footnotetext{
${ }^{88}$ An example would be the 2007 gas pricing dispute (Jain, 2011).

${ }^{89}$ These results could be taken forward using more sophisticated techniques, which are beyond the scope of this working paper, but which represent a potential area of future work.
} 


\section{Findings and Policy Options}

Our findings support the main lines of argument in Section 4.3, which stated that the NELP regime has led to unintended consequences. There are indications of an undesirable ex post market structure (duopsony), of winning bids having been submitted in excess of true valuations, and of licenses being awarded to bidders whose high valuations may not have been derived from the intention to explore. The underlying explanations or reasons for this are manifold - some clear, others less so - all relating to auctions and market design. One conclusion is that the lack of clear, stated objectives prior to the launch of the regime (and of each bidding round) has acted as a constraint on its ex post effectiveness. A second finding relates to the relevance of geology in auction design. The findings on market concentration and the holdup problem appear to be more complicated, as they may be attributed to both auction design and the need to design markets towards aligning government and firm incentives. Further work could also be done on the role of oil price movements. This section outlines some suggested policy areas, based on our findings, which could be considered and worked upon further in future research.

\subsection{Statement of Objectives}

As discussed, ambiguities over the precise objectives of the auction - primarily optimality versus efficiency - have led to controversies ex post over whether the auctions were successful. In Section 7.2 of this paper, we showed that the objectives of optimality and efficiency ${ }^{90}$ are either complementary or mutually exclusive, based on the type of auction that is used, as different auction types incentivize different bidding strategies. In the case of onshore blocks using first price sealed bid auctions, we argued that the primary objective is justifiably optimality (revenue maximization), as optimality and efficiency equate with each other in a scenario where the bidder bids his true value and the auctioneer captures the entire bidder (consumer) surplus. Further, as onshore areas have been relatively well explored, it is justifiable for the auctioneer (government) to aim to maximize revenue from these areas. In the case of offshore deep-water blocks using second price sealed bid (or another dynamic format) auctions, ensures efficiency but not optimality (as shown in Section 7.2) as the winning bidder gains an amount equivalent to his opportunity cost (and the auctioneer therefore does not capture the entire bidder surplus). It is therefore useful for the auctioneer to recognize the objectives of each auction and state them clearly, by publishing them ex ante, to prevent conflict ex

\footnotetext{
${ }^{90}$ To reiterate, in economics, efficient auctions maximize the total seller and buyer surplus. Optimal auctions are those where the seller (in this case the government) captures the entire surplus, thus maximizing his revenue. The objectives of 'optimality' and 'efficiency' can therefore be viewed as 'maximizing revenue' versus 'maximizing social welfare or the gains to trade' and our analysis in Section 7 showed that these two are equivalent only under certain conditions.
} 

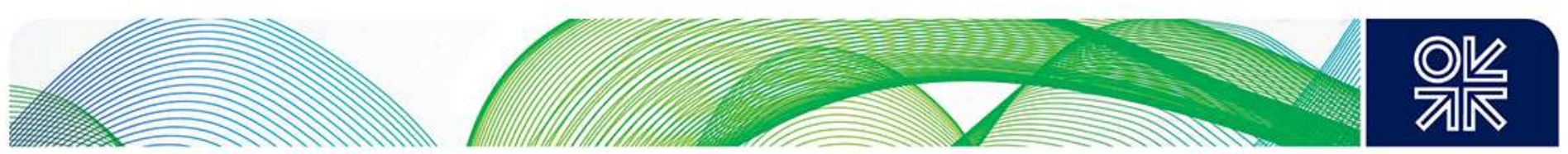

post. The general ambiguity around the goals of the regime, or what constitutes 'success', has in the past added to the atmosphere of uncertainty surrounding participation in the auctions and in the government's decision making.

\subsection{Auction Design and Geology}

The empirical results show that the ex post market structure that has resulted from the NELP auctions resembles a duopsony. The theory shows that smaller and larger bidders (firms) have different elasticities of demand for blocks of different geologies, and that the government (as auctioneer) necessarily faces a situation similar to that of a monopolist facing third degree price discrimination. This supports the case for using different auction formats for blocks with different geologies. Onshore blocks, which attract smaller, non specialist companies, can continue to be auctioned using a first price sealed bid format which, as we have seen, is conducive to encouraging entry - but this would necessarily need to be combined with a reserve price or mechanisms to ensure that bidders bid their true values to ensure optimality and efficiency. Offshore deep-water blocks, which have in the past failed to attract large specialist companies with the necessary capital and expertise, could, however, be auctioned using a dynamic format - such as a second price sealed bid format with a reserve price - combined with measures to counter collusion, identified in the literature as a problem in auctions with repeated interactions. Cramton $(2007 ; 2010)$ suggests that if the government as auctioneer has limited administrative capacity to administer more than two auction formats, the country could split the blocks into two sets, those with 'high prospects' and those with 'low prospects' - the first price sealed bid auction could be used for low prospects, and a dynamic auction format for high prospects. ${ }^{91}$

\subsection{Data: A 'Public Good' Problem}

As discussed earlier, India has struggled to develop a system for the gathering, maintenance and dissemination of updated geological and other information that could be used to conduct successful auctions. As demonstrated in this paper, a policy that engenders symmetry of information can ensure that bidders make their bids less dependent on their 'private values' and more on the 'common value' element - thereby reducing the information rent gained by bidders from their private values, and encouraging a more level field of competition. An implicit objective of the auction regime was for data to become available as exploration progressed - this has, however, not occurred.

Data is arguably a public good and the problem of accumulation and sharing of data can thus be viewed as a public good problem, separate from the auctions per se. As data is shared, private firms

\footnotetext{
91 'Prospects' could be defined in terms of resource potential, extent of exploration or size, for instance.
} 

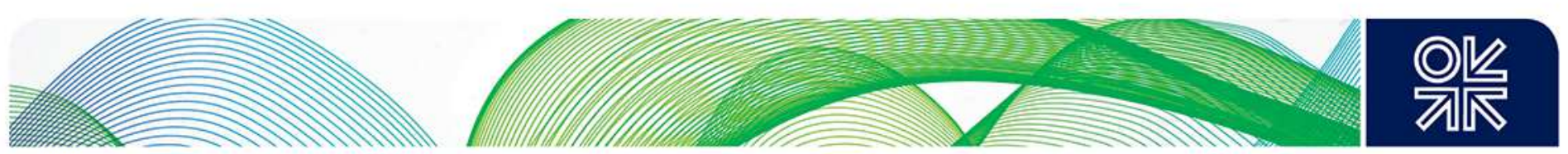

have no incentive to provide it - it therefore needs to be provided by the government, either through carrying out these services itself, or by procuring them for instance through procurement auctions. There are examples of how other governments have gone about gathering or procuring data. One method is to legally mandate the sharing of data with governments; in the UK, the Petroleum Act, 1998 and Electronic Communications Act, 2000, require licensees to maintain and deliver data to the Department of Energy and Climate Change, when requested. Another method is for the state to engage directly in data gathering and dissemination - in Brazil, the state agency, Agencia Nacional de Petroleo (ANP) maintains and administers BDEP, Brazil's data repository. Norway, on the other hand developed a National Data Repository in 1995 through contracting IBM to develop 'Petrobank', which contains seismic and navigational data, well data, production data, and other archived data. Firms contracted to procure data should not be permitted to participate in bidding rounds, due to the obvious problems with moral hazard.

\subsection{Market Design}

Market design closely follows a clear statement of objectives of the regime - namely, once a relative order of importance has been defined, market design can be used to correct for undesirable outcomes. Consider the holdup problem: three potential explanations have been identified in this paper. The first is that firms that won blocks submitted overestimated bids, and later could not fulfil their investment commitments. This could potentially be resolved though a reduction in information asymmetry, achieved through the provision of data, as described above. A second possibility is that the high bids derive from accurate valuations, but that the source of these valuations is not the intention to engage in exploration, but to pursue other objectives, such as increasing the short term value of an asset portfolio or maintaining market share. In this case, the government as auctioneer could impose rules such as the reservation of a percentage of acreage for new entrants so long as these rules are published in advance. A third possibility is that winning firms gain information ex post which makes it inefficient for them to continue exploration (Hotelling, 1931) - while governments consider it inefficient for firms to stop exploring, given their own socioeconomic and electoral goals. Market design could be used to explore incentive mechanisms that would better align firm and government objectives, such as imposing phase wise bonus payments or imposing penalties which would make it inefficient (and unprofitable) for firms to stop exploring compared with the ongoing cost of exploration. ${ }^{92}$

\footnotetext{
${ }^{92}$ The challenge here is to design these mechanisms in a way that firms do not view or include them as sunk costs. One way could be by defining the penalties as proportions of a variable, rather than in absolute values.
} 


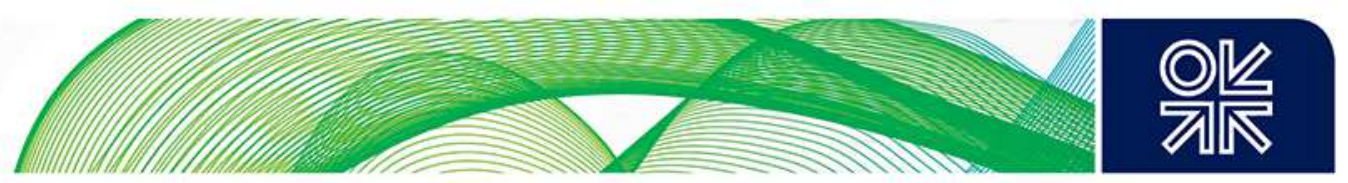

\subsection{Penalties}

The auctions literature shows that, in the absence of adequate penalties, bidders end up bidding for 'options on prizes' rather than for the 'prizes' themselves (Klemperer, 2004). Penalties for unfinished work programmes were brought into the NELP in the eighth bidding round, but have been set at a fraction of the total cost of a work programme committed by the winning bidder. For instance, the penalty for not drilling a well was, in some cases, set as low as 2 per cent of its total potential cost. Penalties thus need to be set far higher. Penalties are difficult to set, and defaults due to the imposition of inadequate penalties have been common worldwide - examples can be found the US spectrum auctions, and in the Australian auctions for satellite television licences (Klemperer, 2004). The imposition of penalties could also be through means other than monetary payments. Some countries, such as Australia, have dealt with defaults on commitments to drill wells by requiring defaulters to carry out surveys in lieu. Penalties could also be imposed in the form of restrictions on bidding.

\subsection{Reserve Prices}

An area for consideration and for further research is the setting of reserve prices in the NELP auctions. Reserve prices are used for two main reasons: first, to guarantee substantial revenue in auctions where competition is weak but the reserve is met; and second, to mitigate the incentive for, and the impact of, collusive bidding - reserve prices mitigate the effects of collusion by reducing the maximum gain from collusive bidding (Cramton, 2010). The US-OCS lease auctions are frequently cited as a successful example of the use of reserve prices. These are set by the Lease Licensing Authority and are based partly on the geological and seismic information that firms are required to submit, and partly on the bids themselves (when more than three bids are received for any tract), the figures being set as a dollar amount per acre, the figure remaining undisclosed during the auction (Porter, 1995). Data shows that between 1954 and 1990, an average of 8 per cent of bids was rejected in US OCS lease auction rounds based on reserve prices. Although reserve prices can be a useful tool in ensuring efficiency, they can be difficult to determine, especially for bidding systems which involve work programme commitments, as opposed to cash bonus bidding. A reserve price set too high may deter bidders, and one set too low may result in inefficient allocation (Cramton, 2010). The NELP rounds arguably contain an implicit reserve price - the highest bid on every bid evaluation sub criterion is set as the benchmark (as discussed earlier) and all bids then evaluated relative to this. Hence the benchmark acts as a notional reserve price. This has not, however, always ensured 

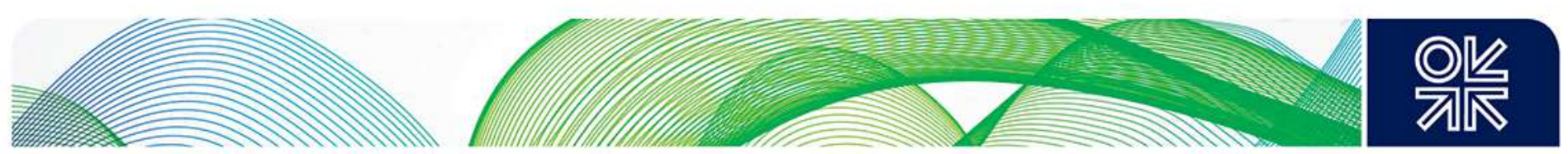

efficient allocation, as the empirical analysis has shown. ${ }^{93}$ The setting of accurate reserve prices is arguably one of the most difficult areas of auction design - although theorists argue that having a reserve price is better than not having one (Whitford, 2007).

\subsection{Strong Institutions}

Governments as bid-takers are multiple-task agents; establishing bidding systems is just one of a set of general concerns they bring to the market environment which include things like industry promotion, regulation, consumer affairs, as well as concerns linked to fiduciary responsibilities (Whitford, 2007, 68). Although seemingly obvious, this point about the need for strong institutions with clear areas of remit therefore needs to be stressed. Arguably, issues such as the lack of an independent and empowered regulator to oversee and coordinate various aspects of auctions and market design have already been recognised and are being worked upon by Indian policymakers. The Directorate General of Hydrocarbons, for instance, does not have the clear independent authority of bodies such as the Norwegian Petroleum Directorate or the US Lease Licensing Authority, which are involved in setting reserve prices and overseeing data collection. As the Directorate is also meant to provide technical consultation and support to the Ministry of Petroleum, and is staffed through secondments from ONGC and OIL, there is no clear separation of the regulatory function. ${ }^{94} \mathrm{~A}$ wider institutional problem relates to conflicts of policymaking between different government Ministries. There have been some instances where, despite blocks being awarded, contracts signed, and in some cases investments sunk, firms have had to indefinitely postpone or withdraw their operations as environmental or defence ministry clearances have been withheld or retracted. Technically, these cases are either classed as force majeure or taken to arbitration; they then contribute to the holdup problem. ${ }^{95}$ Recent measures have however been carried out to try and resolve these problems with inter-ministerial coordination.

In December 2012, a Committee appointed by the federal government published its policy recommendations on reforms to the NELP regime. ${ }^{96}$ These recommend eliminating the bidding on cost recovery, along with the profit sharing based on an R-factor system, and replacing this with a straightforward production level linked payment. Bidders would have to make their bids on the basis

\footnotetext{
${ }^{93}$ An example of the problems with setting a 'relative' reserve price is the Turkish sequential spectrum auction - the government set the reserve price of the second licence equal to the bid price of the first (Binmore and Klemperer, 2002). As a consequence, the company that won the first licence bid aggressively high, so that the second licence remained unsold, creating a market structure favourable to the winner of the first licence (Binmore and Klemperer, 2002).

${ }^{94}$ See Jain (2011) for policy recommendations relating to this.

${ }^{95}$ Examples of stalled exploration operations include ENI in the offshore Andaman Islands, BHP on the west coast, ENPRO in Assam, and Gazprom.

${ }^{96}$ The Rangarajan Committee. This was followed by the Kelkar Committee in 2013, which had yet to make its recommendations at the time of writing this paper.
} 

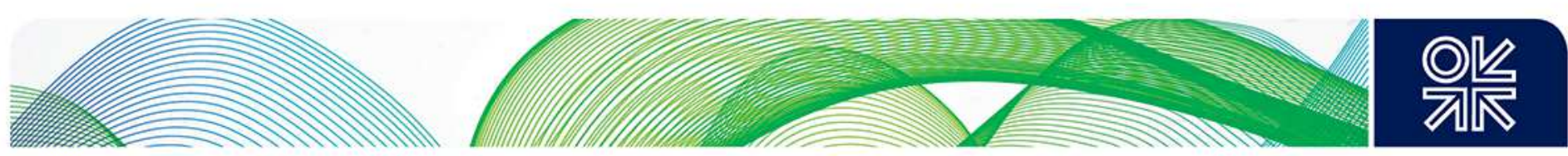

of a 'bid matrix', in which bids are made on different percentage revenue shares for different levels of production and prices (ranging from less than US $\$ 75$ to more than US $\$ 120$ per barrel).

A 'bid bond' amounting to 50 per cent of work programme expenditure has been recommended for onshore blocks, to deter speculative bidding. It is also recommended that the exploration period for deep-water blocks be extended from eight to ten years, and restrictions on exploratory drilling carried out in areas where discoveries are simultaneously being developed be relaxed. Further, the scoring system would be replaced with a procedure that awards the block to the bidder which offers the highest Net Present Value of potential oil and gas production at a 10 per cent discount rate.

These new recommendations address some of the issues highlighted in this paper, but not all. For instance, the elimination of the cost recovery provision prevents companies from inflating capital expenditure in an attempt to delay the sharing of profits from production with the government. Relaxations on exploration cut down some of the red tape firms have faced in the past. The adoption of a bid evaluation system based on net present value is arguably simpler than the current scoring system. However, issues on market concentration and entry remain. Bid bonds could be regarded as sunk costs by firms and risk not influencing their decisions to stop exploration ex post if this becomes inefficient compared to the ongoing costs of exploration. The possibility of different elasticities of demand amongst bidders for blocks with different geologies remains to be considered, along with a clear statement of objectives. And importantly, the public good problem associated with data needs to be addressed. 


\section{Conclusion}

Why, despite nearly 15 years of the New Exploration Licensing Policy (NELP), representing two entire exploration cycles and nine bidding rounds, has this regime yielded inconclusive results on both determining India's resource potential and increasing its domestic production? In this paper, we have argued that the reason cannot be entirely put down to prospectivity, as this is a dynamic concept which is continuously influenced by advances in technology. The reasons for this perceived 'underperformance' can instead be attributed to a combination of factors related to auctions and market design.

All auctions under the NELP bidding rounds are carried out using the same first price sealed bid format in the presence of significant information asymmetries, without reserve prices, no distinction between bidders' differing elasticities of demand for different geological types, and without a clear statement of objectives as to whether optimality (maximization of seller revenue) should be prioritized over efficiency (maximization of the gains to trade), or vice versa. The empirical analysis in this paper shows that this regime has led to the unintended consequences of a highly concentrated market for upstream acreages resembling a duopsony, a 'holdup' problem where acreages are not explored or developed within stipulated time periods, and ex post conflicts over what constitutes 'success' in the auction rounds.

For onshore blocks where resource potential is more firmly established, this leads to a potential failure to maximize revenues (for the government as auctioneer). And for offshore blocks, it leads to holdup problems- which feeds into problems with contract enforcement ex post.

The underlying reasons for this cycle can be summarised in terms of three main factors: first, bidders that have won blocks may have submitted bids in excess of their true valuations, due to a phenomenon known as the 'winner's curse'. Second, the auctions have broadly awarded blocks to bidders with the highest valuations, but the source of these valuations may derive from objectives other than the intention to explore - for instance, the desire to increase the value of an asset portfolio in the short term, or to maintain market share. And third, firms that win bids may gain information ex post which makes it inefficient for them to continue exploring - whilst the government on the other hand finds it inefficient for firms not to explore, given its wider social, economic and electoral objectives. This reflects a misalignment between the incentives of firms and the government. 

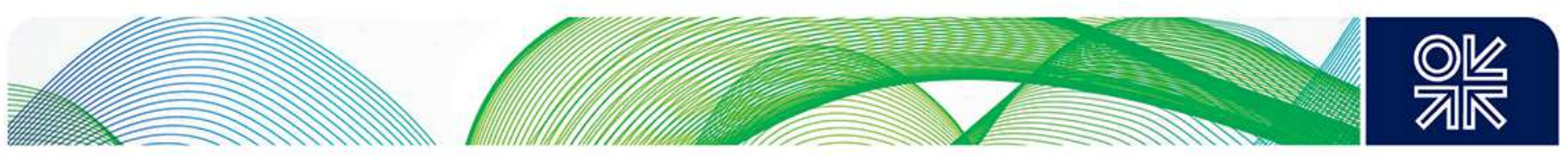

This paper has demonstrated that potential policy solutions lie in tailoring auction formats more closely to bidders' elasticities of demand and geological differences between blocks, and in designing markets to encourage new entrants and better align the objectives and incentives of firms and the government (as auctioneer) - for instance through the use of reserve prices and penalties, to prevent or correct for unintended consequences ex post. The problem of data needs to be viewed separately from the auctions per se as a public good problem.

Whilst the paper outlines several areas where further research is needed, it is evident that the net effect of these unintended consequences of the NELP has been a slowdown in India's domestic exploration, feeding into shortages in meeting supply targets, and the need for expensive imports. 

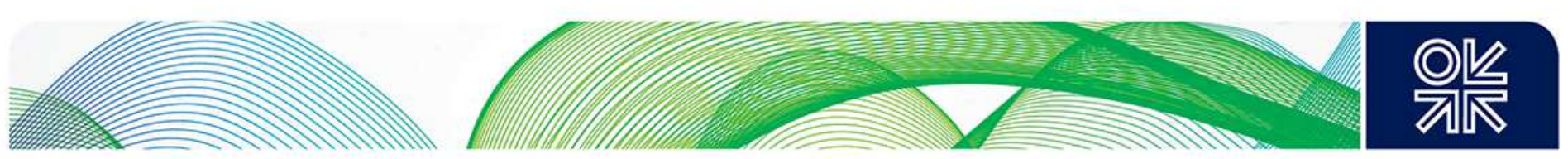

\section{References}

Afualo, V. and McMillan, J. (1996). 'Auctions of Rights to Public Property', in Newman, P. (ed.), The New Palgrave Dictionary of Economics and the Law, Macmillan, London.

Aguirre, I. (2011). 'Welfare Effects of Third Degree Price Discrimination: Ippolito Meets Schmalensee and Varian', IKERLANK Working Paper Series IL 54/11, University of the Basque Country, Available at https://addi.ehu.es/bitstream/10810/6235/1/il2011-54.pdf.

Ashok Chawla Committee Report on Natural Resource Allocation (2011). Obtained by authors.

Athey, S., Levin, J. and Seira, E. (2004). 'Comparing Open and Sealed Bid Auctions: Theory and Evidence from Timber Auctions', Stanford University and NBER.

Binmore, K. and Klemperer, P. (2002). 'The Biggest Auction Ever: The Sale of British 3G Telecom Licences', The Economic Journal, 112 (March), C74-C96.

Boue, J.C. (2002). 'US Gulf Offshore Oil: Petroleum Leasing and Taxation and their Impact on Industry Structure, Competition, Production and Fiscal Revenues', Oxford Institute for Energy Studies Working Paper, SP14.

BP (2011). Statistical Review of World Energy, June 2011.

BP (2012). Statistical Review of World Energy, June 2012.

Bulow, J. and Klemperer, P. (1996). 'Auctions versus Negotiations', American Economic Review, 86 (1), 180-94.

Bulow, J. and Roberts, J. (1989). 'The Simple Economics of Optimal Auctions', The Journal of Political Economy, 97 (5), 1060-90. 

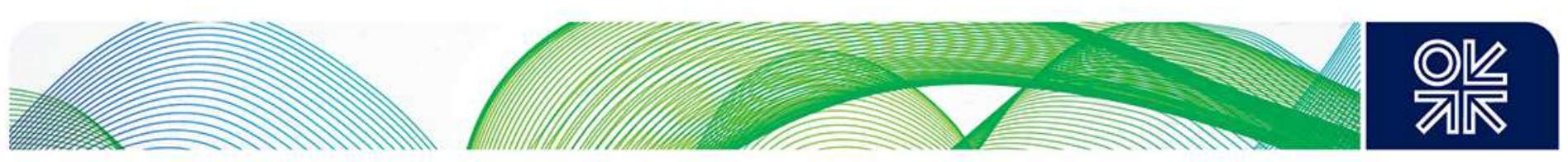

CAG (2011). 'Performance Audit of Hydrocarbon Production Sharing Contracts', Ministry of Petroleum and Natural Gas, Comptroller and Auditor General of India, Report No. - 19 of 2011-12 for the period ended March 2011.

Capen, E.C., Clapp, R.B., Campbell, W.M. (1971). 'Competitive Bidding in High Risk Situations', Journal of Petroleum Technology, 23: 641-653.

Cramton, P. (2007). 'How Best to Auction Oil Rights' in Humphreys, M., Sachs, J. and Stiglitz, J. (eds), Escaping the Resource Curse, New York, Columbia University Press.

Cramton, P. (2010). ' How best to auction natural resources' in Daniel, P., Keen, M., McPherson, C. (eds) The Taxation of Petroleum and Minerals: Principles, Problems and Practice, New York, Routledge.

Directorate General of Hydrocarbons (2005). Hydrocarbon Exploration and Production Activities in India, Government of India Ministry of Petroleum and Natural Gas, New Delhi. www.dghindia.org/Publication.aspx.

Directorate General of Hydrocarbons (2006). Hydrocarbon Exploration and Production Activities in India, Government of India Ministry of Petroleum and Natural Gas, New Delhi. www.dghindia.org/Publication.aspx.

Directorate General of Hydrocarbons (2007). Hydrocarbon Exploration and Production Activities in India, Government of India Ministry of Petroleum and Natural Gas, New Delhi. www.dghindia.org/Publication.aspx.

Directorate General of Hydrocarbons (2008). Hydrocarbon Exploration and Production Activities in India, Government of India Ministry of Petroleum and Natural Gas, New Delhi. www.dghindia.org/Publication.aspx. 

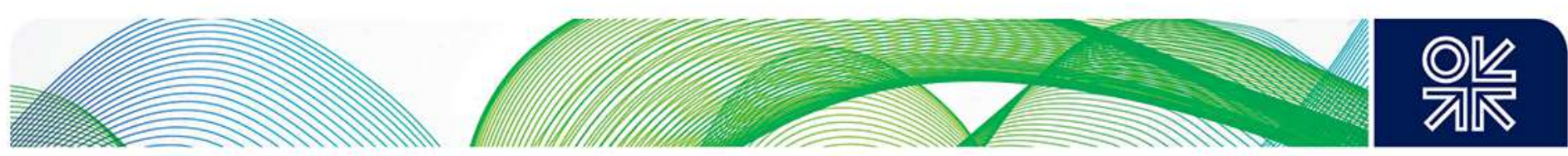

Directorate General of Hydrocarbons (2009). Hydrocarbon Exploration and Production Activities in India, Government of India Ministry of Petroleum and Natural Gas, New Delhi.

www.dghindia.org/Publication.aspx.

Directorate General of Hydrocarbons (2010). Hydrocarbon Exploration and Production Activities in India, Government of India Ministry of Petroleum and Natural Gas, New Delhi.

www.dghindia.org/Publication.aspx.

Directorate General of Hydrocarbons (2011). Hydrocarbon Exploration and Production Activities in India, Government of India Ministry of Petroleum and Natural Gas, New Delhi. Available at www.dghindia.org/Publication.aspx.

Dougher, R. (1987). 'Market shares and individual company data for the US energy markets 19501986', Discussion Paper_014R, American Petroleum Institute, Washington, DC.

EIA (2011). EIA Annual Energy Outlook 2011: with Projections to 2035, US Energy Information Administration, Washington DC. Available at www.eia.gov/forecasts/archive/aeo11/.

Energy and Climate Change Committee (2011). 'UK Energy Supply: Security or Independence?', Eighth Report of Session 2010-2012, Energy and Climate Change Committee, House of Commons, London. Available at www.publications.parliament.uk/pa/cm201012/cmselect/cmenergy/1065/1065.pdf

FE (2008). 'No more delay in NELP VII bidding; E\&P sector upbeat', Financial Express, 23 June 2008.

FE(2006). 'Global majors oppose false commitments under NELP', Financial Express, 23 October 2006.

Fibich,G., Gavious, A., and Sela, A. (2004). 'Asymptotic Analysis of Large Auctions', CEPR Discussion Papers 4331, Available at http://ideas.repec.org/p/cpr/ceprdp/4331.html. 

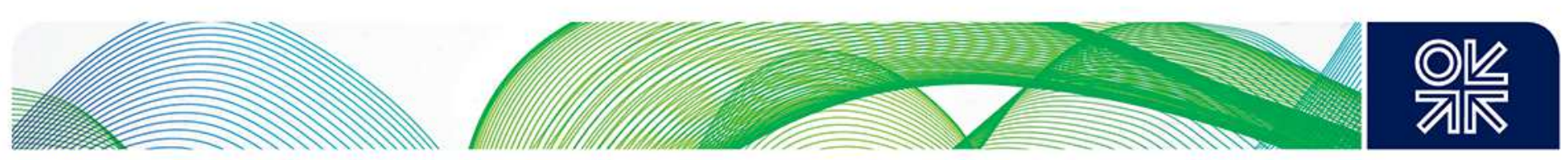

Gilley, O. and Karels, G. (1981). 'The competitive effect in bonus bidding: new evidence', Bell J. Econ, 12 (2), 637-48.

Gol (1999). 'New Exploration Licensing Policy', Available at http://petroleum.nic.in/newgazette/goi1.pdf .

Gol (2013). Twelfth Five Year Plan 2012-17, Planning Commission, New Delhi

Haile, P., Hendricks, K., and Porter, R. (2010). 'Recent US offshore oil and gas lease bidding: A progress report', International Journal of Industrial Organisation, 28, 390-6.

Hansen, R.G. (1986). 'Sealed Bid versus Open Auctions: The Evidence', Economic Inquiry, 24(1), $125-42$.

Hotelling, H. (1931) "The Economics of Exhaustible Resources", The Journal of Political Economy, 39 (2), 137-175.

Hughart, D. (1975). 'Informational Asymmetry, Bidding Strategies, and the Marketing of Offshore Petroleum Leases', Journal of Political Economy, 83: 969-86.

IEA (2012). World Energy Outlook, International Energy Agency.

lledare, O.O., Pulsipher, A.G., Olatubi, W.O., and Mesyanzhinov, D.V. (2004). 'An empirical analysis of the determinants of high bonus bids for petroleum leases in the US outer continental shelf', Energy Economics, 26(2): 239-59.

Jain, A.K. (2011). Natural Gas in India: Liberalisation and Policy, Oxford University Press.

Jain, A.K. and Sen, A. (2011). 'Natural Gas in India: An Analysis of Policy', Oxford Institute for Energy Studies Working Paper No. 50, Oxford, UK. 

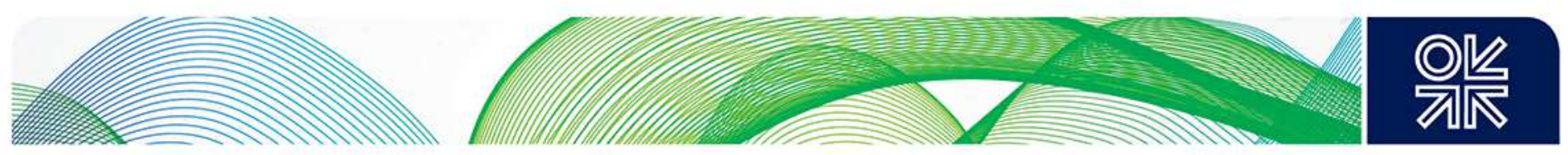

Jayasena, H.S. and Uhanowitage, R. (2008). 'The Effect of Winner's Curse on Post Contract Management', Proceedings from International Conference on Building Education and Research (BEAR). Available at www.irbnet.de/daten/iconda/CIB11417.pdf.

Johnston, D. (2003). International Exploration Economics, Risks and Contract Analysis, PennWell Books

Katakey, R. (2008). 'First-time explorers to gain despite aggressive NELP bidding'. Business Standard, 23 September 2008.

Klemperer, P. (1998). 'Auctions with Almost Common Values: The Wallet Game and its Applications', European Economic Review, 42 (3-5), 757-69.

Klemperer, P. (2004). Auctions: Theory and Practice, The Toulouse Lectures in Economics, Princeton University Press.

Krishna, V. (2009). Auction Theory, San Diego, United States: Academic Press.

Levin, J. (2010) 'Auction Markets', Organisation and Design of Markets, Course Slides, Available at www.stanford.edu/ jdlevin/.../Auction\%20Lectures\%20Part\%201.ppt

Maritz, A. (2003). 'Work Program Bidding in Australia's Upstream Oil and Gas Industry, 1985-99', ABARE e-report, 03.14, Australian Bureau of Agricultural and Resource Economics.

Markham, J.W. (1970). 'The competitive effects of joint bidding by oil companies for offshore leases', in Markham, J.W. and Papanek, G.F. (eds.), Industrial Organization and Economic Development: In Honor of E.S. Mason, Houghton Mifflin, Boston, MA.

Maskin, E. (1984). 'Optimal Auctions with Risk Averse Buyers', Econometrica, 52 (6)1473-518. 

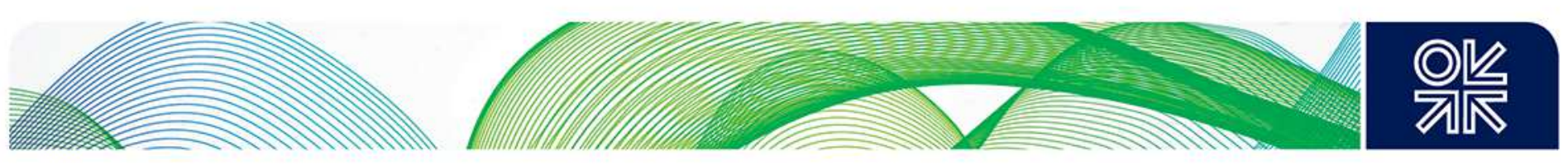

Maskin, E. and Riley, J. (2000). 'Equilibrium in Sealed High Bid Auctions', Review of Economic Studies, Wiley Blackwell, 67(3), 439-54.

McAfee, R.P. (2008). 'Price Discrimination', in Issues in Competition Law and Policy, American Bar Association.

McAfee, R.P., McMillan, J., and Wilkie, S. (2009). 'The Greatest Auction in History', Available at http://vita.mcafee.cc/PDF/GreatestAuctionHistory.pdf.

Mead, W.J., Moseidjord, A., and Sorensen, P.E. (1984). 'Competitive bidding under asymmetrical information: behaviour and performance in Gulf of Mexico drainage lease sales, 1959-1969', Rev. Econ. Stat. 66 (3), 505-8.

Milgrom, P. (1989). 'Auctions and Bidding: A Primer', Journal of Economic Perspectives, 3 (3), 3-22.

Milgrom, P. and Weber, R.J. (1982). 'A Theory of Auctions and Competitive Bidding', Econometrica, 50 (5), 1089-122

MoPNG (1999). Notice Inviting Offers for Exploration of Oil and Natural Gas under New Exploration Licensing Policy, Ministry of Petroleum and Natural Gas, Government of India.

MoPNG (2000). Notice Inviting Offers, Format for Submission of Bids, and Price List of Information Dockets and Data Packages etc. for Exploration of Oil and Natural Gas under New Exploration Licensing Policy: Second Offer of Blocks, Ministry of Petroleum and Natural Gas, Government of India.

MoPNG (2002). Notice Inviting Offers, Format for Submission of Bids, and Price List of Information Dockets and Data Packages etc. for Exploration of Oil and Natural Gas under New Exploration Licensing Policy: Third Offer of Blocks, Ministry of Petroleum and Natural Gas, Government of India. 

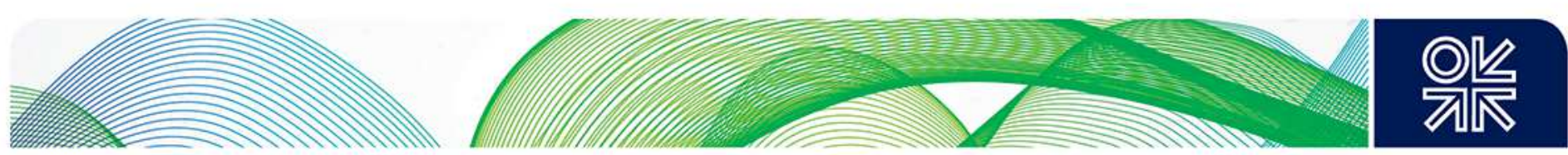

MoPNG (2003). Notice Inviting Offers, Format for Submission of Bids, and Price List of Information Dockets and Data Packages etc. for Exploration of Oil and Natural Gas under New Exploration Licensing Policy: Fourth Offer of Blocks, Ministry of Petroleum and Natural Gas, Government of India.

MoPNG (2005). Notice Inviting Offers, Format for Submission of Bids, and Price List of Information Dockets and Data Packages etc. for Exploration of Oil and Natural Gas under New Exploration Licensing Policy: Fifth Offer of Blocks, Ministry of Petroleum and Natural Gas, Government of India.

MoPNG (2006). Notice Inviting Offers, Format for Submission of Bids, and Price List of Information Dockets and Data Packages etc. for Exploration of Oil and Natural Gas under New Exploration Licensing Policy: Sixth Offer of Blocks, Ministry of Petroleum and Natural Gas, Government of India.

MoPNG (2007). Notice Inviting Offers, Format for Submission of Bids, and Price List of Information Dockets and Data Packages etc. for Exploration of Oil and Natural Gas under New Exploration Licensing Policy: Seventh Offer of Blocks, Ministry of Petroleum and Natural Gas, Government of India.

MoPNG (2009). Notice Inviting Offers, Format for Submission of Bids, and Price List of Information Dockets and Data Packages etc. for Exploration of Oil and Natural Gas under New Exploration Licensing Policy: Eighth Offer of Blocks, Ministry of Petroleum and Natural Gas, Government of India.

MoPNG (2010). Notice Inviting Offers, Format for Submission of Bids, and Price List of Information Dockets and Data Packages etc. for Exploration of Oil and Natural Gas under New Exploration Licensing Policy: Ninth Offer of Blocks, Ministry of Petroleum and Natural Gas, Government of India.

Morgan, J. (2000) "Efficiency in Auctions: Theory and Practice", Paper presented at Conference on Central Bank Operations: Theory and Evidence, Frankfurt.

Muller, S. (2001). 'Auctions', in Smelser, N.J. and Baltes, P.B. (eds), International Encyclopedia of the Social and Behavioural Sciences, Oxford, Elsevier. 

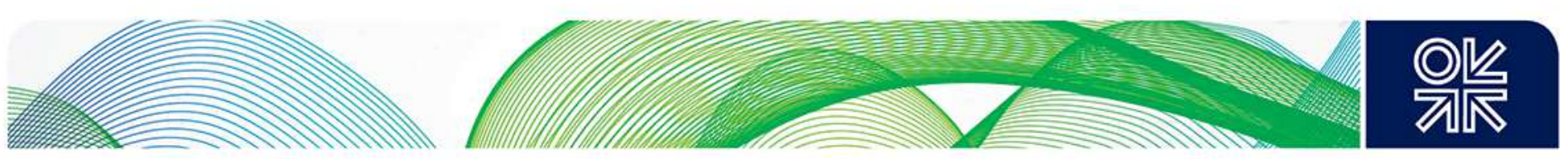

Nambiar, P. (2013) "After 9 rounds of NELP, only 3 blocks producing", Financial Express, 19 August 2013.

Papke, L.E. and Wooldridge, J.M. (2008). 'Panel data methods with fractional response variables with an application to test pass rates', Journal of Econometrics, 145(1-2), 121-33.

Petrofed (2005). Paper on Review of E\&P Licensing Policy, Petroleum Federation of India and Pricewaterhouse Coopers, India. Available at www.petrofed.org

Porter, R.H. (1995). 'The role of information in US offshore oil and gas lease auctions', Econometrica, 63 (1), 1-27.

Ramsey, J. B. (1980). Bidding and Oil Leases, Greenwich: JAI Press.

Reece, D. K. (1978). 'Competitive Bidding for Offshore Petroleum Leases', Bell Journal of Economics, 9 (2), 369-84.

Saidi, R., Marsden, J.R. (1992). 'Number of bids, number of bidders and bidding behaviour in Outer Continental Shelf oil lease auctions', Eur. J. Oper. Res. 335-343.

Sen, A (2012). 'Gas Pricing in India', in Stern, J.P. (ed), The Pricing of Internationally Traded Gas, OIES/Oxford University Press.

Smith, J.L. (1982). 'Risk Aversion and Bidding Behaviour for Offshore Petroleum Leases', The Journal of Industrial Economics, 30(3), 251-69.

Tordo, S. and Johnston, D. (2009). 'Countries' Experience with the Allocation of Petroleum Exploration and Production Rights: Strategies And Design Issues', World Bank Working Paper Draft, June 2009. 

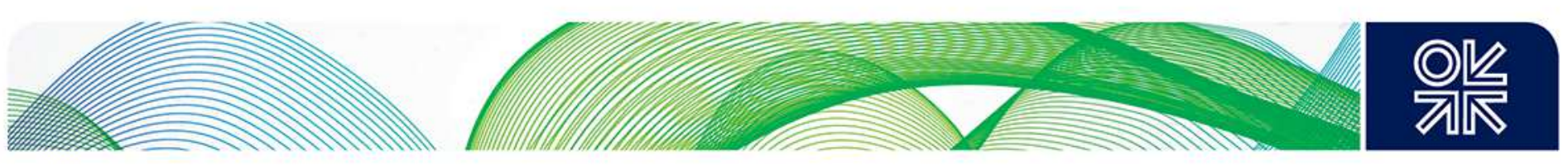

US Energy Information Agency (2012).

Vickrey, W. (1961). 'Counterspeculation, Auctions, and Competitive Sealed Tenders', Journal of Finance, 16 (1), 8-37.

Whitford, A. (2007). 'Designing Markets: Why Competitive Bidding and Auctions in Government Often Fail to Deliver', The Policy Studies Journal, 35(1).

Wooldridge, J.M. (2011). 'Fractional Response Models with Endogenous Explanatory Variables', CHI11 Stata Conference, Chicago.

World Bank World Development Indicators (2012). Available at http://data.worldbank.org/datacatalog/world-development-indicators.

Zhan, R.L. (2008). 'Optimality and Efficiency in Auctions Design: A Survey', in Chinculuun, A., Pardalos, P.M., Migdalas, A., and Pitsoulis, L. (eds), Pareto Optimality, Game Theory and Equilibria, Springer New York. 


\section{Appendix A: Market Concentration in Bidding Rounds}

Figure A.1: Market Concentration (\%) - NELP I

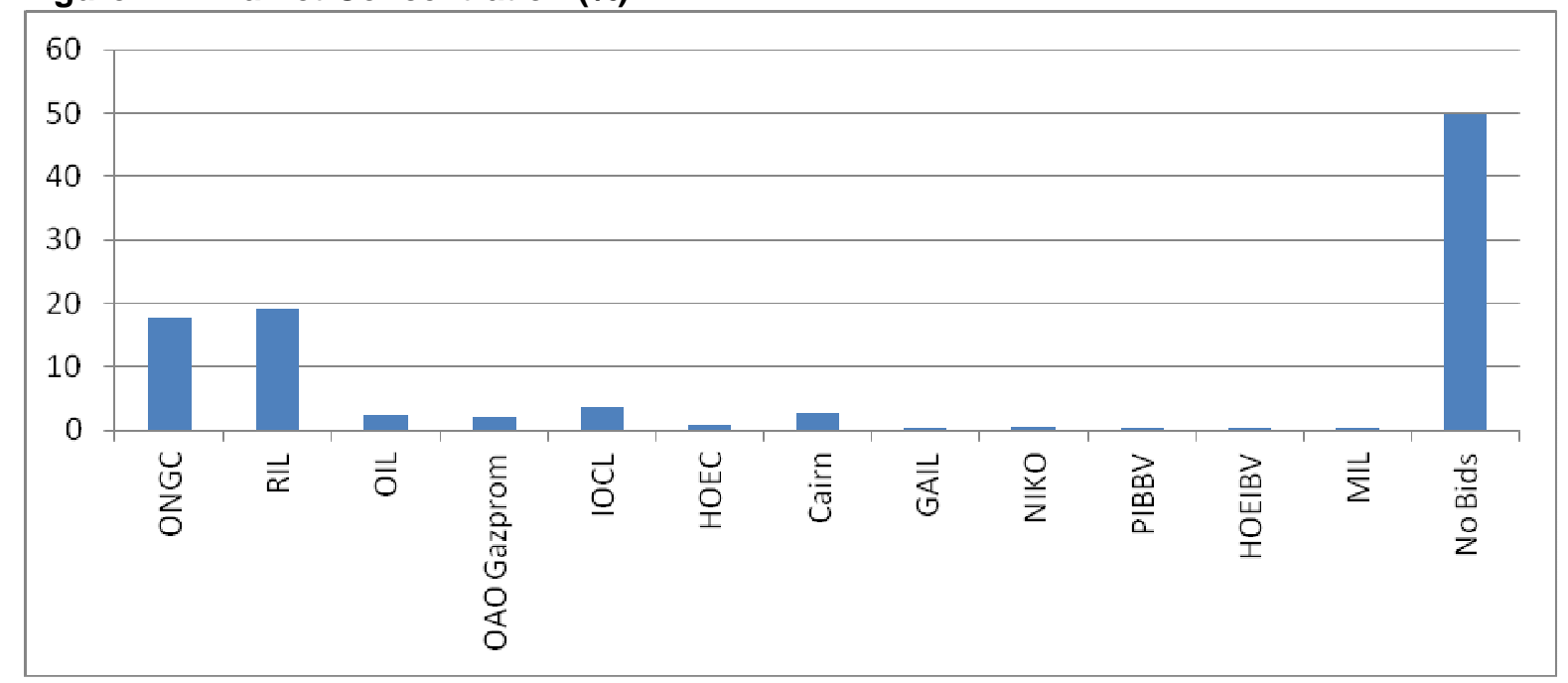

Figure A.2: Market Concentration (\%) - NELP II

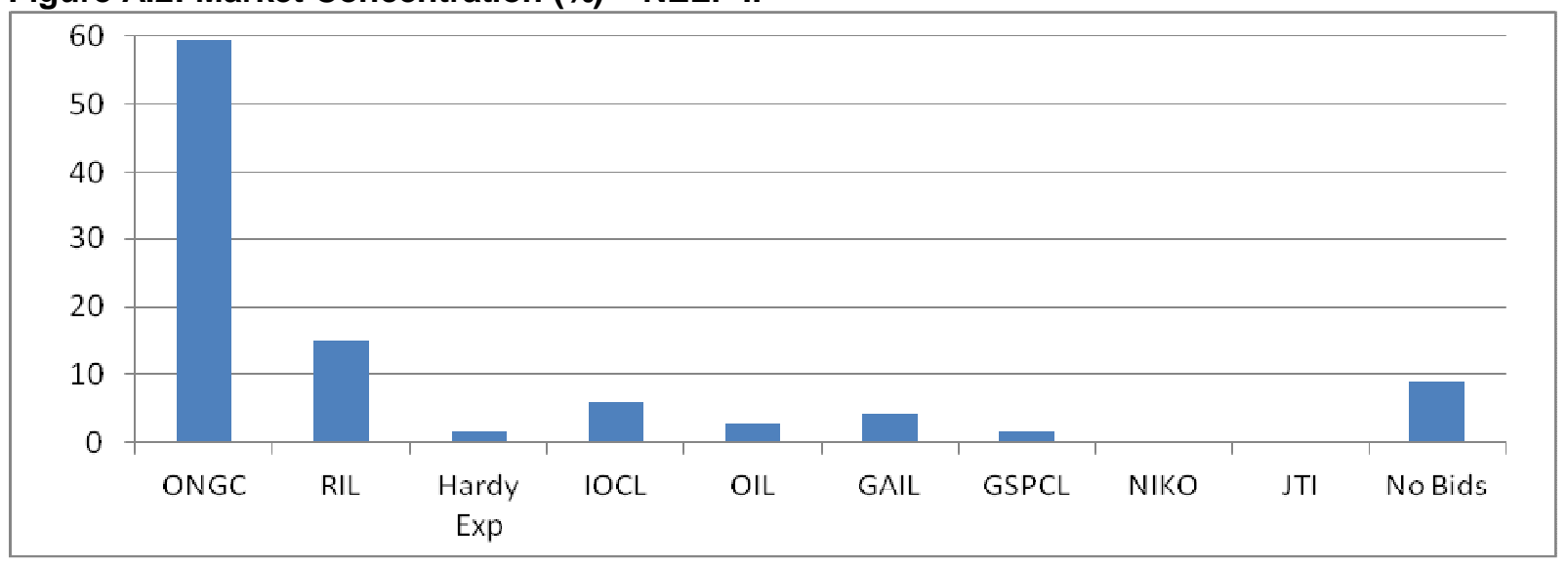

Figure A.3: Market Concentration (\%) - NELP III

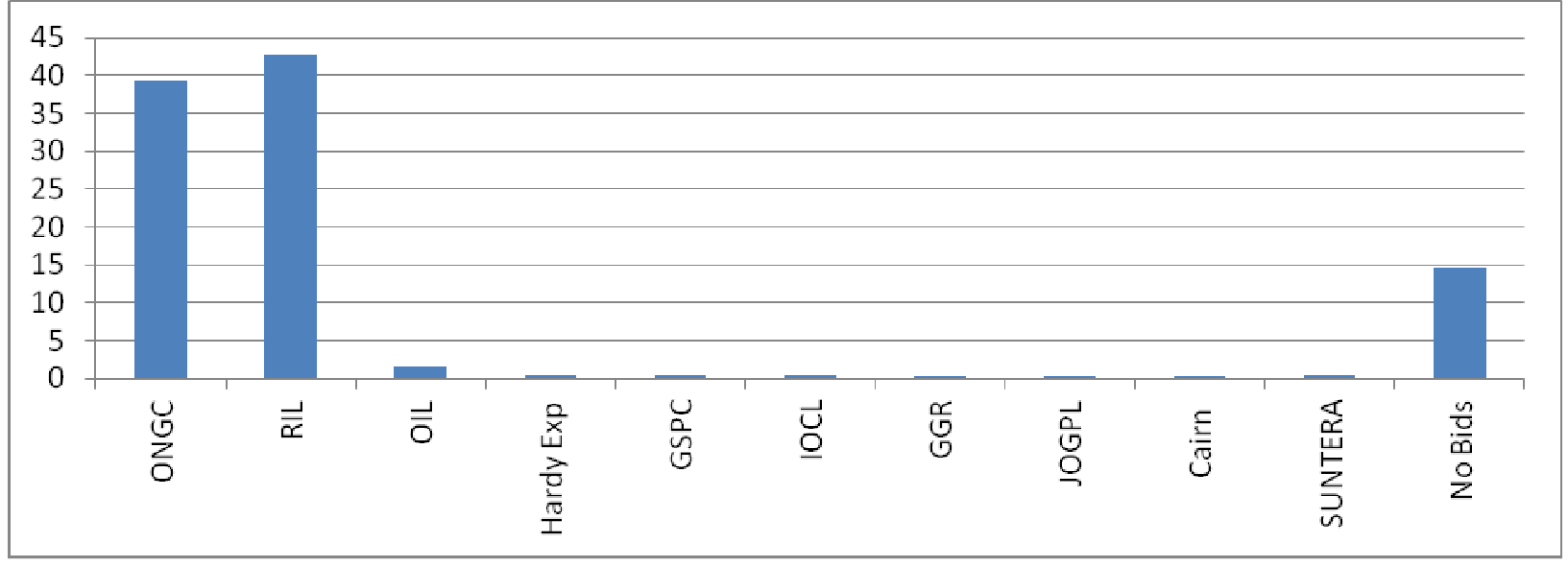




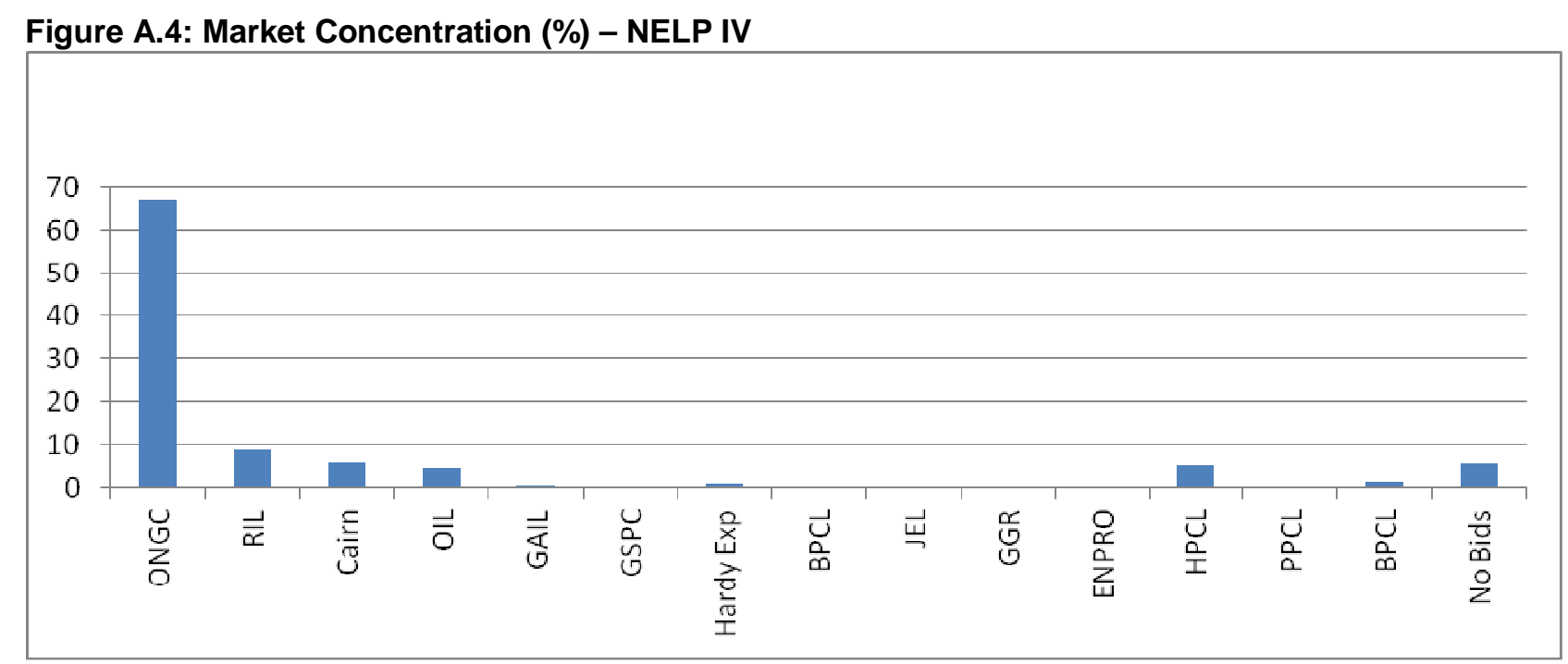

Figure A.5: Market Concentration (\%) - NELP V

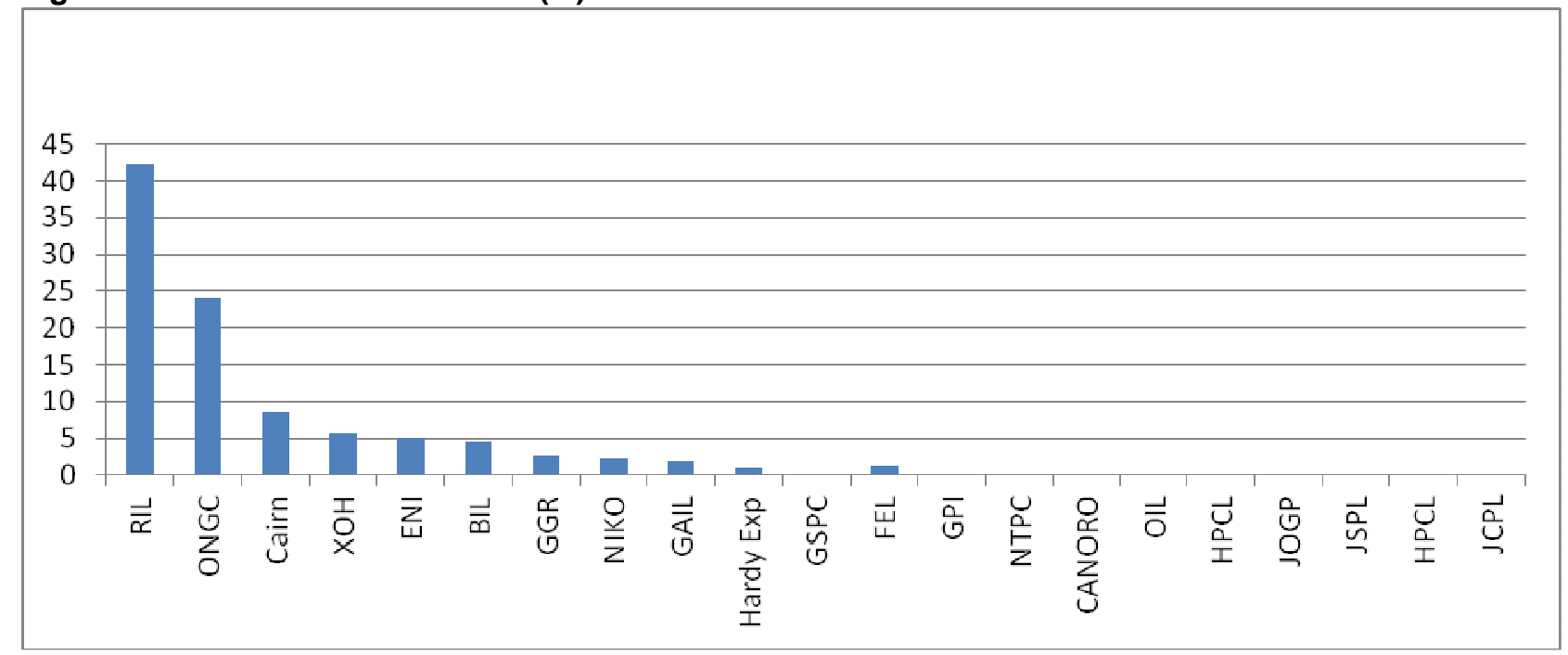




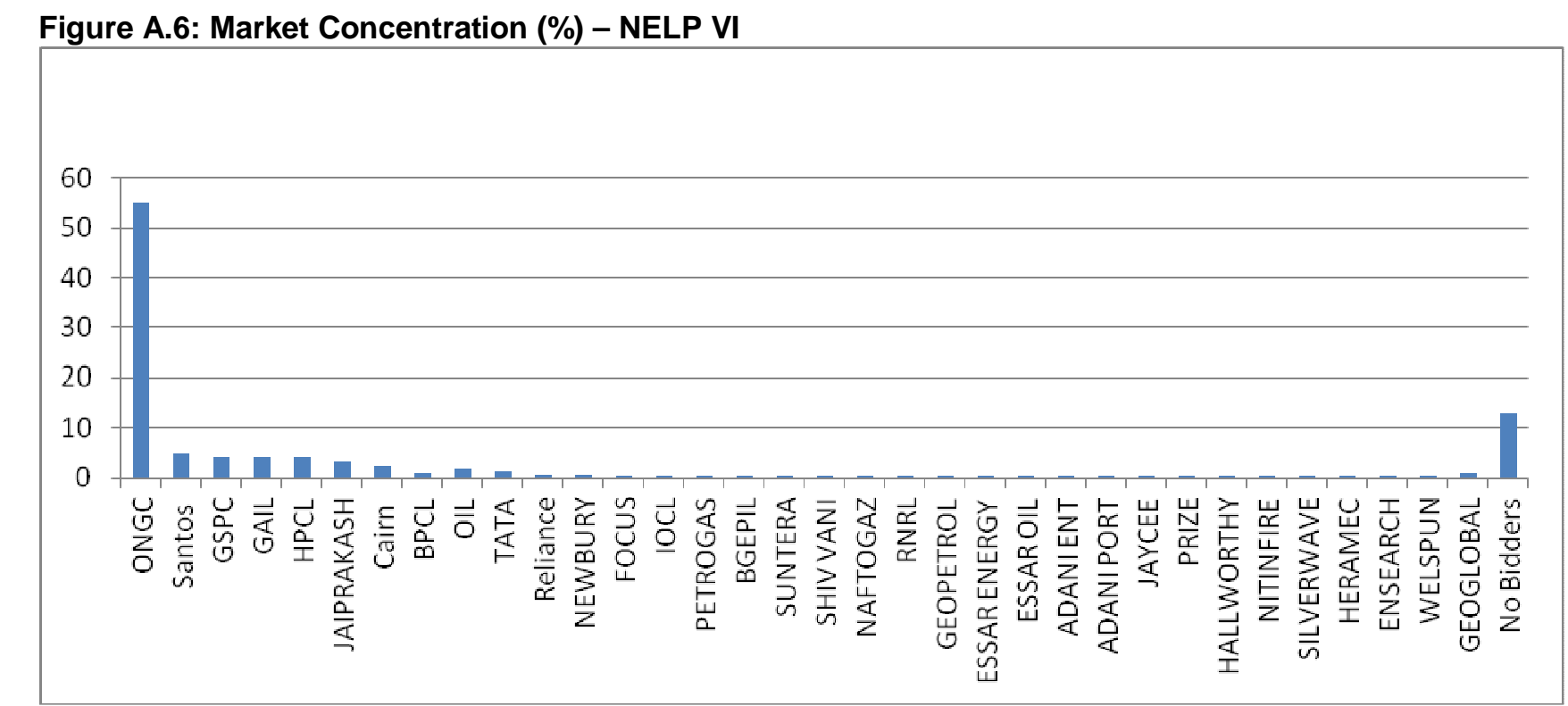

Figure A.7: Market Concentration (\%) - NELP VII

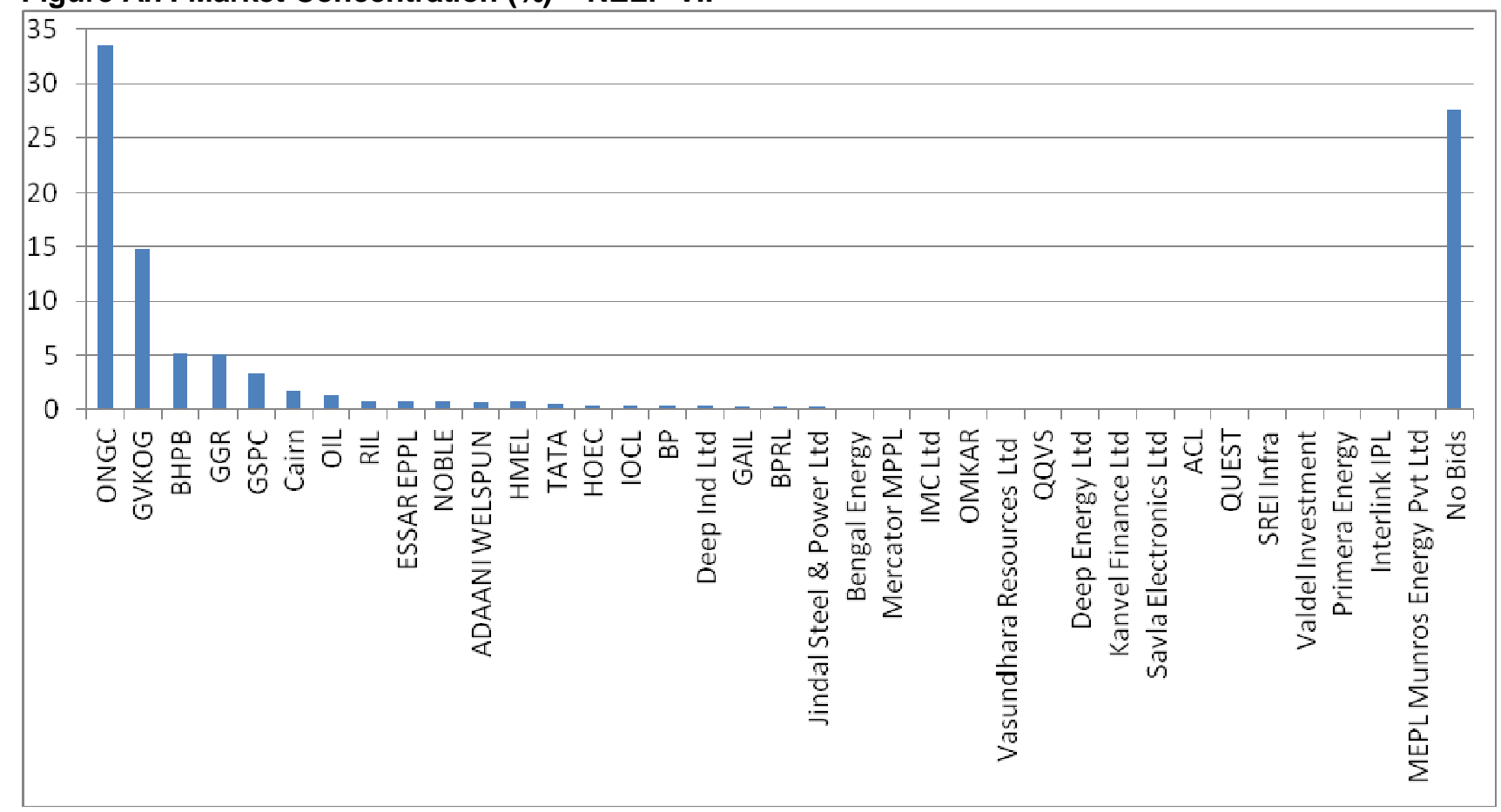




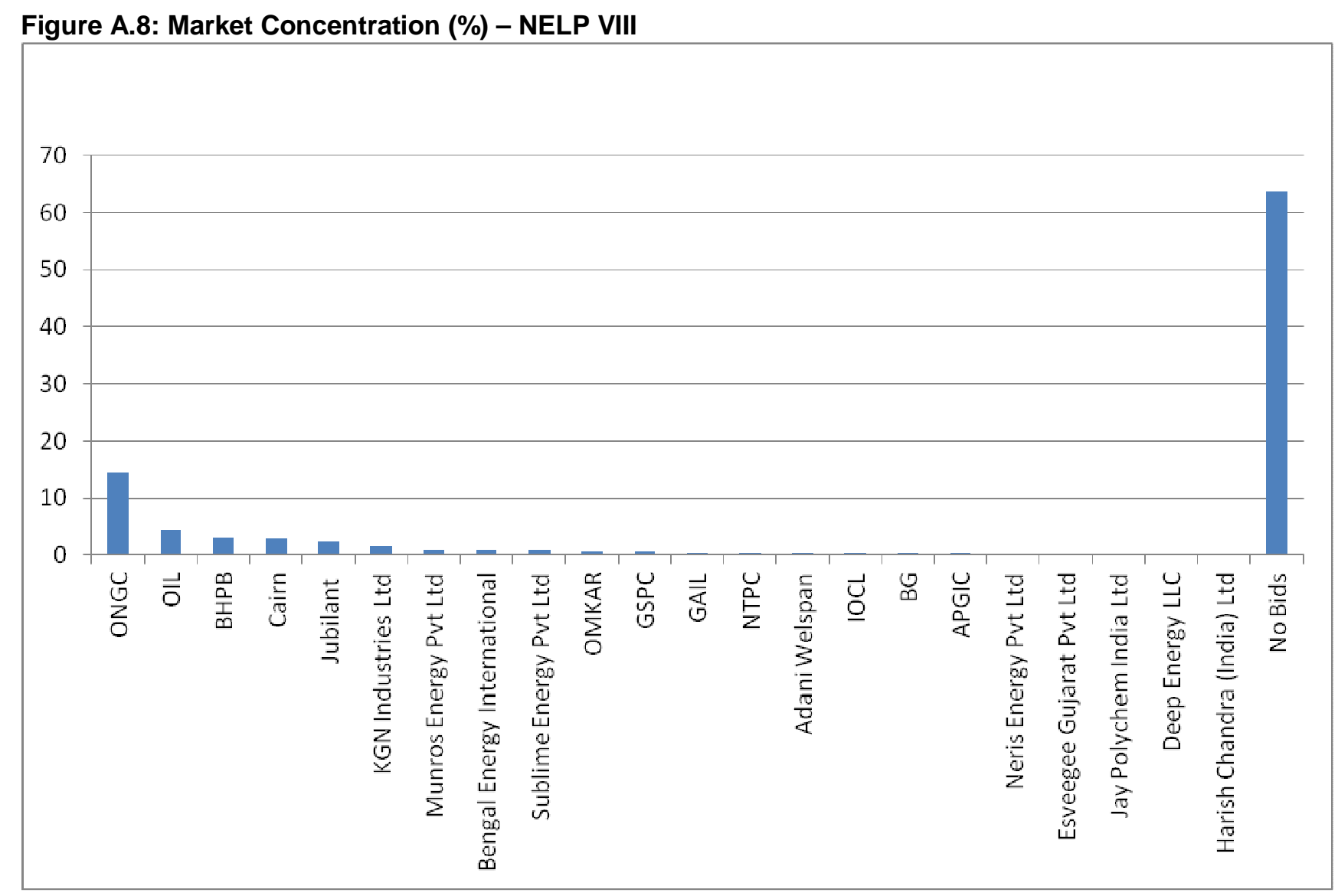

Figure A.9: Market Concentration (\%) - NELP IX

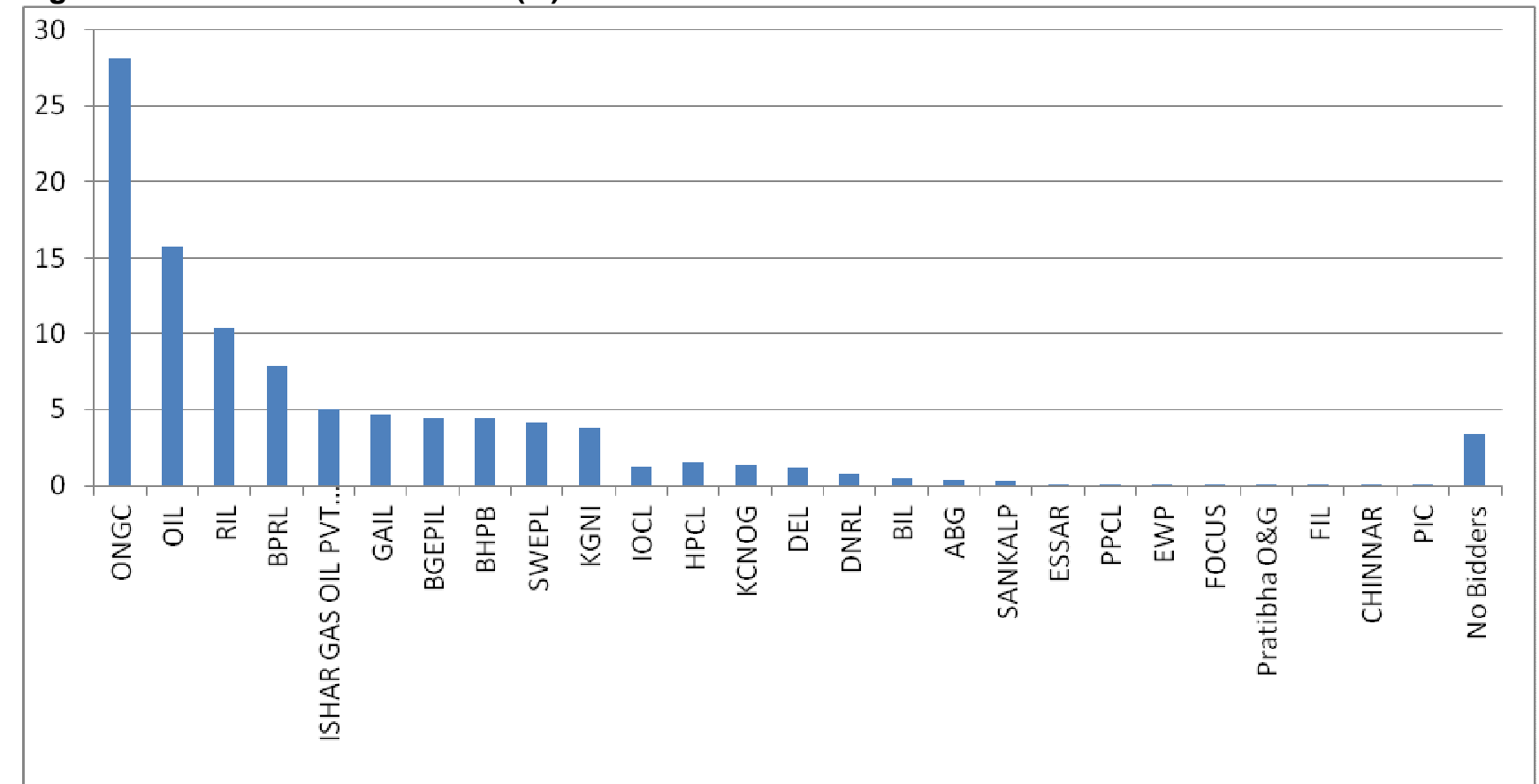

Source: Calculated by authors using Directorate General of Hydrocarbons (2010) and Press Information Bureau of India (various releases). 


\section{Appendix B: Variable Descriptions - Complete Dataset}

\begin{tabular}{|c|c|}
\hline Varname & Description \\
\hline SJ & Solo bid or joint bid $(0 / 1)$ \\
\hline$S M$ & Single bid or multiple bids received for a block $(0 / 1)$ \\
\hline MS & $\begin{array}{l}\text { Bidder (or partner in consortium) is from the two companies with highest market } \\
\text { shares, or not }(1 / 0)\end{array}$ \\
\hline$V A L$ & Total bid score out of 100 \\
\hline BIDS & Number of bids per block \\
\hline PROS & Prospectivity; Category $1 \& 2$ basins (1) or Category $3 \& 4$ Basins $(0)$ \\
\hline$\angle O C$ & Location; deep-water (1) or onshore/shallow-water (0) \\
\hline WEL1 & No of wells in phase 1 of work programme \\
\hline WEL2 & No of wells in phase 2 of work programme \\
\hline WEL3 & No of wells in phase 3 of work programme \\
\hline AREA & Area in square kilometres \\
\hline$C R$ & Percentage cost recovery bid \\
\hline GNPV & Government Net Present Value \\
\hline TECH & Technical bid score \\
\hline FIN & Financial bid score \\
\hline WK & Work Programme bid score \\
\hline FISC & Fiscal terms bid score \\
\hline EXP & Total expenditure (US\$ millions) committed on work programme per block \\
\hline WP1 & Work programme phase 1 bid score \\
\hline WP2 & Work programme phase 2 bid score \\
\hline WP3 & Work programme phase 3 bid score \\
\hline EXPH1 & Expenditure on phase 1 of work programme (US\$ Million) \\
\hline EXPH2 & Expenditure on phase 2 of work programme (US\$ Million) \\
\hline EXPH3 & Expenditure on phase 3 of work programme (US\$ Million) \\
\hline IM1 & Percentage of profit shared with Government at Lower Investment Multiple (1.5) \\
\hline IM2 & Percentage of profit shared with Government at Higher Investment Multiple (3.5) \\
\hline$O P$ & Oil Prices - US\$ per Barrel (2011 Prices) \\
\hline$P$ & Whether a block was auctioned before the 2009 drop in oil price (0) or after (1) \\
\hline$T$ & Whether block was auctioned before or after the 2007 policy changes in NELP $(0 / 1)$ \\
\hline
\end{tabular}


Appendix C: Summary Statistics

\begin{tabular}{|c|l|l|l|l|}
\hline & Min & Max & Mean & Sd \\
\hline SJ & 0 & 1 & .6572581 & .4755859 \\
\hline SM & 0 & 1 & .62 & .4866045 \\
\hline MS & 0 & 1 & .6544715 & .4765098 \\
\hline BAL & 57 & 1000 & 95.21184 & 69.16004 \\
\hline BIDS & 0 & 19 & 2.871921 & 2.899872 \\
\hline PROS & 0 & 1 & .7278912 & .4458045 \\
\hline LOC & 0 & 1 & .3367347 & .4733991 \\
\hline WEL1 & 0 & 18 & 3.261364 & 3.317467 \\
\hline WEL2 & 1 & 5 & 1.879433 & .9744975 \\
\hline WEL3 & 0 & 5 & 1.727273 & .9490175 \\
\hline AREA & 31 & 36750 & 6784.381 & 6737.54 \\
\hline CR & 0 & 100 & 65.27411 & 27.99883 \\
\hline GNPV & 2.12 & 1120.383 & 210.8999 & 221.9289 \\
\hline TECH & 0 & 30 & 8.115625 & 7.062477 \\
\hline FIN & 2.41 & 6 & 4.366591 & 1.024161 \\
\hline WK & 0 & 60 & 34.38608 & 18.69812 \\
\hline FISC & 18.34 & 60 & 47.03898 & 11.34248 \\
\hline$E X P$ & 0 & 265.41 & 46.56802 & 54.878 \\
\hline$W P 1$ & 13.84 & 50 & 47.9975 & 5.714949 \\
\hline$W P 2$ & 1.33 & 5 & 4.520227 & .9946683 \\
\hline$W P 3$ & 0 & 5 & 4.162955 & 1.409424 \\
\hline$E X P H 1$ & .085 & 235.679 & 23.17868 & 34.00768 \\
\hline$E X P H 2$ & 1.003 & 47.16 & 16.86238 & 13.54261 \\
\hline$E X P H 3$ & 1.58 & 76.65 & 16.64897 & 15.18552 \\
\hline OP & 24.26273 & 78.5327 & 54.00906 & 21.19606 \\
\hline$P$ & 0 & 1 & .122449 & .3283626 \\
\hline$T$ & 0 & 1 & .3163265 & .4658349 \\
\hline ROUND & 1 & 8 & 5.11396 & 2.369715 \\
\hline$I M 1$ & 1 & 100 & 54.92314 & 24.84969 \\
\hline IM2 & 0 & 97 & 52.70482 & 26.5032 \\
\hline & & & & \\
\hline
\end{tabular}



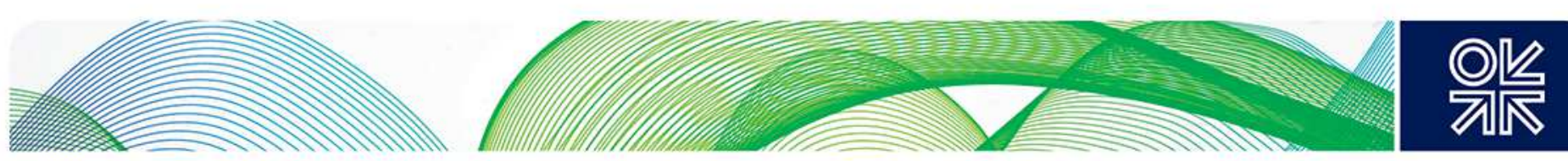

\section{Appendix D: Econometric Method}

The dependent variable of interest is a score between zero and hundred, so that rescaled, it is a proportion between zero and one. We estimate conditional models for proportion-values. Conditional models for proportions can roughly be categorized into models which:

a) parameterize the conditional density versus those that parameterize the conditional expectation,

b) models that take into account the extreme values, $\{0,1\}$, and those which do not.

\section{Beta likelihood model:}

The outcomes $Y_{i}$ given the predictors can be modelled as conditionally Beta-distributed

$$
f Y \mid X \quad\left(Y_{i} \mid X_{i j} \phi\right)=\frac{\Gamma(\phi)}{\Gamma\left(\mu_{i} \phi\right) \Gamma\left(\left(1-\mu_{i}\right) \phi\right)} Y_{i}^{\mu \phi-1}\left(1-Y_{i}\right)^{\left(1-\mu_{i}\right) \phi-1}
$$

where:

$$
g\left(\mu_{i}\right)=X_{i}^{\top} \beta
$$

Here $g:[0,1] \mapsto \mathbb{R}$, is the link function as in GLMs. We use the logistic link function (other possibilities include the probit, complementary log-log, and the log-log). Estimates of the model parameters can be computed by maximum likelihood. However, this model ignores the $\{0,1\}$ values, and further, it assumes that we can correctly specify the conditional distribution of the outcome variables.

\section{Bernoulli QMLE:}

Another possibility is to specify the conditional expectation of the outcome variable as for the logit model:

$$
\mathbb{E}\left(Y_{i} \mid X_{i} ; \beta\right)=\Lambda\left(X_{i}^{\top} \beta\right)
$$

where $\Lambda$ is the CDF of the logistic distribution.

The Bernoulli Likelihood, which can be written as:

$$
L_{n}(\beta \mid Y, X)=n \sum_{i=1}^{n}\left(\left(1-Y_{i}\right) \log \left(1-G\left(X_{i}^{\top} \beta\right)\right)+Y_{i} \log G\left(X_{i}^{\top} \beta\right)\right)
$$

is a member of the linear exponential family (where $G$ is an arbitrary function that maps to $(0,1)$. If we assume that the conditional mean is parameterized correctly, the QMLE from maximizing the Bernoulli likelihood with the conditional mean as above (setting $G \equiv \Lambda$ ) yields the most efficient 

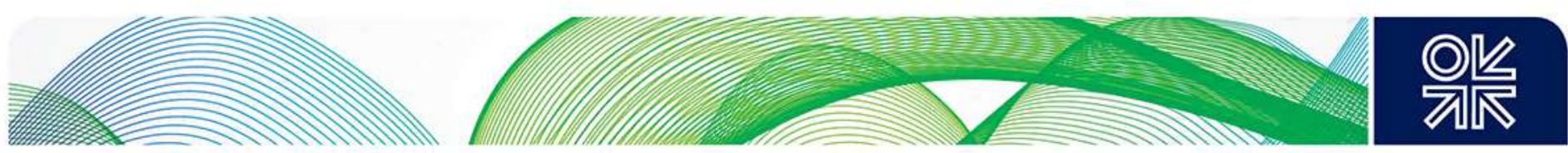

consistent estimator among estimators that specify only the conditional mean (Wooldridge, 2011). This is the fractional logit model.

In both these cases, standard errors of parameters are computed using cluster-robust standard errors where clusters are defined in terms of the auction rounds. 